\title{
Developing the Border Effects Theory in International Trade
}

\author{
by \\ Mykyta A. Vesselovsky \\ Doctoral Program in Economics
}

\section{SUBMITTED IN PARTIAL FULFILLMENT OF THE \\ REQUIREMENTS FOR THE DEGREE OF \\ DOCTOR OF PHILOSOPHY}

\section{FACULTY OF GRADUATE STUDIES \\ CARLETON UNIVERSITY \\ OTTAWA, CANADA}

MAY 2007

(C) Copyright by Mykyta A. Vesselovsky, 2007 


$\begin{array}{ll}\begin{array}{l}\text { Library and } \\ \text { Archives Canada }\end{array} & \begin{array}{l}\text { Bibliothèque et } \\ \text { Archives Canada }\end{array} \\ \begin{array}{l}\text { Published Heritage } \\ \text { Branch }\end{array} & \begin{array}{l}\text { Direction du } \\ \text { Patrimoine de l'édition }\end{array} \\ \begin{array}{l}\text { 395 Wellington Street } \\ \text { Ottawa ON K1A ON4 }\end{array} & \begin{array}{l}\text { 395, rue Wellington } \\ \text { Ottawa ON K1A ON4 } \\ \text { Canada }\end{array}\end{array}$

Your file Votre référence ISBN: 978-0-494-27114-8 Our file Notre référence ISBN: 978-0-494-27114-8

NOTICE:

The author has granted a nonexclusive license allowing Library and Archives Canada to reproduce, publish, archive, preserve, conserve, communicate to the public by telecommunication or on the Internet, loan, distribute and sell theses worldwide, for commercial or noncommercial purposes, in microform, paper, electronic and/or any other formats.

The author retains copyright ownership and moral rights in this thesis. Neither the thesis nor substantial extracts from it may be printed or otherwise reproduced without the author's permission.
AVIS:

L'auteur a accordé une licence non exclusive permettant à la Bibliothèque et Archives Canada de reproduire, publier, archiver, sauvegarder, conserver, transmettre au public par télécommunication ou par l'Internet, prêter, distribuer et vendre des thèses partout dans le monde, à des fins commerciales ou autres, sur support microforme, papier, électronique et/ou autres formats.

L'auteur conserve la propriété du droit d'auteur et des droits moraux qui protège cette thèse. $\mathrm{Ni}$ la thèse ni des extraits substantiels de celle-ci ne doivent être imprimés ou autrement reproduits sans son autorisation.
In compliance with the Canadian

Privacy Act some supporting forms may have been removed from this thesis.

While these forms may be included in the document page count, their removal does not represent any loss of content from the thesis.
Conformément à la loi canadienne sur la protection de la vie privée, quelques formulaires secondaires ont été enlevés de cette thèse.

Bien que ces formulaires aient inclus dans la pagination, il n'y aura aucun contenu manquant.

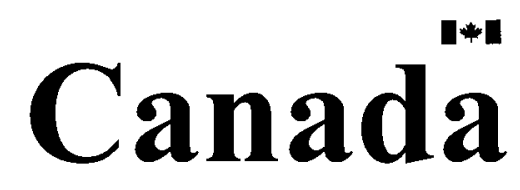




\section{Abstract}

Research on the impact of national borders on trade has shown that internal trade within a country is several times more intensive than cross-border trade between countries. The relative intensity of the two types of trade is usually called the border effect, which is generally acknowledged to be high (between 10 and 22). In this thesis, we first conduct a chronological literature review to survey the developments that took place since McCallum's (1995) seminal paper on border effects. Our findings allow us to argue that the typical gravity models used in this area are not well grounded in theory and often generate biased results. We also hypothesize that the diversity of estimated border effects is due to the differences in study methods and characteristics. To verify this hypothesis we next conduct a meta-analysis of the literature, which features an enhanced variable selection process leading to a better meta-analytic specification; these benefits result from preceding the meta-analysis with the survey. The results of the meta-analysis confirm our hypothesis. We explain most of the variance in the literature estimates and show that the Canada-U.S. border effects are higher than elsewhere.

Based, in part, on the results of meta-analysis, we subsequently derive a model of regional trade in differentiated goods that produces a specification for estimating border effects between Canada and the U.S. The model controls for output, prices, adjacency, distance, and government, and produces estimates superior to those found in existing literature. This is because the methodology used is consistent with trade theory, but does not require the inclusion of remoteness variables or calibration of parameters. The 
resulting border effects between Canada and U.S. range between 5 and 6 over the 19882003 period, much lower than previous estimates.

After obtaining year-by-year estimates for this period, we then demonstrate the shortcomings of this simple cross-sectional approach used in the existing literature by constructing and estimating a 1988-2003 panel which allows us to include trade tariffs among explanatory variables and to use time-series techniques to refine the estimates and plot their time path. Results show that, contrary to common belief, border effects between Canada and U.S. have increased roughly from 2.2 in 1988 to 5.5 in 2003 ; rising non-tariff barriers may be responsible for this effect. Small tariffs are shown to generate large border effects - two-thirds of McCallum's original border effect estimate for 1988 is due to tariffs. We go on to show that these results are dominated by the import effect, implying that Canadian provinces are much more averse to imports from U.S. than U.S. states are to imports from Canada. We link this effect to the change in aggregate trading patterns with third countries and conclude that further development of the model to track trade with all of the country's trading partners would lead to a better understanding of border effect estimates.

In summary, earlier research has discovered a real empirical effect, but reached erroneous conclusions about its magnitude through atheoretical specification and omitted variables. Our well-specified regression model not only produces better estimates, but allows additional insight into the causes and dynamics of the border effects. This versatile model can also be used to analyze border effects in other regions, be refined further to take into account all trading partners, and serve as a reliable basis for welfare analysis. 


\section{Acknowledgments}

I would like to express my deepest thanks to my Thesis Committee of Lawrence Schembri, Ehsan Choudhri, Simon Power and Serge Coulombe. Larry Schembri motivated me by his example and knowledge, and provided firm and decisive guidance; I am deeply grateful to him for his ability to say what he means and to mean what he says. Ehsan Choudhri's help was invaluable to me in my work on chapter four; his calm, unruffled and pleasant style of dealing with the most trying problems one encounters during research has taught me much and instilled confidence in the future of this thesis. Simon Power has made my experience with econometrics more pleasant, and his earnest human touch has many times given me fresh hope and inspiration. Serge Coulombe's passion for and deep knowledge of the field have contributed substantially to the final product. I am also grateful to Richard Brecher for introducing me to the field of international trade, and once again to Larry Schembri for providing funding while this thesis was being conceived.

It was a privilege to be supported by my friends and colleagues at Canada Student Loans. Many arguments and discussions with Kenten Musselman, Jerry Situ, Atiqur Rahman and encouragement from Deborah James, Leesha Lin and others helped improve my work and motivated me to complete it. Special thanks go to Nikita Lyssenko whose extensive help was more appreciated than he will ever know. I thank them for all they did for me in the last six years. 
I acknowledge the spiritual support of the prose and poetry of J.R.R. Tolkien that have so beautifully defined the purpose and meaning of life and never let me forget it. It was a great comfort to know throughout the years that there is always hope.

My wife Irina has been a continuous source of inspiration to me in my work, and her sacrifices to help me achieve my goal are deeply appreciated. Her support has been constant in good times and bad, and her love has been the foundation on which this work could be built.

I dedicate this thesis to my parents, Andrij and Maryna Vesselovsky, and to my dear grandfather Ivan Vasyljovych Vesselovsky, who has not lived to see its completion, but who has never doubted it. I am indebted to them for everything that I am, and I hope that this work repays a small part of my debt.

\author{
Mykyta A. Vesselovsky \\ Ottawa, Canada
}

May 15, 2007 


\section{Table of Contents}

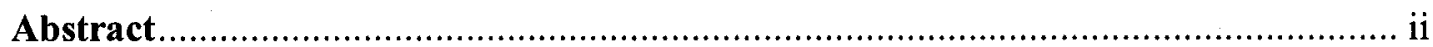

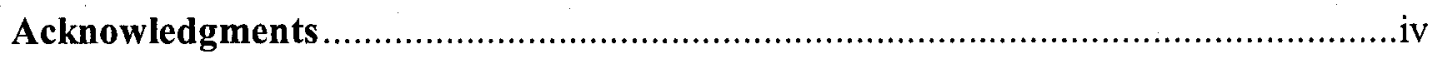

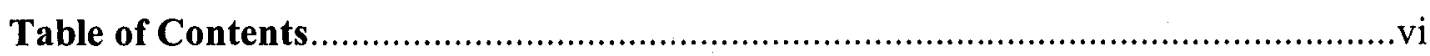

List of Tables

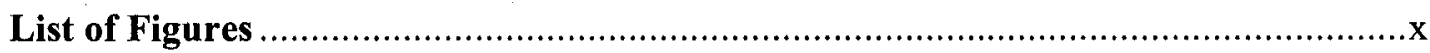

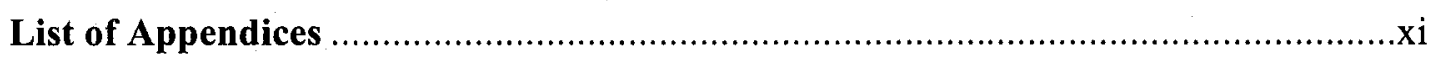

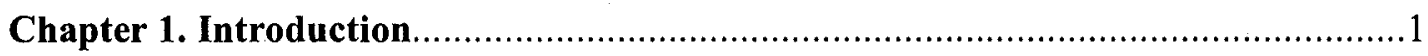

Chapter 2. Border Effects Research: Discovery and Development .......................

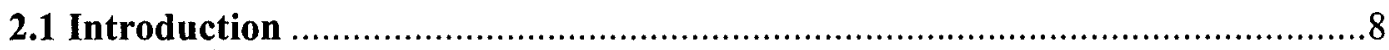

2.2 McCallum and Follow-up - National Borders Matter ................................14

2.3 Early Explanations: the Heyday of Specifications in the Literature...............19

2.4 The Expanding Scope of Border Effects: ............................................ 34

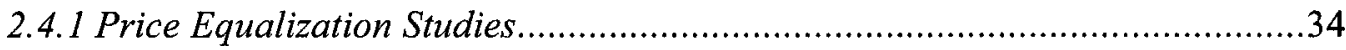

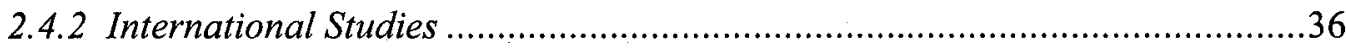

2.5 Theoretical Critique of the Early Border Effect Literature..........................43

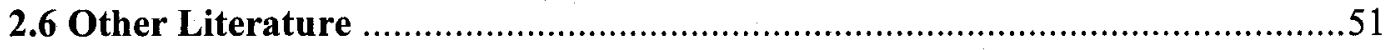

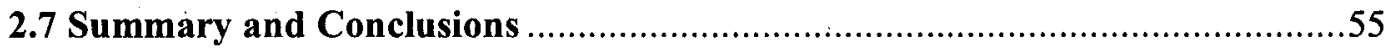

Chapter 3. Meta-Analysis of Economic Research on Border Effects ....................60

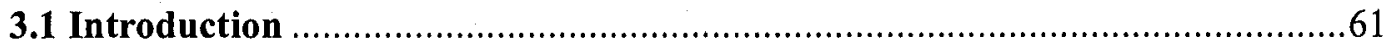

3.2 Meta-Analysis as a Systematic Tool of Inquiry ........................................64

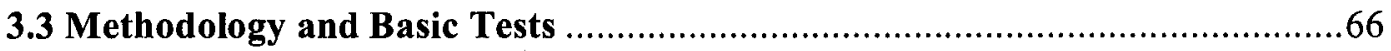

$\mathrm{Vi}$ 
3.4 Specification of the Meta-Regression Variables ..................................... 77

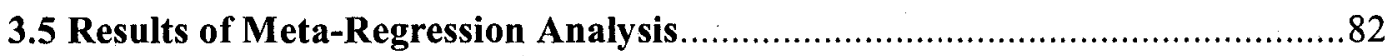

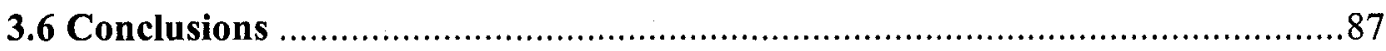

Chapter 4. New Border Effects Evidence from the Canada-U.S. Regional Trade

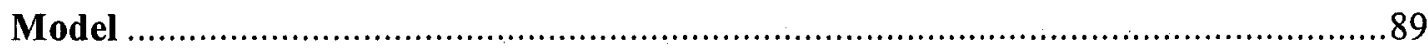

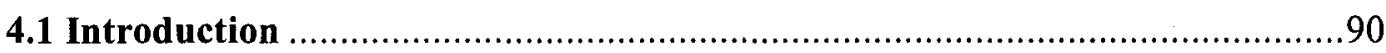

4.2 Research Into Border Effects as a Measure of Integration .........................94

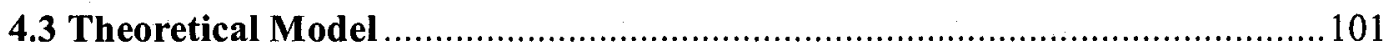

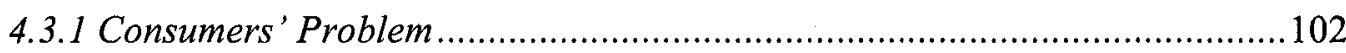

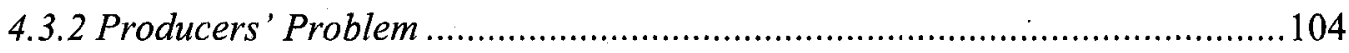

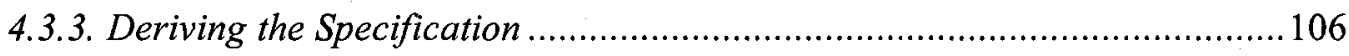

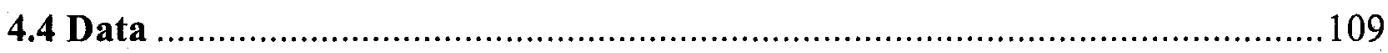

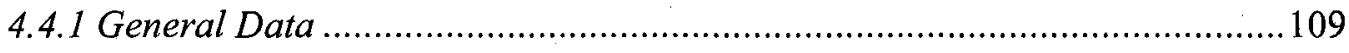

4.4.2 Canadian Interprovincial Trade Data ............................................... 110

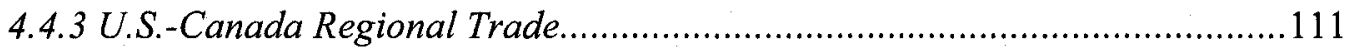

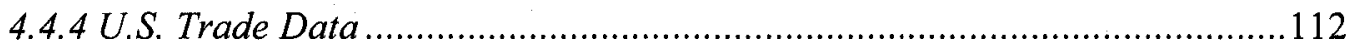

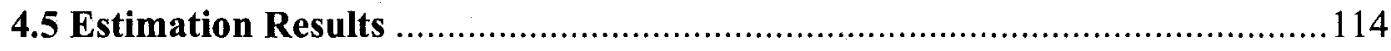

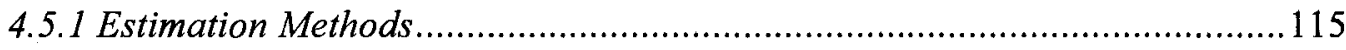

4.5.2 Static Border Effects in a Regional Model ............................................117

4.5.3 Evolution of Border Effects with Time, 1988-2003.................................127

4.5.4 Border Effects by Province and Direction of Trade ...................................135

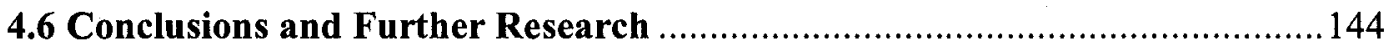

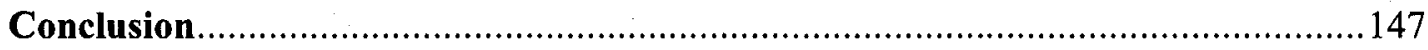

vii 


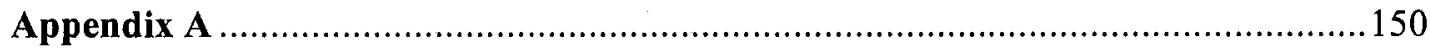

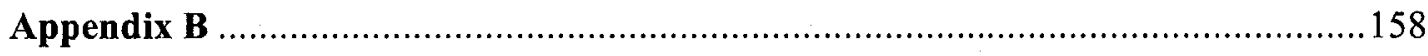

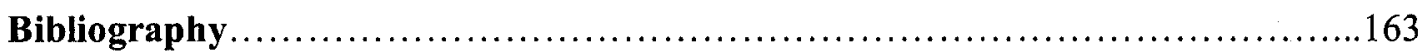

viii 


\section{List of Tables}

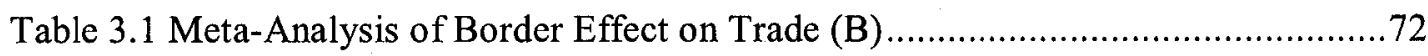

Table 3.2 Sensitivity of Meta-Analysis of B to Individual Studies (Fixed Effects) .........73

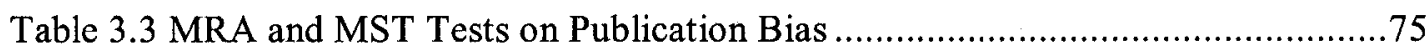

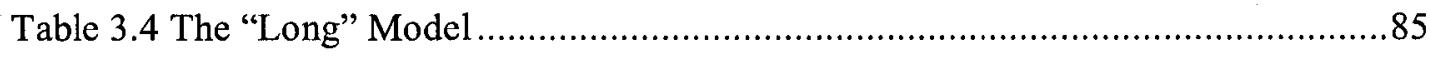

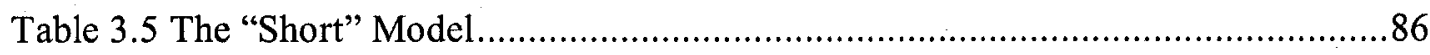

Table 4.1 Canada - U.S. Border Effects, 1988-1991 ........................................ 118

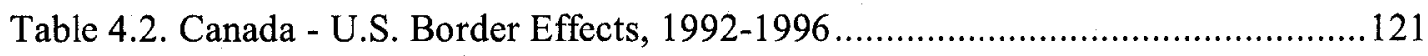

Table 4.3 Canada - U.S. Border Effects, 1997-2003, cross-sectional ...........................122

Table 4.4 Canada - U.S. Border Effects, 1997-2003, panel...................................124

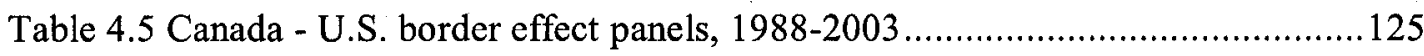

Table 4.6 Border Effects in Time-Series Context, FGLS, 1988-2003 ........................130

Table 4.7 Regional and Time Fixed Effects Panel, FGLS, 1988-2003 ........................134

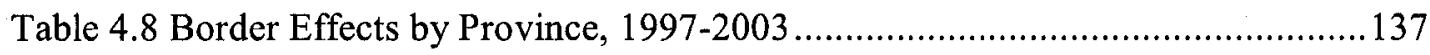

Table 4.9 Border Coefficients for Exports and Imports, 1997 and 2003 ..................... 141

Table 4.10 Aggregates of Canadian Merchandise Trade, 1997-2003 ….....................142

ix 


\section{List of Figures}

Figure 3.1 Funnel graph of 27 studies.................................... 75

Figure 4.1 Cross-Sectional Border Effect Trends, 1988-2003..................... 126

Figure 4.2 Tariff Impact on Border Effect Estimates (FGLS) $\ldots \ldots \ldots \ldots \ldots \ldots \ldots \ldots \ldots 128$

Figure 4.3 Time Impact on Border Effects Estimates (FGLS) ....................132 


\section{List of Appendices}

Appendix A: The Gravity Equation: From History to Practice to Theory..............150

Appendix B: Meta-Analysis Literature..................................... 158 


\section{Chapter 1}

\section{Introduction}

Evidence that national borders continue to matter has been accumulating since 1995 . It is not that these lines on the map cause trade distortion by themselves; they merely delineate the areas within which trade is relatively more intense than between them. These areas are coincidentally known as nations. As long as these different trade intensities persist, implying higher trade costs for goods that are traded internationally, nations (and by extension, national borders) matter for trading purposes. In McCallum (1995), after taking into account economic size and distance, a Canadian province was found to be 22 times more likely to trade with another province than with a U.S. state. Subsequent research in this area has confirmed significant and robust border effects between the U.S. and Canada. Helliwell (2001) estimates the border effect at 11; the same ratio of intensity of Canadian trade to Canada-U.S. trade is implied in Anderson and van Wincoop (2001). These and most other estimates, like 15.2 in Anderson and Smith (1999), are found in the range between 10 and 22. The existence of the border effect has also been confirmed for OECD and EU trade by Wei (1996), Nitsch (2000) and Head and Mayer (2000), as well as international prices and migration patterns (Engel and Rogers (1996) and Helliwell (1997)).

It has been shown by Anderson and van Wincoop (2001) that the high estimates for the Canada-U.S. border effect do not imply a corresponding increase in trade if the border were removed, and that they are due to the relatively small size of the 
Canadian economy when compared to its large trading partner. Moreover, their paper questioned the previous estimates by showing that the gravity models used in estimating border effects have weak theoretical foundations and thus often generate biased results. They also analyzed other features of interest about the border effect: the actual degree of cross-border trade reduction and the real welfare costs of this reduction.

This thesis primarily addresses the issue of proper estimation of border effects as raised by Anderson and van Wincoop. The place of this thesis in the existing research is, to a large degree, to collect evidence already available, analyze it and develop a comprehensive interpretation of this evidence. Our approach is to first undertake a chronological survey of existing literature to chart its development and highlight the primary contributions, trends and areas of concern. In addition to identifying the methods and variables of interest for the subsequent chapters, we are also interested in an account of the birth and early development of a modern economic idea: from the early factfinding, through specification search, to a comprehensive theoretical discussion. This survey is undertaken in the second chapter.

The results of the survey help to inform our work in the third chapter which proceeds to systematize the knowledge on this topic in quantitative manner through metaanalysis. Meta-analysis has come to prominence comparatively recently as a technique that can establish the significance of a particular factor where a narrative review cannot reach a conclusion. Some of the evidence in the literature is conflicting; much of it is difficult to compare directly due to the use of different time periods, countries and study designs. After surveying this evidence, we take stock of it through the use of formal meta-analysis in order to make summary statements about the nature of the border effect 
and the influence of the research methods and variables on the existing estimates. We point out in particular the gains accomplished by doing a narrative review beforehand. The narrative review addresses the weakness common to meta-analysis: the explanatory variable selection process often lacks theoretical foundation. Preceding the meta-analysis with a survey is thus similar to the good practice of developing a theoretical model as a basis for the specification of the empirical model.

Our meta-analysis confirms the existence of statistically and economically significant positive border effects everywhere in OECD, their average magnitude ranging between 7 and 10 . The final form of our equation is able to explain over $90 \%$ of variation in border effect estimates found in the literature. This allows us to predict the magnitude of border effects found by the study based solely on the study's parameters; the main determinant factors are whether or not the estimated equation is derived from theory, whether adjacency is taken into account, and the number of specifications considered. In addition, the Canada-U.S. border was found to exhibit a higher border effect than the average border. These findings establish beyond reasonable doubt the legitimate character of the border effect (i.e. an authentic empirical phenomenon, as opposed to an unfortunate result of econometric misspecification), inform further research, and in particular help us build our theoretical model in the fourth chapter.

The conclusions of the previous two chapters that identify and quantify issues of importance in this area help us to construct a theoretically sound regional model of trade in North America in the presence of border effects. We consider the links between theories of trade and the proper specification of the gravity equation derived from those theories. Supported by the results of our meta-analysis, and following earlier critiques of 
this literature - Anderson (1979), Bergstrand (1985), Deardorff (1998) and Anderson and van Wincoop (2001), we argue that a gravity equation derived from theory is essential for obtaining legitimate results. Gravity equations commonly used to estimate border effects in the literature lack theoretical foundation; this absence results in existing estimates being biased due to improper model specification and omitted variables. Contributing to this is also the lack of time-series analysis of the existing data. Our specification contains the key price variables implied by theory, as well as the effects of tariffs and the role of governments, the latter incorporated theoretically for the first time in the literature. We thus take into account both theory and practice to produce estimates superior to those of prior research. These estimates paint a picture significantly different from that of earlier studies.

We find that international trade between Canada and the U.S. is only between 5 and 6 times less intense than Canadian internal trade throughout the 1988-2003 period, a much lower border effect than suggested previously. Like most of the earlier research, these results represent cross-sectional estimates, i.e. all individual years are estimated separately. Even when in possession of several years of data, the time series approach was rarely used in the literature. This failure to use all available information did not allow earlier studies to trace adequately the dynamics of border effects and explain their time path. It also made it impossible to incorporate trade tariffs into the empirical equation and assess their contribution to the border effect, since in a cross-sectional specification tariffs are perfectly collinear with the border variable.

Our next step is therefore to construct a panel dataset for the $1988-2003$ period and use it to estimate border effects that vary through time for the whole duration of that 
period while controlling for time and regional effects. First, we show that approximately two-thirds of the border effect in 1998 is due to tariffs, confirming that relatively low trade barriers can generate large border effects. Next, we obtain time-series estimates of border effect over the 1988-2003 period while controlling for tariffs, fixed time effects and interactive time effects. These show that, contrary to the earlier consensus of the literature, border effects between Canada and the U.S. have risen from 2.2 in 1988 to 5.5 in 2003. The inclusion of regional fixed effects does not change this conclusion substantially. This increase has passed unnoticed by the literature due to the combination of actual tariff reductions which were not explicitly modelled, as well as misspecification and omitted variables in the gravity equations that were used to estimate border effects. While we provide no full explanation for this increase, we believe that an increase in nontariff barriers, change in preferences underlying the patterns of trade and a more restricted environment in the United States as a result of increased security concerns may all have contributed to the results.

We follow up by disaggregating the border effect by province and direction of trade for the 1997-2003 period. Because trade goes both ways, we can estimate separate border effects for northbound and southbound trade (first implemented by Anderson and Smith (1999)), splitting the border effect in two. From the Canadian perspective, northbound trade is generating the import border effect and southbound trade - the export border effect. Our results show that the Canadian import border effect is increasingly dominating the export border effect, from a 5:1 ratio in 1997 to $11: 1$ in 2003 . In fact, export border effect has reached a low of 1.5 in 2003, meaning that Canadian exporters are only $50 \%$ more likely to export to another province as opposed to a U.S. state - yet 
the corresponding import border effect of 16.8 shows a large relative reluctance to import from the U.S. We suggest an explanation that has to do with the changing aggregate patterns of trade. Over the 1997-2003 period, there was significant growth in Canadian imports from lower labour cost countries such as China and Mexico, while Canadian imports from the U.S. were stagnant. This pattern implies Canadian import substitution of the U.S. goods in favour of other countries; the effect of this process on the Canada-U.S. estimates shows that the estimation methodology used up to now may include the effect of trading behaviour with third countries on the border effect estimates. Thus our model could be further refined by taking into account all of Canada's trading partners to produce unbiased estimates of its border effect with every individual partner.

We conclude this thesis by critically evaluating the work that has been done in the area since 1995, summarizing the state of our knowledge about border effects and outlining the directions for further research on the issue. 


\section{Chapter 2}

\section{Border Effects Research: Discovery and Development}

The subject of international trade theory has traditionally been the exchange among nations, in which English cloth and Portuguese wine were sent across national borders. The internal trade of a nation was rarely the subject of economic inquiry, particularly since the nineteenth century when most modern nations have abolished all internal tolls and trade barriers. From the days of mercantilism, international trade was viewed as crucial to the well-being of the country and a subject of dedicated study, where some of the greatest minds in economics such as Ricardo have left their mark. Meanwhile internal trade was viewed as "business as usual" for a country; little data was collected on it and consequently, little or no effort was made to compare the two types of trade.

It was this comparison of internal and external trade by McCallum (1995) that opened up the field of border effects. In a regular international trade study, the effect of the border can not be determined because all trade crosses borders. Only when intranational trade data is compared with international data can this effect be assessed. To the widespread disbelief of the practitioners of economics (documented in Helliwell (1996)), McCallum found that in 1988 a given Canadian province was twenty-two times more likely to trade with another Canadian province that with a U.S. state, after accounting for economic size and distance. This result was particularly surprising since Canada and the U.S. were considered to be very similar in language, culture, political and legal systems as well as other aspects of life, and the border that separates them was not 
believed to be a serious hindrance to exchanges of any kind. The discovery of border effect thus cast doubt upon the degree of integration of the North American economy and indicated the need to verify, explain and align these surprising facts with the existing international trade theory. A number of studies on the border effect that followed have in effect opened up a new area in the economic literature.

This chapter is dedicated to describing and analysing this literature and its findings. It is as much a study of the border effect as a chronicle of the birth and early development of a modern economic idea, which in the fullness of time takes its place among the established theories that preceded it. In this chapter, a chronological survey of the emergence of border effects literature presents its evolution through the typical steps required to establish a new scientific idea or theory: from the early fact-finding, through specification search, to a maturing theoretical discussion on the place of border effects in the field of international economics.

\subsection{Introduction}

National borders are not just an important aspect of international economics, but its very reason for being. The general theories of money, banking and economic growth derived within the context of a single national economy grow increasingly more complex in implications and testing as the interaction between many economic entities is considered. This complexity has led to the emergence of international economics as a separate channel of inquiry into these interactions; the methods of this inquiry, however, generally differ from the methods used at the national level. For example, the question "why do 
countries trade?" has been the driving force behind most well-established theoretical models of international trade (as opposed to an empirical model such as the gravity equation, which is motivated more by the question "why can't we get good empirical results?"). A corresponding question - "why do people/regions/provinces trade?" - was rarely even considered at the national level; the links that make up the national economy are more often than not taken for granted. Likewise, even when similar questions are asked, a different set of tools and assumptions is typically used to answer them. For example, while exchange rate volatility in international markets inevitably brings up the issue of investors' beliefs and expectations (i.e. the international exchange market is regarded as a set of actors with rational behaviour and informational limitations), a quite different approach is commonly used to analyse national inflation. The latter is almost always explained as a monetary phenomenon. And yet from an objective vantage point in a world of perfect information, national inflation and the dropping value of the currency abroad would be seen not merely as related, but as one and the same event proceeding from the same causes. Thus not only do the flows of trade appear to be impeded and distorted by the national borders, but to some degree the economic ideas and perceptions are as well.

In explicitly recognising the existence of national borders and postulating that the regions of a national state may interact in ways similar to the countries separated by borders (while noting also the important differences in their behaviour), the recent literature on border effects has pointed the way towards a unified theory of regional economic interaction, comprising both intranational and international economic relations while identifying and accounting for the differences between the two. Such a theory 
would define the world economy as composed of two types of elements: economic spaces and borders that separate them. Depending on the level of aggregation, these spaces and the borders separating them into compartments would represent different entities. At the lowest "magnification level" this economic lens perhaps would pick out the "WTO""non-WTO" divide, with a formidable trade barrier between them, or maybe more meaningful dividing lines would be found between the resource, industrial and serviceoriented economies. A closer scrutiny with this lens would show a world of regional trading blocks bound together not just by common tariff policies, but by strong cultural and historical ties - EU, MERCOSUR, ASEAN, NAFTA etc. The next magnification level would be that of nation states, then the level of intranational regional economies, followed by cities, districts, households, until at the very lowest level of aggregation the lens would focus on Adam Smith's ubiquitous consumer, tied by a myriad strings to his butcher and baker with whom he trades, in much the same manner as in Smith's time and bound by the same laws that were first articulated by him. The formulation of such a theory through further research into the nature of borders would link the international economist closer than ever to the main channel of economic inquiry and its universal toolkit. In particular, modelling both the world and individual countries as a collection of regions is a major step on the way to a joint theory of international and intranational trade. Our work attempts to pave the way for this theory by considering the knowledge accumulated so far by the border effects literature and then using it to explain the border effects in North America and elsewhere in a consistent manner.

In a sense, the recognition of internal trade flows as a worthy subject of inquiry and the interest in comparing them to external trade flows stems from the increased 
interdependence and integration among world economies. The reduced importance of the borders that separate countries leads to the two types of trade being more alike. Consider now the apex of that trend - a borderless world, and the place of international economics within it. Goods would still move between Argentina and Italy, and international economics, albeit transformed, would still be relevant as a study of interregional trade and financial flows between different areas of the global state. The simple conclusion is that if the world is becoming more integrated, international economics must follow by becoming more regional - studying not the lines on the map that are meaningless by themselves, but the real differences between nations that lead to additional trade costs and create the illusion of power of the international borders. Studying these borders, one must bear in mind that they are but a manifestation of the nation states that created them to preserve differences among nations, with the seal of all their policies - not just economic ones - imprinted on the "width" of the border and its economic effects.

Today, there exists a wide-ranging collection of literature that deals with border effects in international economics. Since McCallum's (1995) seminal paper, which established the term in the international trade context, dozens of studies have explored the impact of borders not only on trade flows of goods, but also on consumer goods' prices, on labour mobility and in many other areas. These different fields of application will be considered separately in this survey which, however, focuses on the international trade aspect of the border effect, and particularly on the Canada-U.S. border. Although exploring the behaviour of other trading pairs gives us valuable insights into the border effect mechanics, the Canada-U.S. border is our preferred subject of inquiry as it offers many benefits and minimizes potential distortions. It combines the best data available, the 
particularly favourable population distribution and adjacency patterns, the relative geographical isolation of trading partners and finally, one of the largest trade-to-GDP shares in the world. ${ }^{1}$

The contemporary border effects literature can be subdivided chronologically. The preliminary findings stage (1995-1999) was mainly concerned with following up the original research by McCallum; it mostly amounted to small practical variations in the setup of the gravity equation and documenting the resulting regression coefficients for various trading partners. Once the novelty of the concept and the astonishing magnitude of the first results wore off, there was a surprising degree of agreement, if not with the letter, then with the spirit of McCallum's findings: that the national borders still matter more than most people thought was possible. ${ }^{2}$ It also became clear that the national governments and their spheres of jurisdiction "stand in the way" of many economic transactions besides trade in goods (perhaps through revealed preference of the citizens for domestic transactions) - border effects can be found in both labour mobility and capital mobility, and likely in any other exchanges between sovereign states.

In the period that followed (2000 to present), the literature has moved beyond these preliminaries into what may be termed the analytic stage. Border effects became a reality that demanded to be explained; depending on the type of explanations sought, literature became divided into two broad streams: theoretical and empirical. The theoretical branch merits careful consideration and represents the cutting edge of current

\footnotetext{
${ }^{1}$ The interprovincial trade data collected by Input-Output division of Statistics Canada has no parallels elsewhere; almost all of Canada's population is concentrated in a narrow band along the country's border with the United States; both countries are relatively isolated by oceans, with major trading partners (except Mexico) a considerable distance away; finally, Canada's very high trade-to-GDP ratio of $73 \%$ establishes the immediate importance of trade for the Canadian economic structure.

${ }^{2}$ It is quite likely that the author's intent did not stretch far beyond demonstrating this basic fact, which may have become obscured by the recent acclaim for the globalization tendencies.
} 
border effects research. The details will be taken up in due course; it is enough to note here that the focus of the theoretical literature is addressing the weak theoretical foundations for the empirical results obtained during the preliminary findings stage, and the need to improve these underpinnings before interpreting the border effect findings.

The intent of this chapter is thus to follow the development of the theory of border effects and its place within the current of economic research, as well as to identify and sort out the contributions of various studies to this theory. Accordingly, Section 2.2 gives a brief account of the early findings and describes the methods used to obtain them. Section 2.3 considers the initial response to these results that consisted mainly of exploring possible specification errors and better measurement of variables (especially distance variables). In Section 2.4, we describe the simultaneous expansion in scope of border effects studies and different areas in which border effects have been discovered. Section 2.5 discusses the theoretical response to the border effects puzzle, and Section 2.6 examines other contemporary attempts to answer the empirical challenge of high border effects in a world of integrated economies. The conclusion (section 2.7) discusses the directions that the debate may be expected to take and argues that the investigation of the issue of border effects may open new areas of theoretical inquiry in international economics. 


\subsection{McCallum and Follow-up - National Borders Matter}

The inaugural paper of the border effects literature, McCallum (1995) stated in no uncertain terms that the national borders still matter a great deal and the news of the demise of the nation-state had been greatly exaggerated. In his seminal paper, McCallum studied the impact of the Canada-U.S. border on trade between the two countries. The intent was to demonstrate that if these two Western Anglo-Saxon states, which are similar in their legal and political structures, are much more prone to trading internally than with each other, then the same conclusion should apply to most other countries. Hence, the picture of the smoothly integrated global economy, which was gaining currency at the time, would suffer an unsightly tear. McCallum's intuition for his results proved correct if he were to set out to prove that "global village" is today's reality, he would have based his study on some a priori heavily trade-distorting border and attempted to demonstrate that it did not have much of an effect.

The outcome of McCallum (1995) was the simple conclusion that, other things being equal, Canadian provinces in 1988 traded with each other 22 times more intensively than with U.S. states (or between 17 and 29 times more intensively with a $95 \%$ degree of confidence). These findings appeared so unbelievably large that a significant amount of space in that seminal paper and the immediate follow-ups was devoted to illustrating and explaining them, as well as testing their robustness. A classic example is that of Ontario trade with British Columbia vis-à-vis California: the distance to both from Ontario is marginally different, and California's GDP is roughly ten times 
higher than that of British Columbia. Thus in the absence of a border, one would expect trade to also be ten times higher; in reality, Ontario trades more than three times as much with British Columbia as with California. This result is even more surprising if one remembers that Canadian population and industry are strung out in a thin line along the U.S. border, a fact that should encourage trade with the U.S. rather than reduce it.

McCallum's interpretation of his results did not include (as has been sometimes claimed) predictions for change in trade volumes following the removal of the border; indeed, such an exercise is not even considered in the paper. The correct interpretation of his "headline number" is that domestic trade intensities in Canada were 22 times larger than international trade intensities. Its basic message is simply that the national borders, standing as a proxy for various national characteristics, continue to exert a decisive influence on economic activity, including the flow of international trade.

Turning to the technical part of that (methodologically very simple) paper, the equation estimated by McCallum can be written as follows:

$$
x_{i j}=a+b y_{i}+c y_{j}+d d_{i s t}+e \operatorname{DUMMY}_{i j}+u_{i j}
$$

where $x_{i j}$ is the logarithm of shipments of goods from region $i$ to region $j, y_{i}$ and $y_{j}$ are the logarithms of gross domestic products of the trading regions, dist $i j$ is the logarithm of the distance between them, DUMMY $\mathrm{D}_{i j}$ is a dummy variable that takes the value of 0 when the regions are separated by a national border and a value of 1 when they are not, and $u_{i j}$ is a classical error term. 
This equation expresses a simple idea that may be termed "Newtonian economics of trade": the attraction between two economic objects is directly proportional to their economic size (GDP) and inversely proportional to the distance between them. ${ }^{3}$. This constitutes the "gravity approach" to explaining international trade and carries both benefits and drawbacks; it is useful to examine these in turn as they will be crucial for the discussion that follows. It should be also kept in mind that there are many variations on this basic "gravity model", and it has been used in economics for a few decades with great empirical success. The reader is referred to Appendix A for the antecedents of this specification and its theoretical derivation; below we will briefly summarize its key implications.

On the positive side of the gravity approach lies its strong empirical record; it routinely explains $80 \%$ and more of trade between two regions, and it is not unheard of for it to yield $R^{2}$ in excess of $90 \%$ (e.g. "some of the clearest and most robust empirical findings in economics" described in Leamer and Levinsohn (1995)). Its simplicity and intuitive appeal may have just as much to do with its popularity. It is also extremely robust in a sense that its high explanatory power is largely invariant to the selection of countries in the sample as well as the time period.

The principal drawback of a typical gravity equation is its weak theoretical basis. As has been argued by Anderson (1979) and Deardorff (1998), any sensible theory of international trade would predict that trade increases with the GDPs of trading partners, and likewise that it decreases as transport costs increase; in that sense, the message of the gravity equation is largely trivial. An equation of that type can be derived from several

\footnotetext{
${ }^{3}$ Note that the original Newtonian equation features squared distance; moreover, if size is interpreted economically, then so should be the distance (as transportation costs). These issues are addressed in greater detail below.
} 
existing theories of international trade; however, this means that its empirical record cannot be cited as direct support for any one of these theories. This weak basis also leads to another problem: the gravity equation has been estimated in many different forms by different authors. These various forms have been justified by the use of more or less plausible arguments, but rigorous theory had little place in these considerations; indeed, it is hard to imagine that this process would not drift in the direction of the version that produces the "best" results. Meanwhile, the Heckscher-Ohlin theory as well as the monopolistic competition theory imply only certain well-defined forms of the gravity equation, and departures from those forms are not, strictly speaking, consistent with theory - which is the main point of the Anderson and van Wincoop (2001) theoretical critique of McCallum's approach. ${ }^{4}$

McCallum's findings were quite surprising to the international economists, given that the explicit barriers to trade are largely absent between the U.S. and Canada and the two countries are very closely related in language, culture and institutions. Understanding and explaining these unexpected results became a priority. One of the first follow-ups was that of Helliwell (1996). This paper has verified and extended McCallum's findings. It confirmed that the "border effect" - the factor by which intranational trade exceeds international trade in intensity - was around 20 for the three-year period (1988-1990) and surveyed the first set of possible explanations for these results. These were: adjacency effect (proceeding from incorrect determination of the goods' final destination), transportation mode effect (uniform substitution of geographical distances for

\footnotetext{
${ }^{4}$ Similarly, Obstfeld and Rogoff (2000) point out that the explicit introduction of the costs of international trade (including not just transport costs, but tariffs, non-tariff barriers and other trade costs) into the theoretical framework can explain much of the home bias effect that McCallum's findings illustrate, as well as a number of other real trade puzzles.
} 
transportation costs distorting the picture for the regions using, for example, primarily oceanic rather than continental trade) and the entrepot effect (distribution channelling due to economies of scale in importation). The border effect proved quite robust to all of these considerations, ruling out its being a fluke and suggesting deeper underlying causes. Helliwell (1996) made another important contribution by linking McCallum's border effects in international trade with studies on price variability within and between countries (e.g. Engel and Rogers (1996), whose result was that the U.S.-Canada border reduced the covariability of prices by an equivalent of 2,000 miles of distance), and with the capital markets integration literature (where Feldstein and Horioka (1980) showed that the international capital markets may be much less tightly integrated than the national ones). All of these findings have greatly enhanced the significance of McCallum's findings and added up to a surprising hypothesis on the nature of a modern nation: that despite the apparent globalization process, its internal economic linkages are still much stronger than external ones, and the extent of a nation's dependence on international markets and policies may have been greatly exaggerated.

Meanwhile, border effects between other nations became of interest to researchers and the question arose whether the Canada-U.S. border is somehow unique in its sizeable impact on cross-border trade. The difficulty here was and remains the fact that Canadian interprovincial trade data is unique; no advanced industrialized country collects comparable statistics on internal trade. Thus, to estimate the border effect among other country pairs it was necessary to derive a proxy measure of interregional trade within a nation. These estimates of internal trade were obtained using two different methods, which are described in the next section. 
The present review primarily focuses on the estimation of Canada-U.S. border effects. However, it is neither possible nor wise to ignore studies that involve other countries as they have contributed significantly to the theory of border effects in general and have shed some light on the behaviour of the Canada-U.S. border, in particular. It is by studying and comparing to other borders that one is able to determine what is peculiar and what is regular in the results concerning North American borders. Accordingly, general findings of major importance to the theory of border effects are summarized in section 2.3 below, even if they deal with other borders. The international results that consist primarily of extensions in scope and have no decisive implications in the North American context are considered later in section 2.4 - which should not to be taken to mean that these studies are of little relevance (as several points and techniques borrowed from them will enrich the subsequent study of the Canada-U.S. border), but simply as a convenient means of organizing an abundance of diverse material.

\subsection{Early Explanations: the Heyday of Specifications in the Literature}

The borders literature soon expanded after the publication of McCallum (1995), motivated both by the desire to replicate Canada-U.S. border effects across other borders and to explain the existing results. These results still seemed too large to the academic community, and specification error seemed the most likely culprit. The literature at this stage, therefore, attempted to fit a "better gravity equation" to the data and explain the border effect with something known, but overlooked in McCallum's simple specification. All of the papers discussed here continued to specify an empirical gravity equation, 
without deriving the specification from theory, and adding the extra variables to the final specification on an ad hoc basis. This absence of theoretical derivation will later be shown to have been a major weakness of this strand of literature; thus in surveying it now, we are more interested in innovations and development of ideas rather than in the values of border effect estimates obtained by these papers.

The first attempt to combine the approaches of replicating McCallum's results in a new setting and explaining them was made by Wei (1996). Due to the absence of internal trade statistics for other countries, McCallum's approach that divides a country into several regions and examines trade flows between them can not be used for borders other than between Canada and the United States. Wei's approach considers the country itself as the basic trading unit; its internal trade is then compared to its international trade. In Wei (1996), domestic sales served as proxy estimates of intranational trade. Domestic sales were estimated by subtracting merchandise exports from gross output of goods industries, while internal trade distances were generally assumed to be one-quarter of the distance from the domestic capital to the nearest border. In the absence of regional trade data, this approach has few alternatives and so has since been widely used.

Wei's work also introduced the remoteness measures into the gravity equation for border effects estimation. ${ }^{5}$ Other specification changes first made by Wei were his accounting for adjacency, use of common language, and European Community (EC) membership. The upshot of using those measures was the conclusion that although border effects in this specification remained significant, their aggregate level was reduced by an

\footnotetext{
${ }^{5}$ Helliwell (1997) remarked that Wei's empirical remoteness measures were not strictly consistent with the theoretically implied functional forms and consequently took unexpected signs in the estimation process. He went on to suggest a preferable remoteness index that improved the fit and theoretical soundness of the model.
} 
order of magnitude from McCallum's level (an average barrier of 2.6 between the OECD countries). Thus Wei (1996) made a significant claim for the case that the introduction of linguistic, monetary, geographic and other barriers had the potential to fully explain the border effects, and that view was an influential one for several years, until shaken by contrary evidence.

Following up on his earlier paper, Helliwell (1997) experimented with many different specifications, building also on Wei's work and adding variables to control for countries' wealth and population, which affect the elasticities of bilateral trade. The aim of the paper was primarily to establish links with Wei's research and to reconcile the U.S.-Canadian results with OECD results. Thus the dataset for OECD countries was used, and domestic sales and the internal distances were estimated as in Wei (1996). The paper shows that the juxtaposition of McCallum's results with Wei's must necessarily lead to a paradox: Wei's theoretical contention that adjacency and common language reduce border effects leads to the conclusion that Canada-U.S. border effects must be lower than the average OECD effects, while McCallum's estimates are much higher than these. Using modified Wei's procedures (which includes changes to the remoteness index as noted above), the preferred specification of Helliwell (1997) inclusive of all the additional variables resulted in a baseline average border effect of 15.9 between unrelated OECD countries (implying a 6.0 coefficient between Canada and U.S.). These estimates are thus not directly comparable with McCallum's, but are still very high. In addition, even though the paper was following and refining Wei's methodology, its results put his main conclusion in doubt. The introduction of the adjacency, language, EC membership 
and remoteness index variables reduced the apparent size of the border effect, but by no means made it insignificant.

Soon after, Hillberry (1998) took another approach to the problem of measuring interregional trade within a nation. His paper developed a methodology for using the United States Commodity Flow Survey (CFS) to estimate U.S. intranational trade (at the interstate level). He used the 1993 CFS to evaluate not only the geographical pattern of commodity flows within the United States, but also the commodity composition of these flows, with the idea that borders affect not only the volume but also the content of trade. The use of the CFS is associated with some important caveats: exclusion of air and waterborne shipments from the data, industry-to-commodity conversion issues and the necessary assumption that all shipments covered by the survey represent international or interregional trade and not distribution activity. ${ }^{6}$ Building in many respects on an earlier paper by Wolf (2000, NBER working paper version in 1997), Hillberry (1998) measured intranational distance as the distance between the two largest cities in each state, and also took into account suggestions on specification of additional variables in Helliwell (1997). The resulting estimates were nearly equivalent to McCallum's original estimates. These results contrast strongly with Wei's (1996) results for the OECD. Considering the big difference in data sources between McCallum and Hillberry, this result was strongly supportive of the evidence on the North American border effect.

\footnotetext{
${ }^{6}$ The last issue will likely remain debatable for some time, since the same objection can be made to any intra-national data (indeed, to the data at any level). Only a more detailed disaggregation provides an answer, and partial one at that. Even if data at the individual level were available, there is no guarantee that the purchased goods would not be subsequently resold privately, or that their consumption will necessarily occur near the point of purchase. As long as purchase and consumption are treated as equivalent, it is difficult to distinguish between trade and distribution.
} 
The use of the CFS data allowed Hillberry (2002) to develop the idea that one of the reasons for the border effect may be the established pattern of production, inherited from earlier times when the national differences mattered more than they do today. This pattern of production, trade and distribution has led to a long-term adjustment of industries on both sides of the border. In his model, international trade is compositionally different from internal trade; this difference is due to patterns of industrial location and consequent adjustment in the number of traded commodities. By disaggregating trade flows and controlling for the firms' location, this paper obtains a much-reduced border effect of 5.7. Part of the reason that this paper (together with many recent papers, notably Anderson and van Wincoop (2001)) arrives at much lower estimates than McCallum's is not that it directly explains the border effect, but rather changes the research question. The inquiry departs from McCallum's original question of "how much do the national differences affect trade?" and asks rather "what would be the effects of the removal of the border?" These are very different questions.

Historical adjustment of industrial location and trade patterns to the existing borders has been occurring, in some cases, over centuries. These patterns were perhaps originally due to the border $^{7}$ (and all that it implied, e.g. trade policy), but are no longer dependent on it for their continued existence. In the short run at least, the removal of such a border will not lead to a quick and costless readjustment of firms' locations and patterns of trade - which is in effect what these papers assume. Rather, if the existing pattern of trade (dependent on things other than the border: historical patterns of firm location,

\footnotetext{
${ }^{7}$ But strictly speaking, neither are the borders the ultimate first cause - being merely a reflection of political, military and geographical realities. The Canada-U.S. border, being a north-south watershed of North America, reflects a historical pattern of trade driven by geography of transportation routes, with eastwest trade always more intensive than the north-south trade. The point is not that the drawing of the border affected long-term trading patterns, but that both factors were affected by deeper underlying causes.
} 
legislation and tastes) is taken as given, then at least in the short-run McCallum's original estimates describe the situation better. ${ }^{8}$ For example, the effective removal of the barriers to trade between EU states and the consequent opening of the Italian markets to softwheat pasta has not appreciably raised sales of it in Italy from a low level: local traditions and recipes are all against it. Not unless these are to be removed, too, will trade in this item reach the level expected by the "border removal" approach. Conversely, the expectation that border removal would have little impact should not imply that the current border effect is small. We touch upon this issue again in section 2.5 while discussing Anderson and van Wincoop (2001).

Wolf (2000) put into serious doubt Wei's idea that linguistic, monetary and geographic barriers, when properly accounted for, can explain most or all of the border effect. Wolf's paper was the first to use the CFS to estimate intranational trade within the U.S. and to find sizeable border effects ( 3.0 to 3.7 depending on the specification) where none at all should be expected - between the states of the U.S., which are constitutionally prohibited from erecting trade barriers. This definitive finding ${ }^{9}$ of the existence of border effects on the sub-national level was an important factor in directing new research away from mere changes in specification of the gravity equation and towards conceptually new explanations for the border effect phenomenon.

Anderson and Smith (1999) (hereafter AS) take another thorough pass at the meaning of McCallum's and Helliwell's results. Their primary contribution to the

\footnotetext{
${ }^{8}$ Surprisingly, there exists some evidence to answer a seemingly hypothetical question: "what happens if the border is removed?" Section 2.4 describes Wolf (2002) who explores the case of re-emergence of Poland and the effect of the removal of the imperial borders that used to separate it into three parts.

${ }^{9}$ In a European state traditionally composed of small, historically insulated communities with local dialects and customs, finding some internal barriers to trade would not be entirely surprising. But the finding that the U.S. state borders (most of which are arbitrary straight lines on the map) impede trade is of great consequence.
} 
literature lies in introducing the idea that the border effect, previously summarily measured on the basis of total trade flows in both directions, may be disaggregated into two different effects. The authors ask whether the border effect is the same for U.S. exporters as it is for Canadian exporters. The logical theoretical answer to this question supplied in the paper is in the negative, since foreign markets would presumably be of a lesser importance to a U.S. producer (supported by a large domestic market) than to a Canadian one. ${ }^{10}$ Empirically, this answer is supported by the evidence of the paper: the border is perceived differently depending upon which side of it a (potential) trader lies. The logarithm of McCallum's border effect equals 3.09; AS separate all shipments into U.S. exports to Canada and U.S. imports from Canada to obtain flanking coefficients of 3.21 for the former and 2.97 for the latter. Thus AS state that U.S. exporters view the border as a more substantial barrier than Canadian exporters do; the opposite holds true for the U.S. importers. But the alternative explanation may be that Canadian businesses are relatively more willing to export to the U.S. market than to import from there; and it is likely that both factors are combined in these results.

The finding of this (albeit small) difference between the two sides of the border and recognition that the border effect may be disaggregated brings twofold benefits. First, it is analytically helpful to discern that any international border is not a single line but, just like a military front line, consists of two parallel lines of impediments manned by two different forces. The Canadian border line imposes one border effect on the U.S. exports while the U.S. line imposes a different one on the Canadian exports. Secondly,

\footnotetext{
${ }^{10}$ On consideration, the answer would clearly depend on the degree of relative industrial concentration and relative border effects (international vs. intranational, the existence of the latter having been shown by Wolf (2000)), and will vary between different industries. It is possible, for example, for a Canadian governmentchartered natural monopoly to feel less compelled to export than a U.S. private company operating under severe domestic competition.
} 
there is no a priori reason for these two border effects to be the same, even if the border costs are. ${ }^{11}$ Mathematically, the border effect is a ratio between intranational and international trade intensities. If the intensity of internal trade of the two partners is different, border effects will also be different, depending on whose internal trade is used as a benchmark. Only when the internal trade intensity is the same for both countries should we expect the same border effect on both sides. In this light, the practice of lumping imports and exports together for the purpose of estimating the border effect (as in prior and nearly all subsequent estimation) may be viewed as estimating a restricted version of the AS disaggregated equation. Since AS show that these effects are statistically different at the 5 percent significance level, this restriction is also unwarranted. Theoretically, the AS contention is also sound (see Appendix A for derivation of the gravity equation, which generally assumes a one-sided flow of goods). There is one problem implied by this approach, and that is that the import and export flows between any two regions are expected to be the same based on the gravity equation of the paper. Strictly speaking, it is not the fault of the one-sided approach, but of a simplistic gravity equation used in the estimation; a more sophisticated, theory-based specification should not necessarily predict symmetrical import and export values for any regional pair.

AS then extend their analysis to a more detailed level by estimating border effects by region. Prior to AS, the literature considered only one dimension of the border effect: its "width" (e.g. the Engel and Rogers question "how wide is the border?") in the sense of its general restrictive effect on trade. AS inquire into the different "width" of the border

\footnotetext{
${ }^{11}$ Even under reciprocal free trade, same border costs are implausible, due to differences in domestic industrial structure, scale of production and intermittent trade disputes and sanctions.
} 
at different points along it. Having shown that the border effect is not simple and uniform across the border by disaggregating it, the authors proceed to show that neither it is uniform along the border. Different Canadian provinces bordering the U.S. have different border effects, and some of them exhibit large divergences between border effects for imports and exports. ${ }^{12}$ Finally, border effects prevailing against countries other than U.S. are investigated. Despite the economists' strong prior expectations on this issue ${ }^{13}$, the results for Canada reject the notion that its border effect varies by trading partner. Border effects between Canada's twelve largest trading partners are found to be largely the same as between Canada and the U.S. If anything, the former were lower (20.7 vs. 23.1), although the difference between the two was not statistically significant. AS have not shown whether a specialized pattern of trade, measurement bias or some other effect is responsible; however, the result may be specific to Canada, because European studies have shown that other countries have a lot of variations in their border effects with different countries.

AS thus provide an important contribution to the literature. As in all previously discussed papers, their gravity equation is not derived from theory, and the values of their estimates are expected to be biased. However, the disaggregations of the border effect by direction of trade and by region have provided additional insight, and are of assistance in explaining border effects. These explanations, however, "must be nuanced enough to account for substantial provincial variation. Canada-wide explanations - shippers'

\footnotetext{
12 Hence some provinces are identified as export platforms (British Columbia) and some as import platforms (Ontario).

${ }^{13}$ For example, Rauch (1996) shows that networks of trading contacts dependent on common languages and institutions are responsible for much of international exchange, implying that similar nations should have lower trading barriers among themselves.
} 
perception of exchange rate risk $<\ldots>$ - will not suffice". ${ }^{14}$ Paraphrasing this conclusion, we may state that the same approach should be used in accounting for substantial national variation in border effects, and that a global explanation will not suffice either. These results show that likely there is no simple and universal solution to the puzzle, and the variety of border effect findings need to be appreciated and understood rather than "explained away".

One of such universal solutions indirectly suggested in the literature was to redefine the issue of border effects in terms of "home market" effects whose existence could be theoretically supported, and thus explain the issue by justifying relatively larger internal domestic trade. In view of AS results, we note that such a sweeping explanation seems simplistic and may prove inadequate to explain the variety of the border effects findings. The accumulation of data and observations on both international and intranational trade flows over ten years of border effect studies may well have exceeded the empirical contributions of international trade research in the previous twenty. Insofar as a good theory is born from the observation of the facts, this seems a propitious time to develop one, all the more so since the theory of the "home market" effect (first described by Krugman (1980)) is not in itself incontrovertible. For example, Davis (1998) shows in a theoretical model that when identical transport costs are defined for both differentiated and homogeneous goods, the home market effect disappears. Thus the theory presented by Helpman and Krugman (1985) that states that differences in relative market size of

\footnotetext{
${ }^{14}$ Anderson and Smith (1999), p. 36.
} 
trading partners will lead to home bias ${ }^{15}$ represents, by their own admission, a special example dependent on the crucial assumption adopted by them.

In effect, further theoretical discussion of home market effect may not lead to satisfactory conclusions about the variety of stylized facts. These need to be studied directly to help inform theory development. A coherent theory linking the home market effect and the border effect is necessary to account for the variations by industries, provinces and countries. Until such a theory is developed, the home market explanations will remain useful but insufficient, much like common language or adjacency explanations. For these reasons our preference throughout this survey will be for the examination of the issue in the terms similar to those originally stated by McCallum and Helliwell, centering on the comparison of the internal and external trade intensities in an empirical investigation. The appeals to home market effect by some of the studies should not be ignored, but for us the proper procedure seems to incorporate the assumptions that give rise to the home market effect into the derivation of the gravity equation and examine the obtained results, rather than switch the focus of discussion entirely away from the empirical estimation.

To return to the variations on the original gravity model specifications, one must mention Helliwell and Verdier (2001) as one of the latest papers of this strand that seeks to measure the gravity model parameters more accurately. They develop a thorough method for measuring internal trade distances by explicit modelling of urban and rural population structure in each Canadian province; their distance estimates are population-

\footnotetext{
${ }^{15}$ The intuition for this result is as follows: under increasing returns to scale, the producer of differentiated goods faced with choice of a production site will choose the larger country to minimize his transportation costs. As a result, the larger country will end up with a larger share of the differentiated goods industry, leading to a lower price index in this sector and a home bias in consumption.
} 
weighted and dependent on the grid of intra-city and inter-city distances. This spatial analysis results in higher estimates of internal distances, implying higher border effect estimates than obtained by contemporary papers. Thus the authors show that Wei's measures of distance are inadequate for two reasons: they depend on the geography of the neighbour and significantly understate the real internal trade distances.

It should be noted, however, that these results are obtained for Canada only and that its special geography must have a lot to do with the result; it is less clear that internal trade distances in the rest of the world would be either so high or so different from Wei's assumptions. Two papers by Head and Mayer, analyzing the European experience, underscore this point. Head and Mayer (2000) is more extensively discussed in the next chapter; here it is sufficient to mention that they calculate bilateral distances between European regions and weight these by the economic size of the regions. The results obtained in this manner feature generally higher internal distances within European countries and lead to higher border effects than the estimates using Wei's definition of internal distances; however, the effect of the procedure is not as large as in the case of Canada.

In Head and Mayer (2002) the authors take quite a different tack. They argue that there are three basic ways to answer the puzzle presented by the border effects. Either small trade barriers are quite capable of generating large trade costs, or one of the two are mismeasured (trade barriers are underestimated, or border effects are overestimated). They pick the third approach, making this one of the last papers to attempt the argument that the whole phenomenon of border effects is largely illusory. In the study's view, the 
border effects are being inflated because the standard internal trading distances are systematically mismeasured, as relative to external distances.

The main change that the authors introduce to the specification of distance in the gravity model is to work not with geometric approximations, but with continuous states along a line, or in a plane. They introduce the concept of "effective distances" between regions which calculates these consistently with external distances, so that the sum of trade between two states as a function of their distance to each other can be replicated as a function of regional trade and regional distances. Deriving these distance formulas from the general mean function, they obtain smaller estimates than the average distance method that was used previously. This reduces border effects significantly: from a onethird reduction in case of Wolf-type effects (U.S. interstate border effects) to two-thirds in the case of Wei-type effects (European international border effects). This is an impact of such magnitude that the authors were hoping to explain away the border effects entirely with their work; however, what remains of border effect for Europe is still significant and requires further explanation.

The applicability of Head and Mayer (2002) results depends to some degree on the setting. For OECD and EU estimates, they are likely to be important. The authors correctly point out that Wei's approximation is imperfect, and present a better approximation, but it is still not a good substitute for internal trade data. For the CanadaU.S. border, regional trade data is available and so the border effect estimates depend on internal distance and trade approximations to a much lesser degree. In addition, while the derivation of the equation in Head and Mayer (2002) is based on theory, the form of the gravity equation relied upon in deriving effective distance is not, making the result 
somewhat circular. All in all, the extent of the assumptions required to estimate border effects in Europe is presently so great that even significant improvements to the techniques of distance calculation can not compensate for the fact that one is obliged to work without data for the dependent variable. As long as this data is lacking, estimates for Canada-U.S. border must remain the preferred results in the field.

The above section of the survey does not contain all of the factors that potentially influence or explain border effects. This is because these are not dealt with in the literature. One of the two major gaps is the conspicuous absence of the measures of tariff and non-tariff barriers. These are, on one hand, held to cause large border effects, but on the other hand are not included in the estimation explicitly. The truth is that there are plausible reasons for this state of affairs: the lack of data on non-tariff barriers, and the difficulty of including tariffs (which are perfectly correlated with the border variable when the gravity specification is estimated for a single year). Nevertheless, the absence of direct estimates of the effect of tariffs does represent a serious gap in the literature. We attempt to remedy this situation in Chapter 4.

Many other causes are considered to lie "hidden" in the border effects estimates. The underlying differences in information, tastes and preferences may certainly account for some of these effects; networks of trust and knowledge that are sometimes thought to form the basis of trade are yet another class of explanations. To illustrate how biased the border effects estimates may turn out to be, one trade impediment proxied for by the border and identified in Anderson and Marcouiller (2002) was corruption and expectations of corruption. Insecurity resulting from corruption acts as a hidden tax on trade; but neither is corruption the only source of insecurity in the world. Even though 
cross-country institutional variations and differences in institutional quality between Canada and the U.S. may be small, the differential treatment expected by foreign producers may contribute to reluctance to trade, and it is a fact that the level of concern with security in the two countries always differed and continues to do so. One may expect these and other, yet undiscovered, reasons to account for the unexplained parts of the large border effect between such apparently similar countries as Canada and the United States.

The difficulty with the factors mentioned above is that there are few practical ways to estimate their impact. In principle, all these factors can be separated into two classes: sources of home bias (preferences etc.) and sources of trade costs (uncertainty etc.). Then measures of common language and adjacency can to some degree be interpreted as proxy for networks, i.e. sources of trade costs. Networks are likely to be more developed between those who speak the same language and those who live close to each other; and if they are not well developed, costs of trade increase. But unless these variables are introduced theoretically, their potential for added value will not be realized fully. We address this gap in the literature by explicitly introducing several variables that measure home bias and trade costs into our theoretical model of border effects in Chapter 4. 


\subsection{The Expanding Scope of Border Effects: \\ From Mexican Prices to Polish Reunification}

An expansion in the field of border effects occurred simultaneously with the studies revising the gravity equation specifications as described above. Border effect was first identified as simply a coefficient on a dummy variable peculiar to certain Canadian data for a particular point in time. In ten years, it has been acknowledged as a widespread phenomenon, with evidence and implications both inside and outside the field of international economics. To a large degree, this growth in stature had to do with the papers discussed in this section. They established links to other areas in which border effects can be identified, and helped legitimize them.

Two strands in particular can be discerned in this body of literature. The first comes from the field of international financial economics and deals primarily with price equalization along the lines of purchasing power parity (PPP) hypothesis. In essence, price differences between cities in different countries are shown to be greater because of the borders. The second has identified border effects in a broad international context, with applicability to economic history and international relations. Let us consider these two main strands in turn.

\subsubsection{Price Equalization Studies}

Engel and Rogers (1996) represents the early contribution in this area. The authors examined the deviations of consumer prices from the law of one price in 
Canadian and U.S. cities and found that correcting for distance and, furthermore, for nominal price stickiness leaves a residual that is analogous to McCallum's border effect for international trade. National borders thus matter also in international pricing; they exercise their influence by segmenting the goods markets. In addition, the border effect for prices could not be hypothesized to be due to trade barriers only, as was sometimes conjectured in the international trade literature discussed earlier: it exhibited no tendency to fall after the 1989 free trade agreement (in fact, even rose).

Rogers and Smith (2001) examined a set of city price data similar to Engel and Rogers (1996); their data includes Mexico, features a larger sample size (1980-1997), asks more questions and sheds more light on the issue of border effects in international prices. In particular, currency stability plays an important role in reducing border effects. The authors show that the "width" of the U.S.-Mexican border is an order of magnitude larger than the U.S.-Canadian one, yet this difference has nearly disappeared during the period when Mexican currency, the peso, was highly stable. Another finding is that Mexican border towns in the "frontier zone" that have experienced relatively unrestricted trade with the U.S. for many years do not appear to be much more integrated with the U.S. than the rest of the country. This suggests that country-specific rather than regionspecific reasons account for the bulk of the border effect found.

The importance of currency stability is in agreement with Frankel and Rose (2002), who estimate the effect of common currencies on trade and income. They find that adopting common currency may lead to a threefold increase in trade with the other currency union members. In their work, the currency union variable ranks in magnitude along the FTA variable and ahead of common language. Their link to McCallum's 
findings implies that Canadian provinces may trade more intensively with themselves partly due to sharing common currency. Meanwhile, risk and exchange rate variability impede trade with the U.S. and contribute to the hidden costs of trading across the border. Though the magnitude of Frankel and Rose's results may be disputed, both these papers make the case that the different currencies and the resulting fluctuation of exchange rates contributes to the border effect - in pricing as well as in goods trade.

Engel and Rogers (2001) return to the issue of short-run deviations from relative PPP, this time expanding the horizons of research to Europe. A consumer price data set from 55 European cities for the 1981-1997 period results in a high border effect that is very comparable to the one obtained in Engel and Rogers (1996) for Canada and U.S. Since data from many countries is considered, it becomes possible to estimate the local currency pricing effect. Once this effect is factored out, it is found that the border effect remains positive and significant, although becomes much smaller. ${ }^{16}$ Thus even after the exchange rate issues are eliminated from the sample by the advent of the Euro, border effects in prices between European cities are likely to remain significant. ${ }^{17}$

\subsubsection{International Studies}

A first-class contribution that re-opened the subject of trade barriers in the European Union was the study by Head and Mayer (2000) (hence HM). Since McCallum's paper, exploration of the border effect issues has mostly been centered in

\footnotetext{
${ }^{16}$ The magnitude of the border effects in all these papers is highly sensitive to the choice of measurement periods; it is also not directly comparable to the border effects in goods trade, and so is not reported.

${ }^{17}$ In fact, price convergence studies show that most of the convergence of European prices occurs in the early 1990's, before the adoption of the Euro.
} 
North America. While the EU received preliminary treatment in Wei (1996), Head and Mayer (2000) revisited it in possession of extensive data drawn from a number of European databases and available down to 3-digit industry level. This paper was among the first in the field to feature a strong theoretical foundation, and introduced a procedure that considerably simplified the derivation of the final specification from a theoretical model.

HM's regression equation was derived from the monopolistic competition model of trade and hence included price terms (see the discussion of Bergstrand (1985) in Appendix A). There was a problem to solve, though, in that the dependent variable, imports of region $i$ from region $j$, contained an "inclusive value" term that prevented closed-form solution. Through a simple expedient of dividing this variable by imports of region $i$ from itself and taking logarithms, HM obtained a tractable expression and achieved significant innovation: the equation is firmly grounded in theory, and yet the complex suite of remoteness measures is no longer necessary for estimation. The authors also used theoretical restrictions on the coefficients. Together with Nitsch (2000) they firmly put EU on the map of border effects studies; both papers used improved methodology for calculating internal distances and obtained significant, high border effects between European states in the range of 7 to 14, thus definitely bestowing an international status on the border effect phenomenon.

Nitsch (2000) developed alternative methods of distance measurement to estimate border effects within EU. The estimate of the paper was that for twelve European countries between 1979 and 1990, intranational trade was about 10 times in excess of international trade with EU trading partners. Were this paper, largely completed in 1997, 
published earlier, it would be credited with two new ideas that by 2000 have already seen the light of day - specifically, detailed investigation of Wei's earlier EU estimates and the use of new distance measures. By the time of the publication, Helliwell and Verdier (2001) already came up with a more advanced method of distance measurement, and the work of Head and Mayer (2000) was addressing the same questions with stronger theoretical foundations. Nevertheless, the influence of Nitsch's ideas on these papers cannot be discounted.

One of the most interesting international studies of border effects in international context was conducted by Fitzsimons et al. (1999). Their paper finds that there is a "reverse home bias" in trade between the Republic of Ireland and Northern Ireland, meaning that these regions trade more than expected under standard gravity model, producing a "negative border effect". They also find that some other closely integrated country pairs behave in a similar manner (e.g. Norway-Sweden). It can be surmised that what happens in these cases is the following: the very similar neighbouring country is so closely related to the home country by language, culture and history ${ }^{18}$ that it acts as a "second home" for the home country, and exports to it are also subject to enhancement through home bias, just as the internal trade of the home country. This result is a strong statement in favour of the dependence of border effects on cultural, historical, linguistic and perhaps even family links between countries. It also contrasts with the Canada-U.S. case (whose geographic isolation from the rest of the world is not unlike that of the Irish, and whose links are thought to be at least as strong) and suggests that a full explanation of the border effect puzzle must account also for these large differences among country

\footnotetext{
${ }^{18}$ Both Norway and Ireland have been independent for less than a hundred years, and have spent the previous five centuries attached to the crowns of Denmark and England respectively. Denmark was not in the sample of countries examined in the paper.
} 
pairs. In particular, it may be the case that the affinity between the two North American countries, taken for granted in the literature, may have been overestimated.

Wolf (2002) is an unusual paper because it applies the concept of the border effect to the events far in the past and extends it to economic integration topics. It deals with a novel question: how did the re-emergence of Poland as an independent state and consequent integration of its trade and economy in the period between the two World Wars affect the internal trade of this re-created country that for 125 years had consisted of Austrian, German and Russian parts. This unique approach allows one to investigate the crucial question alluded to earlier: what actually happens to trade when a border is removed or created? The case in point features both phenomena: the removal of RussoAustrian-German borders (formerly cutting Poland in three parts) and the emergence of Polish borders with these countries where no borders previously existed. Since the paper's primary aim is to study the re-integration of the Polish market, only the first issue is dealt with explicitly by the author (which may have also been due to the lack of data to explore the second question). A dynamic persistence of the former borders and their strong effect on trade is found, which has declined through time as the country became more homogeneous; however there was clear evidence of home bias in regional Polish trade during the period between the two World Wars (1926-1934 data). In the year 1926, internal trade within the ex-Russian part of Poland was 4.2 times above normal ( 5.5 for the ex-Austrian part and insignificant for the ex-German part). By 1934, the ex-Russian and ex-Austrian home biases have decreased to 3.2 and 3.5 respectively.

A short discussion of this unique evidence is in order. Certainly the most doubtful point is the quality of the data, coming from the Statistical Yearbook of goods transported 
by railway, exclusive not only of all other modes of transport, but of some non-standard railways as well. A more subtle objection is that the home bias may be overestimated because effects of the new Polish borders were not taken into account. In other words, it is likely that the ex-Russian partition would trade more with Russia (as before the reunification) and be less home-biased if there wasn't a recently created Polish border in the way. Thirdly, the home bias of the partitions is not greatly in excess of Wolf (2000) estimates of border effects between the U.S. states, and thus does not constitute sufficient proof that these partitions behaved as separate countries. Yet in any case, it would not be warranted to consider this successful integration scenario as a blueprint for other hypothetical integrations, either in North America or EU. The fact is that these three constituent parts of Poland were still strongly tied historically, culturally and linguistically despite the oppression of their imperial masters and exhibited a consistent desire to reunite their country, thus having a peculiar affinity for trade with each other, similarly to the examples in Fitzsimons et al. (1999). This fact can not be isolated in the regressions of the paper, where every region possesses that quality, but it means that the results are not directly comparable with other findings and possess limited guiding value.

One of the latest papers on European border effects is De Sousa and Disdier (2002) which examines the trade flows of Hungary, Romania and Slovenia. Their internal and external distances use the same methodology and are calculated as the sum of bilateral distances between the constituent regions weighted by the share of the population of each region:

$$
d_{i j}=\sum_{g_{j}}\left(\sum_{g_{i}} O_{g_{i}} d_{g_{i} g_{j}}\right) O_{g_{j}}
$$




$$
\text { where } O_{g_{i}}=\frac{p o p_{g_{i}}}{p o p_{i}} \text { and } O_{g_{j}}=\frac{p o p_{g_{j}}}{p o p_{j}}
$$

pop being the population of country/region, $g_{i}$ are regions of the country $i, g_{j}$ are regions of the country $j$ and $d_{i j}$ is bilateral distance. Internal distances of the region are determined assuming that the region's shape is that of a disk (in this case the internal distance is proportional to the square root of its area). It is not clear, however, whether the combination of these methods is consistent, e.g. whether the disk assumption for a country would be consistent with the internal distances of its regions given by formula (2). Conspicuous also is the absence of the remoteness variables. Subject to further research into this question, and considering that using GDP instead of population leads to very similar empirical results, this methodology would present a simple and accurate way to scale economic distances between regions.

The authors advocate using advanced econometric techniques to correct for the possible bias due to correlation between variables and the unobservable characteristics in the estimates of the border effects. They use an instrumental variable estimator for panel data regression models according to the Hausman-Taylor procedure ${ }^{19}$ to correct for correlation between the explanatory variables. It is unfortunate that, due to the country sample selection, their results - border effects of 31 under ordinary least squares estimation and 52 after the corrections - cannot be compared with results obtained using more traditional methods (which generally indicate that more advanced econometric techniques yield very small differences compared to OLS) and thus provide no opportunity to evaluate the effect of the econometric techniques used. Further research

\footnotetext{
${ }^{19}$ The paper in question has a detailed discussion of the procedure; Hausman \& Taylor (1981) is the original source.
} 
could and should evaluate the practical upshot of the author's undisputable contention that the OLS estimates are biased and inconsistent on a wider set of data.

In conclusion, it may be worthwhile to recapitulate the most important common feature of the research described in this section. The main thrust of all these papers is remarkably uniform, despite the diversity in countries, time periods and variables under study. Whether in Europe or America, whether for movement of goods, prices or workers, nations and national borders matter for trade.

In principle, for a new effect or variable to establish itself in economics, it must pass through several stages of inquiry. Once discovered, its existence must be confirmed by rigorous empirical testing. Thus when the border effect came into existence as an isolated phenomenon, it was first subject to "explaining away", as the early papers in Section 2.3 have attempted to do. The inability to eliminate this effect empirically established its legitimacy and ushered in the second stage of inquiry - finding links between the new variable and the already known variables, in effect "mapping" the place for the border effect in the literature and its explanatory potential. In this section, it was shown how the international economists had verified that the border effect was a widespread occurrence and found it to be dependent on numerous factors that also habitually affect trade and welfare. The third and most challenging stage of winning acceptance had begun for the border effect when it became a subject of rigorous theoretical enquiry. Either it would win approval, become theoretically formulated and subsequently incorporated into theory and textbooks, or be utterly discarded as an empirical quirk without real significance. The details of this trial, still ongoing at the present time, are presented in the next section. 


\subsection{Theoretical Critique of the Early Border Effect Literature}

While the border effect was emerging as a widespread phenomenon, the gravity models used in that research came under fire for lacking a firm theoretical basis. Many models were constructed on an ad hoc basis, building on previous work and adding new elements that did not necessarily flow from theory. A qualitatively new stage in the examination of border effects was thus opened by Anderson and van Wincoop (2001), who pointed out these shortcomings and firmly stressed the need for a model rigorously proceeding from economic theory. They have effectively moved the debate on border effects to a new level by their suggestion that omitted variables bias, improper (or non-existent) derivation of the gravity equation and ad hoc additions to the specification distort the message carried by the gravity equation and make the border effects estimates computed from earlier models largely meaningless. This paper explicitly introduced welfare considerations into the model and stressed the computation of aggregate welfare as the paramount objective of this research, thus single-handedly redirecting much of the subsequent debate on the issue towards the question of the welfare impact of the border. The theory-driven model of Anderson and van Wincoop (2001) (subsequently AvW) merits detailed attention and is discussed below.

The computable general equilibrium model (CGE) of AvW is constructed as follows. Assuming differentiated goods and homothetic preferences (CES utility), consumers in region $j$ are solving the following problem:

$$
\operatorname{Max}\left(\sum_{i} \beta_{i}^{(1-\sigma) / \sigma_{c}(\sigma-1) / \sigma}\right)^{\sigma /(\sigma-1)}
$$


subject to the budget constraint:

$$
\sum_{i} p_{i j} c_{i j}=y_{j}
$$

where $\sigma$ is the elasticity of substitution between the goods, $\beta_{i}$ is a positive parameter, $y_{j}$ is the nominal income of region $j$ residents, and $p_{i j}$ is the price of region $i$ goods for region $j$ consumers. These final prices are the sum of producer prices and unobservable trade costs $t_{i j}$, which will be identified empirically.

Following Anderson (1979), and assuming symmetric trade barriers, the gravity equation can then be derived as:

$$
x_{i j}=\frac{y_{i} y_{j}}{y^{W}}\left(\frac{t_{i j}}{P_{i} P_{j}}\right)^{1-\sigma}
$$

subject to

$$
P_{j}^{1-\sigma}=\sum_{i} P_{i}^{\sigma-1} \theta_{i} t_{i j}^{1-\sigma} \quad \forall \mathbf{j}
$$

where $y^{W}$ is world nominal income and $P_{j}$ is the consumer price index of $j$. Thus the remoteness (or "multilateral resistance") variables, deemed significant in previous work but introduced ad hoc, appear here explicitly as price indices. Trade between $i$ and $j$ is positively correlated with the multilateral resistance of the importer, which is proportional to its propensity to trade with this particular partner relative to the rest of the world.

This key insight, that trade between regions is determined by the relative trade barriers, has led to a cardinal rethinking of the meaning of the results first obtained by McCallum. A large country such as the U.S., with a large internal market, would simply 
not be affected as much by a change in external trade barriers as a smaller country like Canada would be. A trade barrier on Canadian border, however small, increases the trade costs of Canadian provinces with the vast majority of the world's regions, while the same barrier does not matter very much to a U.S. state. This means that the imposition of a trade barrier must raise the relative attractiveness of internal trade much more for Canadian regions than for U.S. regions, leading to much larger increases of internal trade for Canada than for U.S. It is this abnormally high level of internal trade resulting from a trade barrier that leads to the high border effects, which are estimated in comparison to the internal trade levels. AvW's major contribution thus was to establish conclusively that the high border effects estimated for Canada by McCallum and others do not imply that, should the trade barriers be removed, Canadian trade with the U.S. will rise by a factor of 20 or so. Such a move (e.g. a North American political union) would rather sharply decrease the abnormally high Canadian internal trade to a "normal" level; the actual cross-border trade would grow by only about $44 \%$, while Canadian internal trade would drop by a factor of 6 . Meanwhile, the U.S. internal trade would be affected only slightly (down by $25 \%$ ).

Thus the spectacular McCallum's factor of 22 would be reduced, in two stages, to a mere $44 \%{ }^{20}$ Yet the fact is that this analysis, however valid, addresses a different question from the one that McCallum initially set out to answer. The AvW's 44\% estimate determines by how much trade between US and Canada would grow if the

\footnotetext{
${ }^{20}$ This is accomplished in two stages: the omitted variables bias resulting from an atheoretical formulation of the gravity equation is estimated and reduces the border effect to 14.8 , while the subsequent decomposition of the border effect into internal trade and external trade components along the lines of the previous paragraph permits the estimation of the external trade increase in the event of border removal $(44 \%)$.
} 
border vanished overnight along with all the differences between the two countries. ${ }^{21}$ This is the question that McCallum's paper never intended to answer. On the terms of his paper, McCallum's results - broadly interpreted as "national borders matter" - remain as pertinent as AvW's conclusions. The details (Ontario trading 20 times more with British Columbia than it should) may be subject to some correction for the omitted variables bias (multilateral resistance terms), but remain strong, positive and significant.

The main difference between these two seminal papers of the literature thus lies not only in methodology, but to some degree in their outlook. The questions these researchers ask are affected by the side of the border they are looking from. McCallum, assessing the border effects from the Canadian side, emphatically asserts that borders matter - which they indeed do for Canada. AvW, on the U.S. side, conclusively show that the aggregate welfare and trade of the United States are little affected by the border. Both results are equally valid and acceptable - they are simply the age-old maxim that the economic and political sovereignty of smaller nations matters a great deal to them, but not so much to the large countries and not to the world as a whole. It is in the dichotomy between those two viewpoints, and from the comparative evaluation of these two approaches that the current understanding of the border effects puzzle emerges, largely focused on the idea of small border costs that generate seemingly large border effects for smaller countries.

\footnotetext{
${ }^{21}$ It is unlikely that a political or economic union between Canada and the U.S. would lead to a complete overnight removal of barriers to trade between these two countries which are, contrary to first impressions, quite different in government traditions, history, cultural heritage and outlook on world affairs. In view of the European Union's 50-year-long march to Europe without borders and continuing strong evidence of border effects within Europe, the discussion of the eventual equilibrium conditions in a borderless North America must necessarily remain academic for some time to come - since nothing less than complete dissolution of Canadian economic identity would allow the AvW's estimates to be realized.
} 
To summarize, while the merits of AvW's approach are clear: it emphasizes the primacy of theory and takes interest in measuring the final, real effect of the border phenomenon on consumer welfare, there are shortcomings that are less obvious. Its return to sound theoretical foundations in the modeling process implies foundations of a particular nature, dependent on some key assumptions. These could be countered with an argument based on the long-run principles of economic self-interest as evidenced in revealed preference. If, rather than being an oppressive artefact of governmental interference, the existing frontiers are justified by revealed preferences of the economic agents enclosed within and maintained through their continued self-interest, the picture painted by AvW would no longer be satisfactory. When this self-interest of the population no longer exists, borders begin to disappear, as is presently the case in Europe. In asserting the negative welfare effect of the existing borders, one then is merely admitting that the problem is not well-defined and that the equation under consideration is misspecified, and missing important variables that make the border a profitable arrangement to the country's denizens.

Although the AvW argument has been widely and justly praised as an important contribution to the border effects literature, it did not close the debate. It is because there remain potential shortcomings to recognising their approach as final and definitive. In particular, their formulation of gravity equation derived from a computable general equilibrium framework raised objections. Among the first to critically examine the AvW contribution were Balistreri and Hillberry (2006). While accepting the AvW contention that the gravity equation should be legitimately derived, they counter with the objection that AvW's CGE model generates implausible results for the behaviour of several key 
variables such as prices and transport costs. The gap between theory and practice in border literature is thus made manifest: when theory is ignored, estimates are unreliable for positive economic interpretation, but when "too much theory" is brought into play and a GE model is constructed, its predictions in areas other than border effects are inconsistent with empirical evidence.

Section 2.4 has already discussed Engel and Rogers (2001), who examined border effects in prices. Nevertheless, they provide such important theoretical contributions that they should be mentioned again in this section. They break up the observed border effect into two theoretical components: the "real barriers effect" (analogous to the border effects in trade) and the volatile exchange rate effect. The link between border costs, border effects and welfare, fist clearly stated in AvW, is given further development here, with different welfare effects implied by two different types of barriers. In particular, they show that while the "real barriers effect" leads to real welfare losses, the exchange rate effect does not necessarily do so. Thus while the introduction of common currency will eliminate the border effect proceeding from the volatile exchange rate, it may not increase the welfare accordingly. This finding highlights the fact that border effects are not always accompanied by welfare effects and merit consideration as separate items of interest, regardless of whether welfare is affected.

In an innovative paper by Brown and Anderson (2002), the model of trade is developed on the basis of Armington assumption (regional specialization) and internal U.S. trade flows are derived from the CFS (Canadian internal trade data are not considered). The research question (following AvW) is posed in terms of trade increase with the elimination of the border effect and results in an (approximately) $130 \%$ increase, 
or three times the AvW estimate. ${ }^{22}$ Border effects are estimated by 2-digit manufacturing sectors. After controlling for output, distance, wages, productivity and location, the border effect estimates obtained vary between 0.9 (for transport equipment) and 7.2 (food products); all of these are positive and statistically significant. It must be borne in mind that these effects are estimated relative to U.S. internal data and thus are not directly comparable with McCallum's results (that show the ratio between the intensities of Canadian internal and external trade), but with the AvW's result of 1.63 (which is the corresponding ratio for the U.S.). Thus, just as on aggregate, the authors' estimates of border effects exceed AvW's estimates for most sectors (14 out of 18). Some sectors are pointed out as less susceptible to border effects (transportation), while in others tariffs and non-tariff barriers are clearly contributing to high estimates (textile, apparel, food products). There is no single consistent explanation for the behaviour of the sectors - and on this point the paper raises at least as many questions for further research as it answers.

A recent contribution to the discussion on the theoretical foundation and meaning of border effects has been made by Coulombe (2005). He deals explicitly with the differences between McCallum's and AvW estimates and shows that these differences are due to the relative nature of the border effect. Since McCallum's border effect parameter - the exponent of the dummy variable in (1) - measures the ratio of weighted intranational to weighted international trade, it is improper to interpret this parameter as the estimate of absolute increase in international trade should the border be removed. It shows rather that in a 2-country world (a workable assumption for North American economies), a border leads to stronger effects on the small country than on the large one.

\footnotetext{
${ }^{22}$ This is an order of magnitude smaller than McCallum's estimate, as the authors point out, but his paper answered a different question as noted. AvW's estimate is the proper benchmark in this instance.
} 
Thus the tenfold difference between the estimates of border effect from the Canadian and U.S. sides is due to the fact that both estimates measure border effects in relation to the density of their internal trade. The equilibrium level of cross-border trade in a hypothetically borderless North America (if the contradiction in terms can be tolerated) will thus be more intense than internal Canadian trade, but less intense than the internal U.S. trade. Therefore the true size of the increase in that trade will be a weighted average and lie between the two estimates, heavily biased towards that of the larger country. From Canadian perspective, this increase in weighted trade would amount to a factor of 16 and from the U.S. perspective, to 1.63 (whereas in absolute terms AvW estimate this increase at 2.24 as the weighted mean of the two).

The above discussion has largely expounded the significance of AvW's results as interpreted in Coulombe (2005). Coulombe's own contribution was to point out that their analysis is contingent on the special assumption that economic density ${ }^{23}$ (the ratio of GDP to an index of internal trading distance) is proportional to the economic size; or in other words, internal trade distances of the countries are equal. The empirical situation in North America being such that this largely is the case, the point might have been overlooked. However, Coulombe argues that if a hypothetical country with Canada's GDP but only $1 / 10$ the size (in his example, Belgium) was put in its place to trade with the U.S. (their economic densities being equal), its border effect estimates would be quite comparable to the effects estimated from the U.S. side, and both - to the true estimate of the border effect. This result becomes clear if one considers that the intensity of

\footnotetext{
${ }^{23}$ The intuition for economic density may be acquired by analogy with physics. Physical density of a material equals weight over volume and shows how densely the given volume of material is packed with mass. Economic density equals the amount of economic transactions over geographical area and shows how densely the given economic area is packed with economic activity. The concept is similar to GDP per capita and may be viewed as "GDP per shipment distance".
} 
borderless international trade between such two countries would equal the intensity of their internal trade.

Hence, a twofold conclusion can be made from Coulombe (2005), which can serve to summarize the state of the theoretical debate at the present time:

- a McCallum-type border effect is an unbiased estimate of the border effect when the trading countries have the same economic density. When economic density differs, it is biased upwards when estimated relative to the internal trade of a country with lower economic density, and biased downwards when estimated relative to the internal trade of a country with higher economic density, with the true estimate lying in between those;

- $\quad$ it is likely that the typically lower estimates obtained from the E.U. countries (starting with Wei (1996)) are due to the fact that these countries are much closer in economic density than Canada and the U.S. It is also possible that the different border effects across Canadian provinces obtained by Anderson and Smith (1999) are partly due to their differing economic densities.

\subsection{Other Literature}

The main currents of the border effects literature have been discussed above, but there still remain studies that stand apart from the principal trends and do not fit comfortably into any of those currents. These are distinguished from the preceding works by the fact that they either develop a completely new explanation for the observed facts or explore new possible sources for the unexplained components in the border effects estimates. Given all the diverse areas in which the borders effects have been identified, it is unlikely 
that a stand-alone, one-shot explanation of the border effects puzzle, which does not build on previous literature, would be compelling enough to be widely accepted. However, there is still a lot to gain from the attempt. Some of the stand-alone models developed here are ingenious, contribute valuable insights and definitely merit further consideration by the academic community.

A comprehensive attempt to encompass the border puzzle in North America through one plausible model was made in Fairfield (2001). He developed a model in which the economic geography of North America serves as the main explanation for the border effect. According to the evidence of the paper, the industrial structure of North America is characterized by predominant concentration of the raw materials in the West and of the production centres in the East of the continent. Thus trade necessarily involves the flow of intermediate goods from west to east and the flow of manufactured goods in the opposite direction; both flows are assumed to be composed of close substitutes. The paper demonstrated that a model developed under these assumptions implies that small border costs produce high border effects and thus the model accounts adequately for most of the border effect observed in North American estimates, showing that trade tends to flow East-West on the continent rather than North-South. The most salient conclusion of the work is that close similarity between Canada and U.S. has two sides to it: on one hand it would seem to encourage restriction-free trade, while on the other it results in goods that are very close substitutes produced in both countries. As a result, these goods are very sensitive to price and even a minimal border cost can create a significant impediment to trade. The paper also argued against the possibility of excessively high 
border costs faced by traders in North America and showed that they may be as small as transport costs.

In a similar vein, Hillberry and Hummels (2002a) emphasized the role of intermediate input trade as an important component of the explanation of home bias. In their work, however, it is not the economic geography of the continent that matters, but the location decisions of the intermediate goods' buyers and sellers. The trade in these intermediate inputs is highly localized and tends to concentrate production and distribution, leading to more intensive trade and the home bias that arises endogenously. This approach has promising applications - according to this argument, home bias may arise not only within a state, but within a region, a district or a city. This argument may contribute to explaining Wolf's (2000) surprisingly high border effects between the U.S. states.

Directly addressing these results in Wolf (2000), Hillberry and Hummels (2002b) showed that the distributional (wholesaling) activities between neighbouring regions can indeed lead to the rise of home bias. Shipments by wholesalers tend to be concentrated within states, creating a greater intensity of trade within the state than across the state borders. The study also incorporated the export-import price index term suggested by $\mathrm{AvW}$, and pointed out a problem with distance measurement in previous literature. Internal regional distances may grossly overstate the actual distances traveled in the case of co-location between manufacturers of intermediate and final products. The authors supported that point by using shipment level data on actual distances travelled, and found that the distances used by Wolf (2000) greatly overstate (by $40-50 \%$ ) internal regional trading distances and trading distances between adjacent states. Taking all of the above 
factors into account produced estimates of border effects in U.S. interregional trade of only 1.55 , or three times smaller than Wolf's 4.39 estimate.

While the three preceding works stress the importance of economic geography in understanding home bias and resulting border effects, their theoretical foundations would be well complemented by referring to location theory. A good exposition of some elements of this theory that pertain to trade in border regions can be found in Niebuhr and Stiller (2002).

A brief summary of their arguments is as follows. Location theory shows that the economic landscape is affected by the introduction of borders and that location decisions of firms are influenced by the presence of the borders. Firms are discouraged from locating in the border regions as this decision imposes additional costs; the proximity of a trade barrier curtails the feasible supply area and market area. Industrial mix is also affected: the larger market area the firm requires, the further from the border it will choose to locate. Border regions consequently will have little economic activity and predominantly those firms that require little market area will locate there. Consequently, as business and trade tend to gravitate towards the interior of the country/region, these location decisions increase the relative intensity of internal trade and diminish the flow of trade within the border regions and across the borders. Eventually, a self-reinforcing process of agglomeration may occur, strongly influencing the location decisions of future firms and markets in favour of existing centres of population and industry, and away from the borders ${ }^{24}$. These spatial effects seem to warrant an explicit consideration in further modeling of trade between countries.

\footnotetext{
${ }^{24}$ As applied to the North American situation, a significant caveat is that Canadian population is strung along the border with consequent industrial location near the border. The same is not the case for the U.S.,
} 
The issues of transportation costs in the gravity model are not limited to establishing a set of empirically "correct" distances between trading regions. Different modes of transportation should help in explaining home bias rather than hinder research by being difficult to compare. For example, quality of communications may be another important factor. Bougheas et al. (1999) shed some light on the importance of infrastructure in trade models. Assuming transport costs are inversely related to the level of infrastructure, and subject to optimal infrastructure investment, their model predicts a positive relationship between the level of infrastructure and the volume of trade. Issues of optimal investment aside, this result leads one to consider an adjustment to the estimate of transportation costs (which usually consider distance only) that would take into account the quality of road/railroad network in the country or region, as well as allow for alternative modes of transportation with different per-unit costs.

In general, it can be concluded that the authors of the papers included in this section each have a singular contribution to make to the discussion. Although the issues identified by these papers may not always be the primary reasons for border effects, the identification and consideration of those issues in a well-specified theoretical model may add significant value to the process of deriving consistent estimates of the border effects.

\subsection{Summary and Conclusions}

The purpose of this survey has been twofold: to provide a detailed chronological account of the development of an economic theory from individual contributions, and to obtain a

so in this respect the countries are dissimilar. With further research, this different pattern of industrial location may play a more prominent role in explaining border effects. 
bird's-eye view of the literature to better identify the direction of the debate and the quantity and quality of possible explanations to the border effects puzzle. The next chapter will address these issues more formally by a meta-analytical examination of the border effects literature and will prepare the ground for Chapter 4 . That final chapter will develop a regional model of trade between Canada and the U.S. that generates better estimates of the levels and trends in border effects and the factors influencing them, taking into account what has been learned in Chapters 2 and 3.

For an alternative summary of the current levels and trends in border effects, as well as the issues arising from these, Helliwell (1998) and Helliwell (2002) offer a good source - the former discusses the state of the literature before AvW's contribution, and the latter - after. Helliwell (1998) estimates the Canada-U.S. border effects between 1988 and 1996, disaggregating them by year, province, industry and direction of trade. The gravity equations used in that estimation are not theoretically based, and the methods of estimation are largely based on data for single years - in other words, the potential from having a considerable swath of cross-sectional time-series data is not utilized. These estimates, as well as comparable OECD estimates, show signs of decline in border effects over time, which are traced to reductions in trade barriers. Helliwell (2002) then discusses extensions into prices, capital markets, migration and growth, and concludes, in McCallum's vein, that the global economy as of 1990's is in reality a weakly linked patchwork of tightly integrated national economies, and is likely to remain so for some time to come. It goes on to argue that the existing borders and their effects serve important economic purposes: enhancing information and reducing uncertainty, and should rather be viewed as responsible for the economic success of the nation-state rather 
than representative of barriers to trade at the international level. Although there is room for improvement in the study's methods (opened by AvW theoretical contributions), this conclusion remains a plausible one. The case for border effects being efficient within a completely specified model of trade that encompasses interregional and international trade made by Helliwell (1998) is one that should receive further development in the literature, taking into account the points made since its publication.

Helliwell (2002) provides a survey of the current situation in the border effects literature after AvW have emphasized the importance of theory. Having made the seminal contribution to the field by verifying McCallum's results, explaining their importance, as well as contributing to better distance estimation, the author now examines a broad range of issues raised in the literature published since. The reader is referred to this excellent summary as much for the details as for the thought process itself. Helliwell's preferred explanation for the unexplained portion of border effects is the impact of the intangible and yet powerful bonds of the "networks of shared norms and trust", personal contacts, knowledge of local preferences and all the little things that make one prefer his local grocer to a mall supermarket, subscribe to local newspapers and "buy Canadian". It is a compelling suggestion and, if ways of properly implementing this factor in further research are found, may be instrumental in helping understand the border effect.

Having surveyed the literature in detail above, we wish in closing to present our own summary of the topic. The political and economic climate of the 1990's was particularly favourable for believing in the inexorability of the process known as globalization. The fall of communism, the union of Germany, the expectations of peace 
and prosperity and the emergence of market economy as the only credible economic philosophy seemed to make complete economic integration of nations into a global economy a plausible and even imminent scenario. And the enthusiasm for this scenario may have led some to believe that the world economy is further advanced along this path than was actually the case. It is against this background that McCallum's original findings cautioned the practitioners of economics against wishful thinking, showing that the ties that bind together a nation are still much stronger than international trading links.

The development and acceptance of these results as legitimate empirical findings through studies by Helliwell (1996, 1997), Wei (1996) and Hillberry (1998) played an important role in establishing the border effects as a subject of economic inquiry. Links to other fields (to price literature by Engel and Rogers (1996, 2001), to currency unions by Frankel and Rose (2002) etc.) have demonstrated that border effects in international trade have a wider interpretation than expected.

These laws have been challenged by Anderson and van Wincoop (2001), and after heavy revision and reconsideration have been put on a firm theoretical basis. After their contribution, there can hardly be a place for a study that does not derive its model from theory. Meanwhile, several variables of importance (such as tariffs) have still not been explicitly dealt with, and econometric methods routinely used in other fields (such as panel data analysis) have not been applied. Thus there remain serious gaps in the field, gaps that this thesis intends to address.

Currently, the two principal strands of the border effects literature are the linkage between border effects and welfare, and developing and refining better estimates for border effects through the use of a theoretically sound model. Based on our survey, we 
believe that although much work was done on calculating and describing border effects, the consensus on this issue remains elusive and the existing methods still have significant room for improvement. This compels us to take the latter approach, and in doing so attempt to integrate the contributions of the literature surveyed above. Such integration should be achieved by deriving generally consistent empirical estimates from a theorydriven model; only then could the welfare question be properly investigated. We devote ourselves to this task for the rest of this thesis. Chapter 3 conducts a formal meta-analysis of the empirical findings; the findings are used in chapter 4 to construct a regional model of trade that aggregates the best practices and the theory behind international trade. That model goes on to obtain better estimates of levels, trends and factors behind the border effects in the international goods trade between Canada and the United States. 


\section{Chapter 3}

\section{Meta-Analysis of Economic Research on Border Effects}

The preceding chapter has surveyed the development of the literature on border effects during the past decade and identified the primary trends, contributions and areas of concern. This third chapter now proceeds to systematize the knowledge available on this topic in a quantitative manner. The techniques of meta-analysis allow us to pose and answer several questions about the border effect, aggregating the contributions of the literature into one model. Meta-analysis is a well-developed technique that can establish the significance of a particular factor even in cases where a narrative survey would be forced to conclude that the evidence is inconclusive. We argue that just as a narrative survey may be insufficient to make a conclusion, so can the meta-analysis be incomplete and biased without a narrative survey that follows the literature development and identifies variables of interest and significance to meta-analysis. A combination of narrative and meta-analytic surveys gives us the knowledge of best practices in the area and strongly positions us to take these into account in the last chapter, where we build and estimate a regional model of border effects.

Our meta-analysis confirms the existence of significantly positive border effects everywhere in OECD with the average magnitude between 7 and 10 . We also investigate whether findings in this area are subject to a publication bias. ${ }^{25}$ The explanatory (or moderator) variables are able to explain over $90 \%$ of variation in border

\footnotetext{
${ }^{25}$ Also known as the "file drawer" problem, publication bias arises when studies that obtain statistically significant estimates have a higher probability of being published than those that don't, the latter being relegated to a researcher's file drawer. This problem is recognized to have the potential to cause a nonsignificant effect to be perceived as significant.
} 
effect estimates found in the literature. The variables that influence the study results are determined to be: the fact that the equation is derived from theory (border effect estimates are lower in those studies), taking adjacency into account, and the number of specifications considered (more specifications lower the border effect estimate). There is evidence that the research studying the border between Canada and the U.S. obtains a higher border effect; there is also some indication that the border effect generally decreases with time. Also important are the results which indicate a lack of effect (or weak effect) for the variables that are extensively discussed within the literature, i.e. distances (internal and international) and remoteness measures. Our findings establish beyond reasonable doubt the authentic empirical character of the border effects (as opposed to them being an artefact of econometric specification), inform further research and help us build our theoretical model in the next chapter.

\subsection{Introduction}

Since McCallum's (1995) seminal paper, the literature studying border effects has expanded greatly. Dozens of publications on the issue have come out, - from those merely adding a piece of information to the amassed knowledge to the ones attempting to definitively settle the issue and close the debate. No matter how balanced and extensive, a narrative literature review may not be able to do justice to such an array of empirical results. Whether it happens through omission bias, author's bias or undue stress on some of the selected opinions, it is all too easy to misrepresent the course of scientific thought on a given issue. To ensure a comprehensive approach to the border effects problem, we 
wish to evaluate this literature more formally, with the use of statistical methods that summarize and analyze the empirical results of the individual studies. This will take the form of meta-regression, a form of meta-analysis particularly suited to the evaluation of empirical research in economics and other scientific fields.

The chronological review of the literature in the first chapter has recorded differing and changing attitudes to the problem of border effects and has shown how the approaches in this area evolved through time. It has also described the economic environment surrounding the issue and thus enabled us to identify the variables of interest that may, according to various researchers, be involved in the border effects puzzle. The meta-analysis is a natural follow-up to this review, since most of the necessary identification and survey work has already been accomplished.

At this point, our aim is to contribute to the theory of meta-analysis by pointing out the gains to be reaped from doing a narrative literature review beforehand. Stanley (2001) makes a strong argument for meta-analysis as a more formal and objective process than a narrative review. This point is well taken, yet we wish to go further and demonstrate that a combination of a narrative review with meta-analysis produces a number of positive spillovers and achieves superior results to those that can be obtained if either procedure were done separately. This synergy occurs because the literature review (preferably chronological) can enumerate and describe the variables that emerge as important as well as theoretically sound in the process of field development. Thus it addresses a weakness common to the meta-analysis process: the explanatory variables selection is often not grounded in theory and determined pragmatically. Combined with small sample sizes typical of meta-analysis and low degrees of freedom, this weakness 
leads the researcher to pick and choose among many candidates for moderator variables for the final equation. This process of variables elimination is likely to leave in the ones that "work", i.e. prove significant, at the expense of those that do not. While this process will lead to a conclusion regarding which variables have effect in the particular (small) sample, its applicability to the universe of all possible studies is dubious, because the technique at the variable selection stage is fundamentally atheoretical. Only by applying the "good" econometric practice of postulating the equation design before estimation can we hope to obtain consistent results, and this is only possible by identifying the theoretically important variables beforehand by means of a literature review.

Meanwhile in the main channel of inquiry, this meta-analysis produces three main benefits. The sensitivity of the empirical results to the research methods and variables used is determined (for example, the exact calculation of internal trading distances does not seem to be crucial, while the theoretical derivation of the gravity equation is). Second, we can assess the contributions and importance of different variables in the border effects puzzle, as these are weighted by time, number of observations, significance etc. Finally, and perhaps most importantly, an answer to the question "how large and economically meaningful are the border effects?" is obtained at the hitherto unprecedented level of precision, as the significance of close to 30 studies is combined into one. These results are then intended to be used in further research to construct a "definitive" version of the border effects equation that is based on the insights obtained from the narrative and meta-analytic reviews. 


\subsection{Meta-Analysis as a Systematic Tool of Inquiry}

Undoubtedly there are some who will claim that meta-analysis is not necessary to answer that last question, since there is little disagreement in the literature on the fact of the existence of large border effects - nearly all of the papers on the issue will readily answer it in the affirmative. Others will point out that combining well-known published studies using "good" methodology and sound theoretical background with more obscure ones and giving them equal weight is a practice that cannot lead to credible conclusions. And others still will assert that meta-analysis is simply not a valid tool from the econometric point of view and that any combination of empirical results from different papers is unjustified.

We will now answer all of these concerns in reverse order, starting from a general case for meta-analysis. When several independent studies are conducted on a subject, a meta-analysis allows for combining their results for a stronger statement on the phenomenon under study. In addition, it also permits the assessment of the method and design of a particular study by reporting to which degree these affect the study's reported results. This helps explain the variation between individual studies in scientific terms and shows that a certain proportion of the result is due to a particular approach - rather than dismissing the approach itself as "suspect" or "atheoretical", as a literature review often does. The techniques of meta-analysis have already found widespread use in many social and exact sciences since first introduced by Glass (1996) and (1997). In medical science, for example, it has established the effectiveness of streptokinase (Hunt (1997)), evaluated the risk of second-hand smoke (He et al. (1999)) and coronary bypass surgery (Held et al. 
(1989)). Recent economic applications of meta-analysis, to name but a few, include the effect of common currency on trade (Rose and Stanley (2005)), the investigation of gender wage bias (Stanley and Jarrell (1998)) and the meta-analysis of the effects of immigration on wages (Longhi et al. (2005)). These and other studies claim impressive results for meta-analysis: an ability to achieve clarity in ambiguous topics, identify or refute a genuine empirical effect and neutralize bias inherent in narrative reviews.

In general, while meta-analysis certainly can suffer from omission or misrepresentation, it is liable to these errors to a much lesser extent than the conventional literature reviews. This has been already recognized in other fields and meta-analytic techniques are now becoming accepted in economics - if coronary bypass surgery can be judged by meta-analysis, surely the economic questions can, too. Stanley (2001) documents the widespread use of meta-analysis in economics over the past two decades. Gender wage gap, union wage premiums, minimum wage effects, benefits of endangered species, Ricardian equivalence - these have all been evaluated by meta-analysis in the 90's. In particular, while the conventional surveys tended to refer to empirical evidence on Ricardian equivalence as "extremely ambiguous", a meta-analysis finds clear evidence of non-Ricardian behaviour in the economy (Stanley (1998)). And in the field of international trade, Rose and Stanley (2005) conduct a meta-analysis on the effect of common currencies on international trade, finding that a currency union significantly increases trade (by $30 \%$ to $90 \%$ ). Perhaps, then, the time to evaluate the border effects puzzle with meta-analytical techniques has also come.

The concern about mixing the "good" with the "bad" studies is unjustified as well. The meta-analysis itself is a tool by which the "bad" shall fail and the "good" prevail. If 
all relevant studies from a standard database are included, there is no selection bias in the study. The meta-analysis will then show how the results are affected by the different methods. It can also bring to bear such methods as sequential exclusion of various studies based on different criteria and gauging the impact on the study results - tools completely outside of the range of conventional literature reviews. Finally, if the study is found to be "bad" and rejected, meta-analysis can identify and document specific characteristics that prompted the decision, providing a more formal and objective process of elimination.

Lastly, those who believe there is no question about border effects being economically meaningful are, strictly speaking, simply "counting votes" in the literature. Their beliefs may be affected by publication bias (studies that find border effects insignificant may not get published) and the vote-counting approach itself should be considered obsolete in view of possibilities that meta-analysis offers. The sound criteria for determining the character of the underlying empirical effect are the positive results of significance, bias and specification tests available to a meta-analyst. It is with these in mind that this study embarks upon a meta-analysis of the border effects literature.

\subsection{Methodology and Basic Tests}

The process of selection of studies for this analysis is made with the intent not to leave out any paper containing the empirical estimates of border effects, whether it is published or not. A keyword search for border effects and border puzzle of the standard EconLit database and other socio-economic databases was undertaken, followed by the search of all references to the seminal paper by McCallum (1995). A review of all these references, 
including the latest unpublished papers, has resulted in 24 empirical studies with border effects estimates, all of which will be included in the analysis. One preferred estimate is chosen from each study, ${ }^{26}$ with the exception of three studies that yield two estimates each; one of these studies also produces estimates with labour mobility, and others produce U.S.-based estimates as well as Canada-based. At a later stage, we exclude these three additional observations in order to have an unbiased, if shorter, sample. Naturally, there are many more papers in the area that have been excluded from the final count; some of them do not produce empirical estimates, others produce estimates which are not comparable to the rest (for example, in the area of prices) or are too disaggregated to be compared.

Some of these estimates may be viewed as more "seminal" or "important" and others perceived as using "flawed" or "obsolete" methodology. Nevertheless, these will be controlled for in the process of meta-analysis and so every estimate has equal weight. Appendix B reports all the studies and estimates selected.

At the core of every study estimating border effects in international trade is the gravity equation specification of trade. Because the theoretical antecedents of this specification have been preceded by strictly empirical use, the empirical gravity equation has been specified in many different ways in the literature mainly due to practical considerations. The simplest form of the gravity equation is based on the following hypothesis about trade between two partners:

$$
X_{i j}=A Y_{i} Y_{j} / D_{i j}
$$

\footnotetext{
${ }^{26}$ We pick the preferred estimate if identified by the author and one which seems most representative of the paper as a whole otherwise.
} 
where $i$ and $j$ are two trading partners, $X_{i j}$ is the volume of trade between them, $Y_{i}$ and $Y_{j}-$ trading partners' GDPs, $D_{i j}$ - the economic distance between them, or the cost of transporting traded goods between the partners, and $A$ is a vector of other variables. Thus the simplest gravity equation of international trade is the logged form of (1) with small letters representing the natural logs of the variables above:

$$
x_{i j}=\beta_{0}+\beta_{1} y_{i}+\beta_{2} y_{j}-\beta_{3} d_{i j}+\beta_{4} a+\varepsilon,
$$

Both (1) and (2) imply that trade is expected to grow with the economic size of the partners and decrease with distance between them, which is expected of any reasonable trade theory. Hence there is difficulty in claiming the positive empirical results from a gravity equation as an argument in favour of any of those theories. This issue is discussed in more detail below. The typical gravity equation may include several other variables in the $A$ vector, such as estimates of remoteness of alternative trading opportunities, squared distance or GDP terms, and various dummies for common language, trading bloc etc. One commonly used specification includes population as an additional measure of country's economic size; this specification is referred to as augmented gravity equation. Overall, this simple equation is one of the most successful empirical specifications in international economics; the gravity model is robust and powerful, routinely explaining $80 \%$ and more variation in trade between countries. First implemented in international trade independently by Tinbergen (1962) and Poyhonen (1963), it invokes the simple mechanism of Newtonian physics by drawing a parallel 
between the forces of gravitational attraction and economic ties to explain exchange of goods, services, migrants and other interactions between countries and regions. In doing so, however, it bypasses economic theory and creates some difficulties with fitting the estimation results into it.

As remarked above, the theoretical foundations of the gravity equation are less clear and legitimate than its empirical performance. Several attempts have been made to rectify the problem and to derive the gravity relationship ex post from the established international trade theories to legitimize it. Anderson (1979) has shown that the gravity model can be derived from expenditure share equations with commodities distinguished by place of production. Several studies done in the area since have derived the gravity model from models of trade in differentiated goods; these concentrated mainly on full specialization models and are covered in a survey by Helpman (1999). Deardorff (1998) followed with an influential paper, deriving the equation from the Heckscher-Ohlin model under certain transport costs assumptions and arguing that the gravity model as a consequence cannot be a test of any of these trade theories; however, this view has since been questioned by Evenett and Keller (2002) and Feenstra, Markusen and Rose (2001). These studies evaluate differences in predicted parameter values for the gravity variables and conclude that increasing returns to scale are mostly responsible for the home-market effect in differentiated goods, this theory being better suited to explaining large volumes of intra-industry trade between economically advanced countries. On the other hand, much of the trade in homogeneous goods between North and South may fit comfortably into a Heckscher-Ohlin factor endowments framework. Both of these papers emphasize an important point: models that predict full specialization in differentiated goods find no 
empirical support. The process of derivation of the gravity equation from the various international trade models is presented in Appendix A. In the final analysis, these derivations have not served to legitimize the popular gravity equation; if anything, almost the opposite is true. By showing that the specification is just an empirical regularity which must hold in any reasonable model of trade, and that the actual theoretical formulations are more complex and diverse than what is usually estimated, this process has made a case against the empirical approach to gravity and advocated a direct role for theory in the process of arriving at the specification, if the estimation results are to have any theoretical meaning.

The above discussion illustrates that empirical success is largely taken for granted in the area and that good empirical results are not likely to exonerate those models based on general usage and not on strict application of theory. It is thus crucial to differentiate the "common" gravity equation from the one driven by a specific theoretical structure, and our meta-analytic procedure will allow us to do so.

The estimates of the border coefficient typically (but not always) enter the gravity equation in implicitly logged form. For consistency, we transform all estimates into a log of the ratio of weighted intra-national trade to weighted international trade ${ }^{27}$ and call our dependent variable $B$. We expect it to have a linear dependence on the vector of the underlying characteristics of various studies that enter as independent variables. Specifying a regression equation with these as explanatory variables for $B$, we divide through by its standard error to correct for heteroskedasticity, and obtain an equation with

\footnotetext{
${ }^{27}$ Thus for a typical McCallum-type estimate, the dependent variable is the logged border dummy.
} 
$t$-value of $B$ as the dependent variable and all the dependent (moderator) variables divided by a scalar standard error of $B$.

The first hypothesis test that should be made at this stage is whether or not $B=0$ in the literature. The original test is due to Fisher (1932) and tests the null hypothesis of no individual significance in every case considered, leading to no overall significance. Under the null, the p-value of every estimate is randomly selected from a normal $[0,1]$ distribution; if so, minus twice the sum of natural logs of these p-values is chi-square distributed with $2 N$ degrees of freedom. In this study, the Fisher test statistic for our full sample equals 2168 , drawn from $\chi^{2}(54)$, and thus the hypothesis can be rejected at any significance level. The Edgington test with a small-sample correction leads to the same conclusion.

The assumptions underlying Fisher's test, however, are so restrictive as to render its applicability dubious. Studies are presumed to be independent and homogeneous, and all conducted under a null hypothesis that the true border effect is zero. Considering the variation in specifications in this area and the fact that the border dummy in some specifications can accumulate the explanatory power of omitted variables, it is unlikely that these assumptions hold. Although the result of the Fisher test may indicate a strong positive border effect, these concerns dictate the necessity for other tests.

Exploring the variation of the estimates in the literature is the next logical step. If the border effect estimates in the literature are truly drawn from a standard normal distribution with a mean of zero and a variance of one, then the sample variance between the t-values of the studies should also tend towards unity. Testing the sample variance, we find that it equals 170 instead, rejecting the hypothesis of the standard normal 
distribution for the underlying population at any confidence level. This result implies that the studies are coming from different populations and the differences between these populations give rise to the excessive variance that should be investigated further.

Table 3.1 shows the combined meta-estimates of the border effect in international trade from the 27 studies that produce empirical estimates of this effect. The fixed-effects estimates presume that the population from which the studies are drawn is the same; the random-effects estimates allow for the treatment variations between studies to influence results.

Table 3.1 Meta-Analysis of Border Effect on Trade (B)

\begin{tabular}{|c|c|c|c|}
\hline & Pooled Estimate of B & $\begin{array}{c}\text { Lower Bound of } \\
\mathbf{9 5 \%} \text { CI }\end{array}$ & $\begin{array}{c}\text { Upper Bound of } \\
\mathbf{9 5 \%} \text { CI }\end{array}$ \\
\hline Fixed & 1.970 & 1.930 & 2.009 \\
\hline Random & 2.283 & 1.890 & 2.676 \\
\hline Fixed, without Helliwell & 1.901 & 1.859 & 1.942 \\
\hline Random, without Helliwell & 2.114 & 1.673 & 2.555 \\
\hline
\end{tabular}

Although there is some heterogeneity in the data, and the upper bounds of the random-effects estimates are considerably higher, the overall message is consistent: there are similar, large border effects under both approaches. The $95 \%$ confidence intervals range from 1.9 to 2.7 , indicating that border effects between two countries/regions are somewhere between 7 and 15 . The average effect is closer to the lower bound due to the logged nature of the border effect dummy; it ranges from 7 for the fixed-effects to 10 for the random-effects model.

Removing Helliwell's five studies (the most influential multi-paper author) does not affect these results in any significant manner. Further, removing any individual'study 
does not cause the confidence intervals or estimates to deviate significantly from the average; all the values remain positive and in the vicinity of 2 (table 3.2).

Table 3.2 Sensitivity of Meta-Analysis of B to Individual Studies (Fixed Effects)

\begin{tabular}{|c|c|c|c|}
\hline Study Omitted: & Coefficient & $95 \%$ CI, lower & 95\% CI, upper \\
\hline 1 & 1.94 & 1.90 & 1.98 \\
\hline 2 & 1.97 & 1.93 & 2.01 \\
\hline 3 & 2.30 & 2.25 & 2.34 \\
\hline 4 & 1.97 & 1.93 & 2.01 \\
\hline 5 & 1.95 & 1.91 & 1.99 \\
\hline 6 & 1.97 & 1.93 & 2.01 \\
\hline 7 & 2.04 & 2.00 & 2.08 \\
\hline 8 & 1.97 & 1.93 & 2.01 \\
\hline 9 & 1.97 & 1.93 & 2.01 \\
\hline 10 & 1.88 & 1.84 & 1.93 \\
\hline 11 & 1.96 & 1.92 & 2.00 \\
\hline 12 & 1.98 & 1.94 & 2.02 \\
\hline 13 & 1.94 & 1.90 & 1.98 \\
\hline 14 & 1.97 & 1.93 & 2.01 \\
\hline 15 & 1.96 & 1.92 & 2.00 \\
\hline 16 & 1.96 & 1.92 & 2.00 \\
\hline 17 & 1.95 & 1.91 & 1.99 \\
\hline 18 & 1.93 & 1.89 & 1.97 \\
\hline 19 & 2.04 & 1.99 & 2.08 \\
\hline 20 & 1.83 & 1.78 & 1.87 \\
\hline 21 & 1.97 & 1.93 & 2.01 \\
\hline 22 & 1.98 & 1.94 & 2.02 \\
\hline 23 & 1.99 & 1.95 & 2.03 \\
\hline 24 & 1.99 & 1.95 & 2.03 \\
\hline 25 & 1.97 & 1.93 & 2.01 \\
\hline 26 & 1.97 & 1.93 & 2.01 \\
\hline 27 & 1.88 & 1.84 & 1.92 \\
\hline Combined & 1.97 & 1.93 & 2.01 \\
\hline
\end{tabular}

The previous results all assume homogeneity, i.e. the existence of a common mean for all the border effects. This assumption can be tested with a $\chi^{2}$-based Q-statistic with (n-1) degrees of freedom; the resulting statistic is 2209 with 27 degrees of freedom. This constitutes a proof of heterogeneity in the sample, as expected from the estimates above. Therefore we are further justified in exploring the sources of additional variance, not just through a simple random-effects model, but through a meta-regression analysis 
that could properly attribute variance to the particular elements and methods of study design.

Before we proceed to the meta-regression, it is interesting to determine whether there is evidence of publication bias. There is a potential problem with sample selection if published works are not chosen randomly, but instead filtered through some criteria related to the study approach, design or results. It is alleged that one of the standards of publication in academic literature is demonstration of significant results; papers that do not make that grade are not typically published, but instead accumulate in the researcher's file drawer (hence another name for publication bias, the "file drawer" problem). This selection bias could potentially generate significant findings where there are none, or inflate a weak effect to make it appear stronger. Formal tests for publication bias will help establish whether the high significance that is the hallmark of the border effects literature is at least partly due to the publication bias.

A quick and simple way to gauge publication bias is to use a so-called funnel graph, which is a scatter plot of precision (the inverse of the standard error, or $1 / \mathrm{se}$ ) against the estimated effect. In the absence of publication bias, the graph should resemble an inverted funnel and be roughly symmetrical. ${ }^{28}$ Note that an asymmetry does not necessarily indicate publication bias: it may also be a sign of methodological heterogeneity between studies. Conversely, a symmetrical but "hollow" and excessively wide plot may conceal evidence of publication bias. Examining Figure 3.1 does not suggest an unequivocal conclusion. That there is some asymmetry in the graph is clear,

\footnotetext{
${ }^{28}$ This is because estimates should then vary randomly and symmetrically around the true effect, regardless of its magnitude. The expected inverted funnel shape is due to predictable heteroskedasticity. Small-sample studies will have typically larger standard errors, hence less precision, and will be located near the bottom of the graph (Stanley (2005), p. 314).
} 
but the question is whether it is the publication bias that is the issue here. The eyeballing of the funnel graph should thus be supplemented by other techniques of publication bias detection. We will use the existing MRA analysis of the $t$-value vs. precision due to Egger et al. (1997), a meta-significance test due to Stanley (2004), and standard tests due to Begg (1994) and Egger (1997); the results of the first two are presented in Table 3.3.

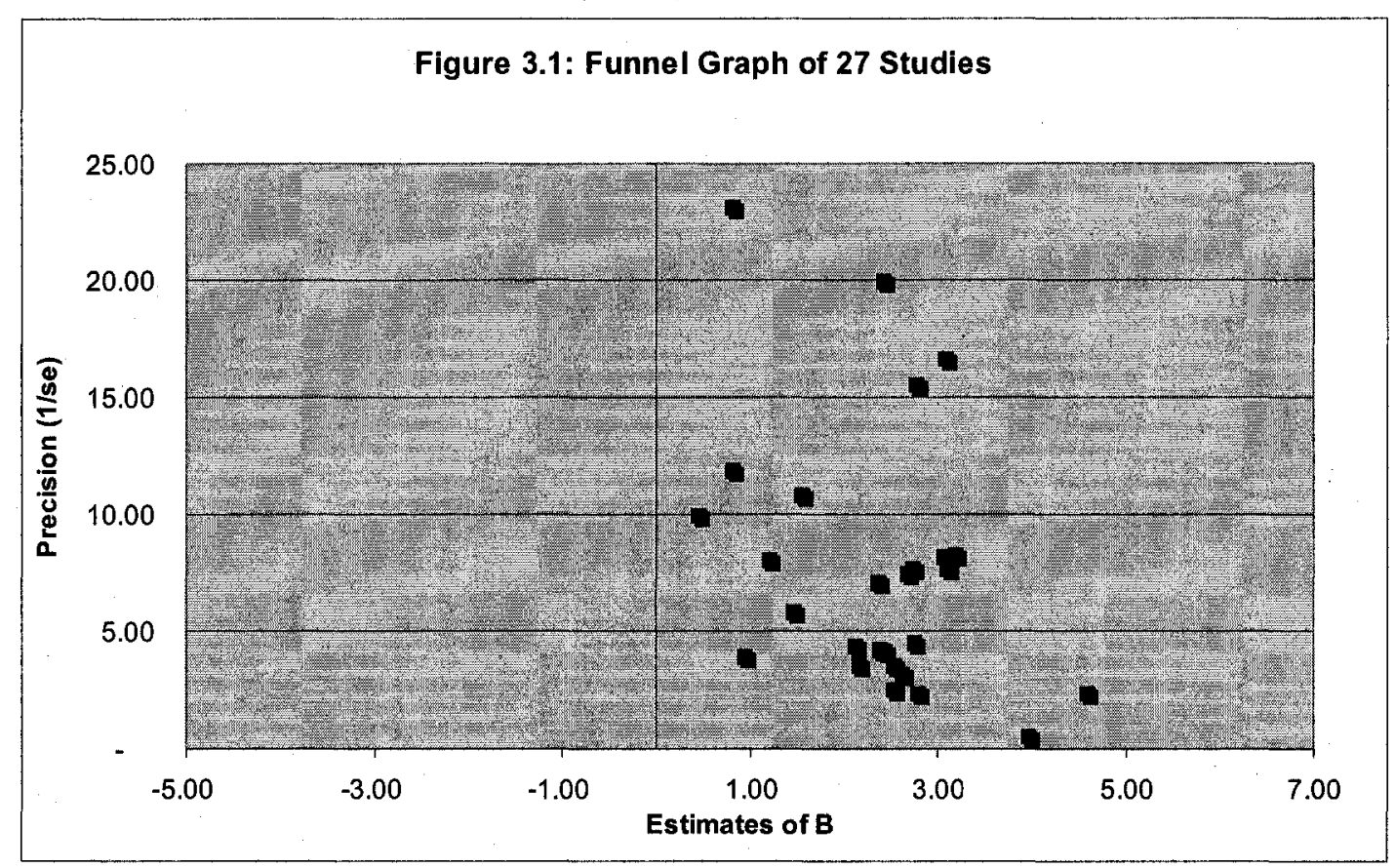

Table 3.3 MRA and MST Tests on Publication Bias

\begin{tabular}{|l|c|c|}
\hline \multicolumn{1}{|c|}{ Independent Variables: } & \multicolumn{2}{|c|}{ Dependent Variables } \\
\hline & $t$ & $\ln (t)$ \\
\hline Intercept & $3.32(1.04)$ & $2.31(4.23)$ \\
\hline $\mathbf{1} / \mathbf{s e}$ & $1.68(2.95)$ & - \\
\hline $\ln (\mathbf{n})$ & - & $.03(0.36)$ \\
\hline
\end{tabular}

The first column shows the results of regressing the $t$-value on the precision, which is equivalent to regressing the effect on the standard error. The latter regression 
can be obtained from the former by multiplying both sides by the standard error. Thus the intercept of the former regression is analogous to the coefficient on the standard error in the latter regression. If there is publication bias, we expect this variable to be significant: higher standard errors must be associated with higher effects. However, the intercept of 3.32 is insignificant here, leading us to doubt the existence of publication bias. Simultaneously, as discussed in Stanley (2005), the significance of the coefficient on $1 / \mathrm{se}$ (precision) is another sign that the empirical effect in the data is real and not manufactured by publication bias.

Formal tests for publication bias (Begg's rank correlation and Egger's linear regression tests) were also conducted, although these have low power and cannot be conclusive on their own. Higher levels of accuracy in smaller studies are the sign of a publication bias that can be detected by Begg's test; it fails to detect any in our case $(z=-$ $0.73, P=0.466$ ). Egger's method regresses SND (standard normal deviate, i.e. the ratio of effect to its standard error) on the standard error. The resulting intercept estimates the degree of asymmetry in the funnel plot; positive values indicate that smaller studies tend to produce more significant estimates. The intercept value in our case is positive, but not significant $(\mathrm{a}=3.32, \mathrm{P}=0.287)$. Similar results are obtained when Helliwell's papers are excluded from the sample.

Overall, with the possible exception of the difficult to interpret funnel graph, the result of the publication bias tests indicate it is either absent or is not a significant problem. 


\subsection{Specification of the Meta-Regression Variables}

As discussed above, the dependent variable for the next stage of meta-analysis is the $t$ value. These are taken from our sample of studies and normalized to account for the fact that they are coming from $t$-distributions that differ in their degrees of freedom. The variance in the dependent variable must now be explained by the "moderator variables" the characteristics of method, design or data of the studies that are believed to have an effect on its conclusions; these will enter the regression as independent variables.

The theory of meta-analysis does not provide a comprehensive guide on the issue of independent variable selection. The existing recommendations tend to favour a pragmatic examination of the particular field or issue to decide which variables are required for meta-analysis. In our opinion, the ambiguity of this technique compares unfavourably with the rigorous emphasis on including all available studies made at the earlier stage. If the aim of meta-analysis is to minimize bias inherent in narrative literature reviews, a more structured approach at this stage is to be recommended. The difficulty arises because it is of course impossible to be all-inclusive at this stage, as the number of variables (including dummies) that could be thought of as useful would greatly exceed the available sample size. A decision on what to include and what to leave out is necessary.

In making this decision analytically justifiable, it seems prudent to avoid all actual estimation until theoretically sound variables are pre-selected as explanatory factors for the differences between estimates in the literature. To avoid making this decision in the dark or basing it wholly on one's personal feelings as to what is important and what is 
not, conducting a narrative review and assessment of the literature as a preparatory step to meta-analysis is a good idea that we believe should be adopted in the field as a regular procedure. In this way, the narrative and meta-analytic reviews complement each other with their strengths and thus serve to minimize the author's possible bias. A variable can be extolled as important in the narrative review beyond its actual significance, but then its effect will be put into proper context by the meta-regression; conversely, if a metaregression is unable to deal with some variables because of data limitations or other constraints, the narrative review can give it its proper discussion space. ${ }^{29}$ Proceeding in this manner will allow us to take a more objective and comprehensive approach to metaanalysis, leading to a higher quality of results.

The independent variables can be loosely divided into three classes: study characteristics, sample characteristics and treatment characteristics. In the context of the field, it is the first two classes that are largely relevant for the independent variable selection process. In addition, within the three classes some of the variables can be thought of as essential and others as discretionary.

The essential variables are required to conduct the necessary significance and consistency tests and should be present in every meta-analysis to fulfill its theoretical promise. We identify the following variables as essential:

Time (variable AVYEAR). The average year of data used in the study. This is necessary because the underlying parameter that is being investigated is likely to change from year to year. Also, the methods used to study a particular problem may evolve with

\footnotetext{
${ }^{29}$ This situation may arise if all of the literature follows a particular sample selection or model setup process, i.e. an OECD dummy is impossible to estimate if all of literature focuses on EU only, and a common-language dummy can not be evaluated if the field is limited to trade relations between Englishspeaking countries - and yet these variables are clearly important in general.
} 
time. Although it may seem more appropriate to capture this latter effect with a publication year variable, the publication year is arguably less accurate than the average year of data, because publication may be delayed for several years, while methods are evolving quickly. As a consequence, two papers published in the same year, for example, may belong to two different eras in their approach. Due to these considerations, the average year variable is considered a better proxy than publication year and is used to capture the described effects ${ }^{30}$.

Publication (variables PUBLISHED, MAJOR). Publication bias is a common concern in meta-analysis. Because there may be a bias in acceptance of results depending on their significance, the set of published papers may not represent a random sample from the universe of all possible studies on the topic. To address this bias, we construct a two-level variable to include in he meta-regression in addition to the publication bias tests implemented earlier. The PUBLISHED dummy takes a value of 1 for the paper published in an academic journal, 0.5 for a working paper in a series (e.g. NBER, CEPII) and 0 if unpublished. Further, for the papers published in the 14 major economic journals (as per the JSTOR database definition) the MAJOR variable is coded as 1 and for others as 0 .

Observations (variable OBS). Incorporating the number of observations or, alternatively, degrees of freedom, allows us to perform an important test for the general validity of the empirical phenomenon under study. As the sample size increases, the probability of successfully rejecting a false null hypothesis grows proportionally to the

\footnotetext{
${ }^{30}$ There is a potential bias for studies covering long periods of time (e.g. 1960-1990 study would have the average year of data equal to 1975). Fortunately, long studies tend to split their coverage into separate regressions for shorter periods. The problem is dealt with by picking the latest period (e.g. 1985-1990 in the above example).
} 
square root of the sample size. This implies positive association between the number of observations in the study and the power of the test - of course, only if the null is false and so there exists an actual empirical regularity in the population. Other things equal, studies with a greater number of observations will tend to reject the false null more often. Consequently, if the null hypothesis is false there will be a positive and significant relationship between the number of observations and the dependent variable, which is the normalized $t$-statistic of the border effect estimate of the study. The association is independent of all the other features of meta-analysis and is reminiscent of the consistency property of an estimator; in fact, it was defined as "test consistency" in Poirier (1995).

In addition to these essential variables, other variables of particular relevance, including study and method characteristics, were identified through the literature review of the previous chapter and these include:

\section{AREA AND SCOPE variables:}

- NAM dummy: 1 if the study includes North American countries, 0 otherwise

- WEU dummy: 1 if the study includes Western European countries (2000 EU), 0 otherwise.

- CANUSONLY dummy: 1 if the study is on the US/Canada border only.

STUDY variables:

- LENGTH: number of years under study.

- SPECS: number of specifications considered by the study.

- THEORY dummy: 1 if the study derives its equation from theory, 0 otherwise.

\section{DISTANCE TREATMENT variables:}


- INTDISTVAL dummy: 1 if internal distance values are computed, 0 if imputed.

- DISTANCE dummy: 1 if distance measures are complex (geometric approximations etc., 0 if simple (straight-line distances etc.)

BORDER-SPECIFIC variables (pertaining to the topic of study):

- COMLANG dummy: 1 if the study failed to account for the common language factor (and 0 if it was included).

- $A D J$ dummy: 1 if the study failed to account for the adjacency factor.

- TRMODE dummy: 1 if the study failed to account for transportation mode effects or quality of communication effects.

- DISTRIB dummy: 1 if the study failed to account for entrepot effect or the distribution pattern (wholesale/retail).

- REMOTE dummy: 1 if the study failed to account for the theoretical remoteness measures.

- TRBLOC dummy: 1 if the study failed to account for trading bloc membership.

- SPATIAL dummy: 1 if the study failed to model the spatial distribution of industry, resources, networks or customers.

- SCONLY dummy: 1 if the effect is measured from the perspective of a small country only (i.e. the model uses internal trade data only for a small country).

- LCONLY dummy: 1 if the effect is measured from the perspective of a large country only (i.e. the model uses internal trade data only for a large country).

- GOV dummy: 1 if the study failed to consider the role of the government.

Note that these are only equal to 1 if the preferred equation of the study fails to account for the variable/method in question, and equal 0 both when it is accounted for or 
is impossible to account for. This methodology consistently indicates the presence of influences of these variables in the border effect estimates. For example, any study dealing only with the US-Canada border would have COMLANG $=0$ and $A D J=0$ because there is no way to control for them in that setting; the zeros would also correctly indicate that the border effect estimates from this study are net of the effects of these variables, i.e. baseline estimates. If the study were to add Mexico to the sample and introduce $C O M L A N G$ and $A D J$ variables to the equation, they would again be coded as zeros because the estimated border effect is still net of the effects of those variables. However if that study could account for common language and adjacency, but did not do so, its border effects will be inflated, which is meant to be captured by COMLANG $=1$ and $\mathrm{ADJ}=1$.

Unfortunately, lack of degrees of freedom and the nature of the data force us to exclude some of these theoretically important variables. Only one study fails to account for the common language effect; conversely, only one study considers the effects of transportation mode and government. We therefore have to exclude the COMLANG, TRMODE and GOV variables from the final specification.

\subsection{Results of Meta-Regression Analysis}

The usual meta-analysis technique is to include one preferred estimate from each study. Due to few observations, an attempt was made to subdivide some of the studies into two parts and treat them separately. This was attempted only when the study was naturally predisposed to such a division. For example, when alternative border effect estimates are 
derived from the internal trade of two countries using different sources of data, we felt it permissible to treat them as separate observations. This procedure was implemented for three studies; since in total 24 studies containing empirical estimates of the border effect are found, we consider both the "base" sample with 24 observations with one estimate from each, and the "extended" sample with 27 observations. We put more trust in the results for the base sample, considering it to be less biased than the extended version, yet expected some efficiency gains from the use of the latter due to the increase in degrees of freedom. The results were very similar, and so only the base sample results are presented here because we feel them to be more reliable.

Specification search was approached in a "Hendry spirit", that is, starting from a general model that is theoretically plausible and testing down to specific variables through significance tests and overall fit. We started with an all-inclusive model for the variables described above and used alternatively a set of weak and a set of strict criteria in model selection. We found that convergence is generally achieved to one of the two models: the "long" version (using weak criteria) and the "short" version (using strong criteria).

The "long" specification results are presented in Table 3.4. The overall significance of the model is clearly demonstrated by the strong $F$-statistic of 83 . Further, $97 \%$ of the variance in the estimates of the studies is explained. Not all the variables are significant at $5 \%$, but these are left in the "long" version because removing them tends to decrease adjusted explanatory power and create problems with variable omission as identified by RESET test. Overall, several variables are found to influence the border effect as follows: 
- Canada-US dummy is positive and significant at $10 \%$, indicating higher border effects between the U.S. and Canada than elsewhere.

- Average year of study is negative and significant, indicating that estimated border effects decrease with time.

- Border effect grows with number of observations, indicating a true empirical effect ("test consistency").

- Border effect decreases with the number of specifications in the study, which may be explained by greater choice of estimates and a tendency to pick a lower one as more conservative or plausible (given that the high border effects were treated as unbelievable for some time).

- Theory dummy has a significant negative impact: equations strictly derived from theory find lower border effects than the average study.

- $\quad$ Failing to take adjacency into account increases the estimated border effect.

- Internal distance measures and trading bloc membership enter negatively, but are not significant.

- Large-country estimation implies larger border effects which is contrary to theory. There are only two estimates that possess the large-country property; one of them is limited to internal U.S. border effects and both use the U.S. Commodity Flow Survey data. This may explain the result; to account properly for the large-country estimates, a more complicated dummy structure than the sample size allows may be necessary. 
Table 3.4 The "Long" Model

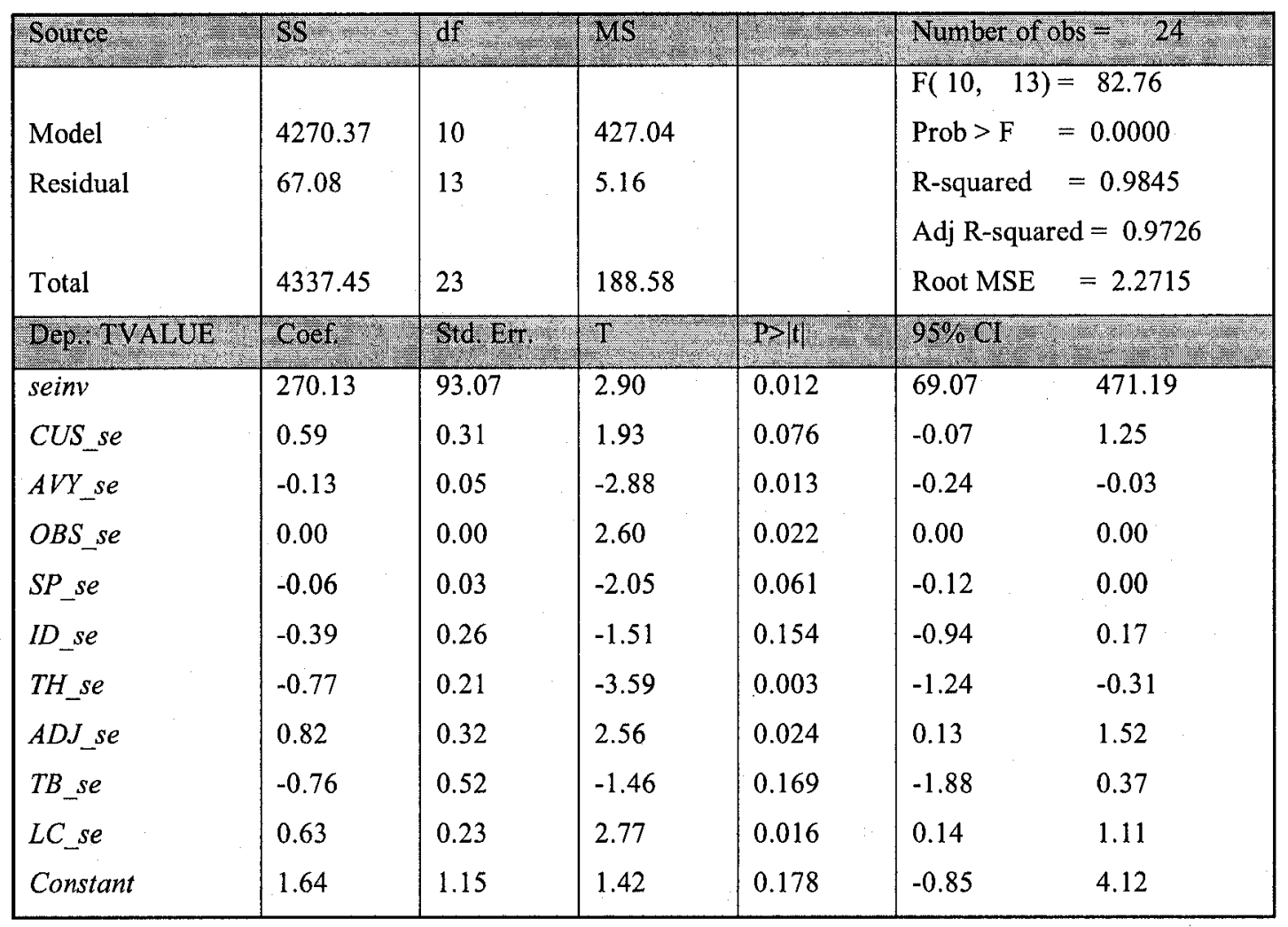

The results of the_Ramsey RESET test show that under $\mathrm{H}_{0}, \mathrm{~F}(3,10)=1.54$, and $\mathrm{P}$ $=0.2645$. Hence the test finds no evidence of omitted variables.

Conducting the specification search under the alternative, stricter selection criteria yields a specification labelled the "short" model. It contains fewer independent variables; however all of the variables are significant at $1 \%$. Table 3.5 presents the results. 
Table 3.5 The "Short" Model

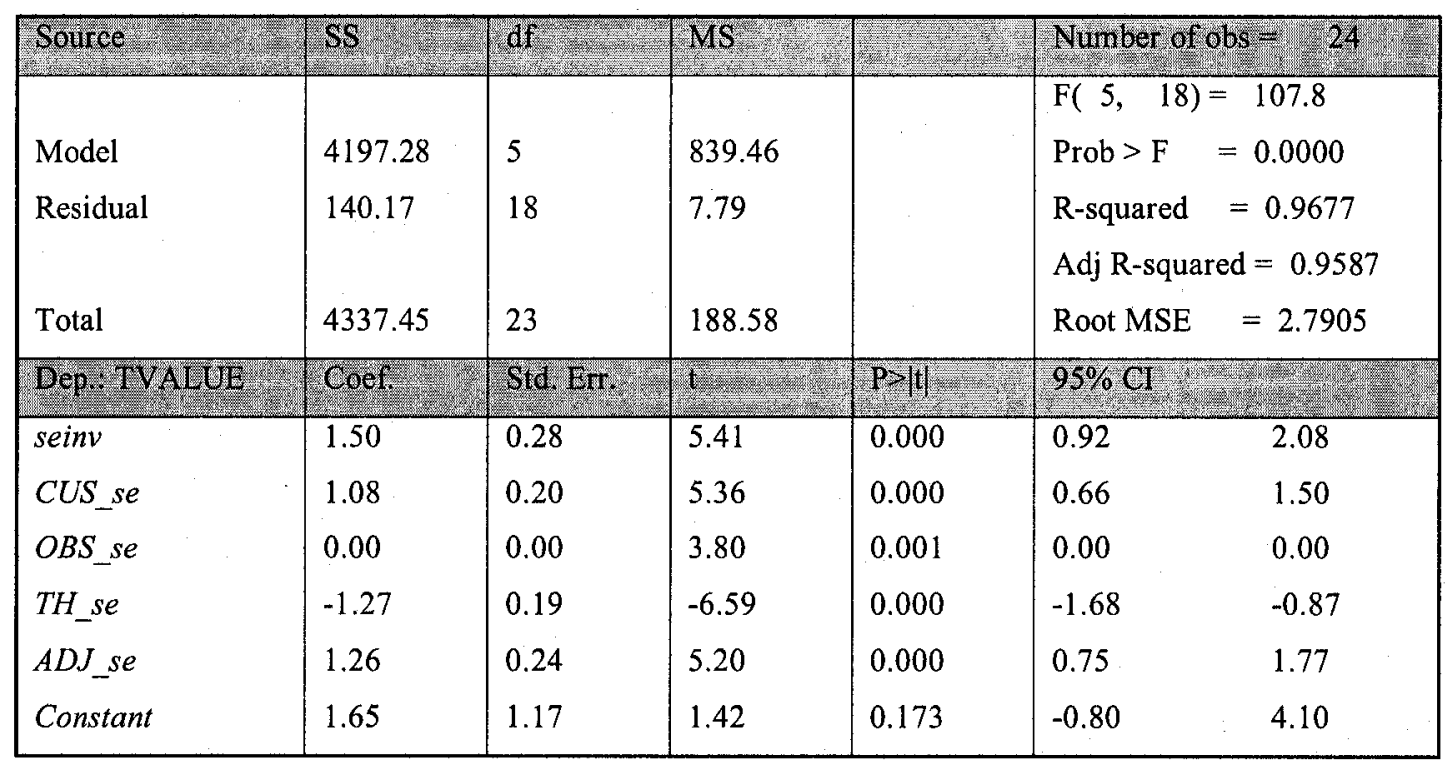

The "short" model also exhibits very high significance $(F=108)$ and explanatory power $-96 \%$ of the variance is explained with this model. For the variables that are included in it, the results are quite similar to the "long" model. The theory dummy is still negative and the adjacency dummy is positive. Canada-US dummy is highly significant and positive, indicating once again that the Canada-US border has a greater effect on restricting trade than other borders, and the number of observations enters positively, indicating an authentic empirical effect.

Specification tests on the short model yield the following results: for Ramsey RESET test under $\mathrm{H}_{0}, \mathrm{~F}(3,15)=7.52, \mathrm{P}=0.0027$. This shows evidence of omitted variables; indeed, using very strict selection rules often results in this. However, the obtained model is efficient and parsimonious, using just four variables to explain most of 
the variation in the border effects literature. Both models pass the standard heteroskedasticity tests ${ }^{31}$.

The log-linear specifications were also tested; their results tend to explain $55-60 \%$ of variation in the data, and generally yield weaker results compared to the results of the linear model. The variables common to both approaches are theory and adjacency, entering in a similar fashion as before. Some atheoretical effects (large country and trading bloc effects enter negatively) are also occasionally found, as well as the result that border effects tend to decrease with time. Most of those models pass the RESET test and the White heteroskedasticity test.

\subsection{Conclusions}

Overall, the results of the meta-analysis seem to be strong and consistent. The border effect as a whole is strongly confirmed by the pooling results from the literature, ranging between 7 and 10 for an average border. There is also little evidence of publication bias, and in any case the number of meta-analytical confirmations for the border effect is beyond any possible publication selection problem. Nearly all of the variance in the literature can be explained by study- and treatment-specific variables. Finally, several variables that have a significant effect on the border effect estimates have been identified.

Theory has been shown to be one of the crucial variables, and failing to account for adjacency is a major and significant omission. There are some signs that precise measuring of the actual internal trading distances would reduce the border effect, but it is

\footnotetext{
${ }^{31}$ A good test of the two models would be an out-of-sample forecasting exercise. Unfortunately, our study is severely limited in the degrees of freedom. Any excluded study would thus represent an unacceptable loss of information for the main meta-regressions.
} 
not a robust finding. Using complex distance measures, however, is not found to be important. Finally, far from being a transparent line between two similar countries, the Canada-U.S. border effects reflect a greater than average reluctance to trade between these two nations. Further comparative research into this unexpected finding is recommended. The next chapter establishes a regional theory-based model framework in which this investigation can be conducted. 


\section{Chapter 4}

\section{New Border Effects Evidence from the Canada-U.S.}

\section{Regional Trade Model}

This chapter uses the theory of trade in differentiated goods and the conclusions of the preceding chapters to construct a theoretically based regional model of trade in North America and estimate border effects arising from it. Theory is crucial because earlier critiques of the empirical gravity equations - Anderson (1979), Bergstrand (1985), Deardorff (1998) and Anderson and van Wincoop (2001) - are supported by the results of our meta-analysis in chapter 3 , which indicates that a gravity equation with a theoretical foundation has a significant impact on the results. Our specification contains the key price variables implied by theory, as well as the effects of tariffs and the role of governments; we also introduce the use of time series techniques to the field on a data panel stretching from 1988 to 2003 . We thus take into account both theory and practice to produce estimates superior to prior research. These estimates paint a picture significantly different from that of earlier studies by McCallum (1995), Helliwell (1998) and others.

There are four principal conclusions from this chapter: a) border effects between Canada and U.S. are much lower than suggested by most of the previous research; b) the decrease in border effects with time established in the literature is shown to have been largely due to the omission of tariffs as an explanatory variable; including tariffs and making use of time series techniques shows that Canada-U.S. border effects net of these 
factors have actually risen with time; c) national and regional governments in North America are one of the explanatory factors for border effects, and d) the overall border effect is found to be largely import-driven, meaning that Canadian provinces are much more averse to importing from the U.S. than to exporting there.

\subsection{Introduction}

Over the past two decades, two major free-trade agreements have been implemented to enhance the economic integration of North America. Yet the same period of time was marked by the rise of the border effects literature that has questioned the degree of this integration - first in North America and then elsewhere. This literature, reviewed in earlier chapters, reaches a general conclusion that the differences among nations continue to affect substantially the pattern of trade (a more accurate rendering of McCallum's "national borders matter"). Significant differences are invariably found when international trade intensity is compared with the intensity of internal trade; the magnitude of these differences ranges between 2 and 50, as shown in the meta-analysis of the preceding chapter. These differences may be interpreted as representative of the unexplained factors that cause the merchandise trade across an international border to deviate from the pattern predicted by the gravity equation. Although the gravity equation is one of the most frequently and successfully used tools of international economics, there is no agreement on what causes the border effects and what specification is the most appropriate to estimate them. This study introduces a model of trade between the regions that answers some of the unsolved questions in this area and also challenges some of the 
old answers. The purpose of this chapter is, first, to develop a theory-driven model of regional trade between Canada and the U.S.; second, to estimate the various types of border effects that arise from it; and third, to employ time-series and econometric techniques to determine the time path of the border effect in a sixteen-year setting.

Merchandise trade in the model is assumed to be driven by differences in varieties of produced goods, first explored in Dixit \& Stiglitz (1977) and Krugman (1980). This model is modified in three ways, namely: by introducing the geographical origin of goods, as in Head \& Mayer (2000), by making the model regional rather than national, and by adding important (heretofore usually omitted) explanatory variables to the model. The combination of the unique Canadian data on regional trade flows, the geographical situation of the two trading partners and their many institutional similarities make the Canada-U.S. border the most promising test of this model.

We now have access to sixteen years of data (1988-2003) on Canada-U.S. merchandise trade flows which are first analyzed cross-sectionally for compatibility with earlier results, and then with time series techniques in a panel setting. The time series panel allows us to control for the effect of additional variables (such as tariffs) that can not be incorporated in a single-year cross-sectional estimation. The results of this exercise suggest that a theory-driven model produces a fairly narrow band of estimates for border effects between Canada and U.S. over this period. These are significantly lower than suggested by most previous research - between 4 and 7 cross-sectionally for all years, and between 2 and 6 in a panel setting. The model estimates are very robust to the choices of estimation techniques, and all the explanatory variables in the final version of the regression model are highly significant in explaining regional trade. 
The results obtained with the use of time series panels are of particular interest. A common finding in the literature is the decline of the border effects through time; in particular, it was claimed that the Canada-U.S. border effects have declined significantly after 1988. This result was thought to be due to the phase-out of tariffs following the adoption of the Canada-U.S. free trade agreement in 1989. We show that this observed decline in border effects was largely explained by tariff reductions, confirming the hypothesis of the literature. Furthermore, the influence of even a small tariff on the border effect estimates is found to be very large - a 3.5\% average tariff level in 1988 approximately triples the border effect estimate in that year. However, as tariffs are usually a known factor, and inflate border effects greatly if not explicitly modeled, we see no justification for leaving them out of the empirical specification as was done in previous studies. Our border effects estimates are thus "net" of tariffs, and represent, by definition, a combination of unexplained or omitted factors. It is in this sense that we discuss our results throughout this chapter.

When tariffs are modeled and included as explanatory variables along with fixed time effects and time-border interaction terms, border effects are actually shown to have persistently increased during the 1988-2003 time period: from 2.2 in 1988 to 5.5 in 2003 . Overall, this result may be viewed as the second part of the warning, the first having been delivered by McCallum in 1995: not only do border effects exist in a globalising world but they may also be increasing. We show that this increase has passed unnoticed by the earlier studies due to the combination of exclusion of tariffs, misspecification and omitted variables in the gravity equations used for estimation. Also, previous studies were not done in a panel context. We believe that a compensating rise in non-tariff barriers, 
changes in preferences underlying the patterns of trade and the increased security concerns in the United States may all have contributed to the observed increase in border effects over the 1988-2003 period.

Further analysis by Canadian region shows that the model yields results broadly consistent with previous research, notably Anderson \& Smith (1999) and Helliwell (1996, 1998). A significant difference from these studies is discovered when estimating the border effects by direction of trade: all Canadian provinces and the country as a whole show a strong border effect for imports, and much lower (for some provinces even insignificant or positive) border effects for exports. This means that while Canadian provinces are nearly as willing to export to the U.S. as they are to other Canadian provinces, they are relatively unwilling to import goods from the U.S., and likely make up the shortfall by importing from the rest of the world. In particular, an ongoing increase between 1997 and 2003 in import border effects vs. the U.S. (from 11 to 17) may be due to the rising importance of the low-labour-cost countries as a source for Canadian imports. This implies a triangular pattern of trade that can bias the border effect estimates that are produced across a single border using only trade data for the two countries in question. The ongoing changes in trading patterns with other suppliers should be taken into account - an important observation for further research.

Lastly, the effect of the explicit introduction of the government motivated by its supposedly discriminatory policies in favour of the domestic suppliers has been significant in the expected direction. This justifies our conjecture that "buy national" policies give a relative boost to intranational trade vs. international trade and that the 
involvement of the government in the economy is one of the explanatory factors for the border effect.

The remainder of this chapter is organized as follows: in section 4.2 , we present a short review of the directly relevant research and its contributions, with particular stress on the Canada-U.S. studies and methodologies (a full review of the literature may be found in chapter 2). In section 4.3 , we develop a theoretical regional model of trade in differentiated goods, incorporating the theoretical critique of Anderson (1979), Bergstrand (1985), Deardorff (1998) and Anderson and van Wincoop (2001), and derive a specification that can be estimated by linear regression techniques. Although in many papers the data section can be relegated to an appendix, for a border effect study the data sources often play a crucial role. Therefore in section 4.4 , we discuss the data requirements of the model and our solutions to the data issues that arise. Section 4.5 presents the estimation results obtained with several estimation techniques and the decomposition of border effect by region and direction of trade. Section 4.6 concludes and draws implications for further research.

\subsection{Research into Border Effects as a Measure of Integration}

The empirical demonstration of the continued relevance of the international borders, even those believed to be relatively innocuous such as the Canada-U.S. border, was first performed by McCallum (1995). His seminal paper on the Canada-U.S. trade used the newly available data source unique to Canada: as a highly decentralized federation, Canada was the only country in the world to collect and publish data on its 
interregional merchandise trade flows. Combining this data with international trade (also disaggregated by region) allowed the border effect to be estimated through the gravity model by comparing the international trade of Canada to its intranational trade after correcting for economic size and distance between the regions.

Before the discussion of McCallum's results, a few notes on the gravity model are necessary. First and foremost, it expresses an empirical regularity well known to trade economists, stating that imports of country $i$ from country $j$ (or, more generally, the trade flows between the two) are directly proportional to the GDPs of these countries and inversely proportional to the distance between them. Taking logarithms of both sides of this statement results in a standard log-linear form of the gravity equation, which is occasionally augmented by several other variables thought to be of empirical importance. Its empirical success in explaining the majority of trade flows and its robustness in doing so for various places and periods have led to efforts to legitimize its success by providing a solid theoretical foundation for the equation. At present, the gravity equation has been derived both from models of trade in differentiated goods and the Heckscher-Ohlin factor endowments model. Recent research into border effects emphasizes that theory must be taken seriously, and any gravity equation used should be derived from theory. Appendix A discusses the gravity equation and its derivation in more detail, and points out the elements that result from a specification's theoretical origin.

Using the simple empirical gravity equation and specifying a dummy for crossborder trade, McCallum has shown that after taking size and distance into account, a Canadian province trades on average twenty-two (22) times more with another province than with a U.S. state. These findings were met with a mix of curiosity and disbelief; 
while the disbelief subsided as the results were confirmed by follow-up research, the curiosity has since generated dozens of publications. Wei (1996) showed the existence of border effects for the OECD countries, and Helliwell $(1997,1998)$ confirmed and extended McCallum's findings. Helliwell's research also linked McCallum's results to other fields. He pointed out in Helliwell (1997) that the phenomenon found by McCallum is not isolated, and that border effects essentially equivalent to McCallum's were found by Engel \& Rogers (1996) in their study on price variability, by Feldstein \& Horioka (1980) - for international capital markets; the author's original research in the same paper finds border effects in migration. These linkages established the place of border effects in international trade and led to the current interpretation of the border effects as a proxy for the unexplained factors in differences between the nations, causing the border between them to appear to diminish trade after all known and quantifiable factors are accounted for by the model.

For the purpose of this chapter, there are three main threads in the current literature on border effects ${ }^{32}$ that are relevant: assessing the impact of border effects on welfare, using additional variables to explain the border effect, and constructing theoretical explanations for this phenomenon (preferences- or networks- based). Although the first approach has yielded some interesting results (generally, border effects are found to result in relatively small welfare effects), we consider this research question somewhat premature as well as somewhat vague. It is premature because the theoretical critique levelled at the border effect estimates finds them biased; a better specification is necessary to estimate their true size (which is the approach advocated by us). It is vague

\footnotetext{
${ }^{32}$ A full treatment of the evolution of this field has been done in detail in Chapter 2 of this thesis.
} 
because it is not clear how borders can consistently generate welfare losses in market economies with democratic political systems.

This last point might require an explanation. The national borders created and maintained by democratic governments (research was mainly done on European and North American OECD members) can be reasonably assumed to represent the will of their populations. If these populations are presumed rational, it is not clear why welfarereducing borders would not be dismantled by them. Hence, either the borders must create greater welfare gains in other areas or their welfare effects are not calculated correctly. The latter is a strong possibility as the border effects represent unknown factors, and the assumptions about those must necessarily be uncertain. For example, if nationalism is part of the utility function, welfare losses from trade are more than offset by welfare gains from living in a nation-state among people with shared norms and culture. This argument is not meant to introduce ad-hoc factors to invalidate existing welfare measurement models; the reasoning is that these models must necessarily be omitting variables because their premise of voluntary welfare losses by rational economic agents is at odds with the economic theory. ${ }^{33}$

Our approach, then, is to leave aside the welfare issue and to put the calculation of the border effects on a more solid theoretical basis by deriving the empirical model from a theoretical framework. A well-defined theoretical model will permit a more precise interpretation of the empirical results, in particular the issues of size, direction and

${ }^{33}$ On the other hand, the estimates of welfare impact of the borders can prove to have a useful interpretation. If the economic welfare losses due to the trade-decreasing features of the existing borders are more than compensated for by the positive welfare effects of their presence (such as nationalism), one could put a price on nationalism. At the moment when the borders are dispensed with, in such a manner as is currently ongoing in the European Union, their negative economic welfare effects (which can be calculated) must equal their positive welfare effects due to nationalism. 
intertemporal behaviour of border effects. Once a generally accepted methodology is developed for the measurement of border effects, it will open the way for their very useful interpretation - to assess the true degree of economic integration between the goods sectors of any two economies. The evolution of border effects through time will then serve as an indicator of the pace of this integration. It is our hope that this study may contribute to the development of such generally accepted methodology.

It remains difficult to estimate border effects for countries other than Canada because of the lack of reliable internal trade data to compare against international trade flows. Wei (1996) introduced a methodology that measures internal trade as gross shipments in the goods sectors less merchandise exports, and internal distance as onequarter the distance to the nearest state. This method has been criticized as producing inconsistent trading distances, and much work has been done since on improving internal trading distance estimates, for example Leamer (1997), Helliwell \& Verdier (2001), Head \& Mayer (2001), Nitsch (2000). In particular, Helliwell \& Verdier (2001) argue in favour of measuring population-weighted internal distances that take into account intra-city, inter-city and rural population distributions; this study uses their internal distance estimates. However, there has been no corresponding advance in internal trade flows statistics for other countries, and as of now, there are few alternatives to Wei's proxy to measure internal trade in countries other than Canada. ${ }^{34}$ Such an alternative exists in the United States, where Hillberry (1998) pioneered the use of the Commodity Flow Survey (CFS) to produce estimates of internal trade; it is not without its problems. The issues associated with the use of the CFS data are discussed in the data section.

\footnotetext{
${ }^{34}$ For a detailed discussion of Wei's proxies and research and critique associated with them, see Chapter 2.
} 
This variety of methods and geographical locations has produced a series of border effect estimates varying between 2.6 and 50 , depending on the country and time period in question. There has been a general tendency for the Western European countries to exhibit smaller border effects that Canada-U.S., and also a tendency for the border effects to decrease over time (usually explained as the result of increasing economic integration). A considerable variety of specifications have been developed and a number of additional explanatory variables such as common language, adjacency etc. have been introduced to the gravity equation with the hope of explaining the border effect. Facing this assortment of variations, Anderson and van Wincoop (2001) delivered a strong message: only gravity equations explicitly derived from international trade theories should be used to estimate border effects; ad-hoc specifications suffer from omitted variables and model selection biases. This paper has shown that previous research has paid only lip service to trade theory, and the gravity equations commonly used did not include the crucial price variables and remoteness (or multilateral resistance) variables. Anderson and van Wincoop (2001) started two important trends in the literature: more emphasis on theory, and consideration of the welfare impact of border effects ${ }^{35}$.

Most purely theoretical models in this area, however, proved to suffer from difficulties in deriving a specification that can be estimated. Anderson \& van Wincoop (2001), for example, found it necessary to derive a CGE model to obtain a partially testable equation, requiring assumed values and calibration for the elasticity parameters; the complexity of that approach and an alternative to it were pointed out by Feenstra (2002). From this critique stems the importance of the contribution to the field by Head and Mayer $(2000,2001)$. These papers significantly simplified the derivation of a linear

\footnotetext{
${ }^{35}$ The contribution of Anderson and van Wincoop (2001) is discussed in more detail in Chapter 2.
} 
specification from a model of trade in differentiated goods (i.e. under monopolistic competition). After deriving the final expression of trade flows from exporter to importer from their model, they divide it through by the corresponding expression for trade flows from importer to itself (i.e. the internal trade of that importer). The resulting expression is log-linear in ratios of the main variables of the model, and the remoteness variables implied by theory (describing the distance of the importer from every other trading partner) cancel out. This result takes advantage of the property of independence from irrelevant alternatives of the CES demand function, and leads to a much simpler final specification that can be fully estimated, and depends only on the ratio of explanatory variables for the importer and exporter countries.

We follow McCallum (1995) in being curious about border effects, Anderson and van Wincoop (2001) in taking theory seriously, and Head and Mayer (2000) in making. the decision to take theory seriously an easier one. Our specification is derived from the theory of trade in differentiated goods. We differ from previous research by deriving a regional (as opposed to national) model of trade and by augmenting it with additional relevant explanatory variables. These new elements come from innovations incorporated by other papers and the results of meta-analysis of the literature. ${ }^{36}$ The results imply that several variables such as common language, adjacency (both introduced by Wei (1996)), weighted internal trading distances (due to Helliwell and Verdier (2001)) as well as some measures of the shared cultural, social and political networks significantly influence the estimated border effects. The meta-analysis also indicates that papers deriving their equation from theory find lower border effects. These conclusions influence our approach to deriving the final specification of the regression model, as shown in the next section,

\footnotetext{
${ }^{36}$ The meta-analysis is contained in Chapter 3 of this thesis.
} 
where we take advantage of the Canadian regional trade flows data to construct a more detailed model of international trade in North America than has been attempted before.

\subsection{Theoretical Model}

The previous Canada-U.S. trade models treated the regions as agents, but by and large specified their trading relationship ad hoc in a plausible gravity setting. On the other hand, theoretical models of border effects under monopolistic competition that used the Head/Mayer simplification have been employed only in the European Union-OECD setting and so were specified at the national level. To our knowledge, they have not been used in a regional setting to explain the Canada-U.S. trade. We combine the two approaches to construct a theory-based regional model of trade in differentiated goods. Each region is treated as an independent agent, trade flows between the regions include both intra- and international trade and these are compared to the internal trade within the regions themselves. This approach permits greater insight into the trading behaviour of the regions and should lead to a more coherent specification of the gravity equation, which can address the research question about economic integration between national economies and among their constituent regions.

We start with the same general specification of preferences as Head \& Mayer (2000) in their national trade model, and we extend that model to regions operating as independent entities. Let there be $K$ countries, each divided into $r_{k}$ regions $(k \in 1 \ldots K)$ for a total of $R=\sum_{k} r_{k}$ regions which trade with each other. In all subsequent notation, we shall denote an importing region with $i$ and an exporting region with $j$. 


\subsubsection{Consumers' Problem}

All of the varieties of goods, denoted by $v$, are differentiated, and each variety is produced by a different firm. The varieties produced by each region are assumed to weigh equally in the utility function. The utility of the representative consumer in region $i$ is a CES function. This function depends on the quantities of all varieties consumed from all the exporting regions ${ }^{37}$ and consumer preferences $a$, and is characterized by the constant elasticity of substitution $\sigma$ :

$$
U_{i}=\left(\sum_{j} \sum_{v=1}^{n_{j}}\left(a_{i j} c_{i j v}\right)^{\frac{\sigma-1}{\sigma}}\right)^{\frac{\sigma}{\sigma-1}}
$$

where $n_{j}$ is the number of varieties produced by an exporter region $j$.

Consumption in the region $i$ of all the varieties of goods from region $j$ is expressed by $c_{i j}$. These goods are purchased at the price $p_{i j}$, common for all the varieties of region $j$ 's goods imported by region $i$, and representing the C.I.F. price of goods delivered into region $i$. Thus the total expenditure of each region on imports from all regions (including itself) can be expressed as:

$$
m_{i}=\sum_{j} m_{i j}=\sum_{j} c_{i j} p_{i j}
$$

\footnotetext{
${ }^{37}$ These include the region $i$, and thus the varieties imported from itself.
} 
where $m_{i}$ can be interpreted as total imports value (including imports from itself) and the bilateral imports value $m_{i j}$ denotes imports from a particular region $j$.

Maximizing (1) subject to the budget constraint (2), we derive the following expression for the bilateral imports of region $i$ from region $j$ :

$$
m_{i j}=\frac{a_{i j}{ }^{\sigma-1} n_{j} p_{i j}{ }^{1-\sigma}}{\sum_{r} a_{i r}{ }^{\sigma-1} n_{r} p_{i r}{ }^{1-\sigma}} m_{i},
$$

where $a_{i j}$ represents the consumer preferences of region $i$ with respect to the goods of region $j$, and $n_{j}$ is the number of varieties produced by region $j$.

Direct estimation of (3) is difficult because its logged form includes an intractable remoteness term, which depends on the values that are already in the equation and furthermore is supposed to contain information on all the possible trading partners. To obtain a specification that significantly simplifies estimation, we follow Head and Mayer (2002) in setting $j=i$ in (3), which results in an expression for $m_{i i}$. Dividing the bilateral flows in (3) by these internal flows $m_{i i}$ we obtain the expression:

$$
\frac{m_{i j}}{m_{i i}}=\left(\frac{a_{i j}}{a_{i i}}\right)^{\sigma-1}\left(\frac{p_{i j}}{p_{i i}}\right)^{1-\sigma}\left(\frac{n_{j}}{n_{i}}\right)
$$




\subsubsection{Producers' Problem}

On the production side, we assume that there are a large number of firms, each producing a differentiated variety. All firms use the same technology in which labour is the only input. Following the Dixit and Stiglitz (1977) model of monopolistic competition, the cost function of a firm in region $j$ is assumed to contain a fixed component and a unit input coefficient, both multiplied by the wage rate. This cost function is written as follows:

$$
C_{j}=w_{j}\left(F+c q_{j}\right)
$$

where $c$ is a unit input coefficient converting output produced into hours worked, $F$ is a fixed cost (in terms of hours worked) necessary for production, and $w_{j}$ is the wage rate in region $j$.

Profit maximization implies that marginal revenue is equal to marginal cost. Recall that $\sigma$ is the implied elasticity of substitution. Thus:

$$
p_{j}=\frac{\sigma c}{\sigma-1} w_{j}
$$

where $p_{j}$ is the factory gate price of output in region $j$, same for each variety because wage rates are equalized due to perfect labour mobility. Market equilibrium is obtained from a zero-profit condition. Setting the profit function equal to 0 , using (6) and solving for quantity produced by any firm, we obtain: 


$$
q=\frac{F(\sigma-1)}{c}
$$

If the total value of production in the region is denoted as $v_{j}$, and the quantity produced by each firm is $q$, then:

$$
v_{j}=q p_{j} n_{j}
$$

The price $p_{i j}$ depends on the factory gate price $p_{j}$ and the barriers to trade separating the two trading regions. These barriers include transportation costs and tariffs on trade between the regions. Following previous research, we use a non-linear function of distance as a proxy for transportation costs. While transportation costs are defined for all regional pairs, the tariff barriers are different from zero only if the regions are in different countries. The effect of tariffs is also allowed to be non-linear as there is some evidence that the increase in trade costs resulting from a tariff is not linearly proportional to the tariff size. ${ }^{38}$ Thus:

$$
p_{i j}=\left(1+T_{i j}\right)^{\theta} d_{i j} p_{j}
$$

\footnotetext{
${ }^{38}$ Theoretically, the marginal effect of a tariff may be expected to be inversely proportional to the tariff size. At low tariff levels, a trader still faces fixed costs of information and compliance with the tariff schedule. Thus, in the environment of small decreasing tariffs between Canada and the U.S. in the 19881998 period, even marginal tariffs could generate relatively substantial barriers to trade, and thus influence prices in a non-linear manner. This non-linear relationship between tariffs and trade is consistent with the observed large expansion in Canada-U.S. trade after the 1989 Free Trade Agreement; this expansion cannot be easily explained by a linear relationship between tariffs and trade costs because the level of bilateral tariffs was relatively low when the agreement was signed.
} 
where $d_{i j}$ is the distance between regions and $T_{i j}$ are tariff barriers between the regions in different countries.

\subsubsection{Deriving the Specification}

We turn now to the more detailed consideration of the preferences term $a$ in the utility function. Basic consumer preferences consist of a random term $\varepsilon_{i j}$ and a general preference for domestic goods. This reflects the unknown source of home bias that translates into the border coefficient of the equation. Preferences are also affected by the strength of informal networks between the regions: shared norms, trust, customs and culture. Although difficult to measure, their importance has been stressed in the literature, most recently in Helliwell (2003). We propose to capture a measure of these family, cultural and social networks by defining a so-called linguistic affinity between regions $i$ and $j$. Sharing a linguistic tradition of a trading partner is assumed to facilitate networks and connections that form the basis of trade.

The meta-analysis of the literature showed significant adjacency effects. We incorporate this as an additional measure of network effects - a preferential affinity for goods from a region sharing a border with the importer. This adjacency effect presumes that sharing a border leads to sharing some of the neighbour's networks, norms and values through common historical and cultural evolution. A region is considered to share a border with itself. 
Lastly, preferences are also assumed to depend on the common government. Governments usually adopt and promote "buy domestic" policies, enhancing trade between the intranational regions. As mentioned above, other unexplained effects in addition to those specified by the model are captured by the border effects dummy $B$. Including these terms results in the following general specification for consumer preferences:

$$
a_{i j}=\exp \left[\varepsilon_{i j}-\beta B_{i j}-\eta A D J_{i j}+\lambda L_{i j}+\gamma G_{i j}\right]
$$

where $B_{i j}=0$ if $\mathrm{i}$ and $\mathrm{j}$ are in the same country and 1 otherwise

$$
\begin{aligned}
& A D J_{i j}=0 \text { if a shared border exists or } \mathrm{i}=\mathrm{j} \text {, and } 1 \text { otherwise } \\
& L_{i j}=\sum_{l=1}^{M} L_{i l} L_{j l} \text {, where } l \in 1 \ldots M \text { is the number of languages spoken in a region and }
\end{aligned}
$$

$L_{i}$ and $L_{j}$ are the proportions of speakers of these languages in the region. ${ }^{39}$

$G_{i j}=0$ if the regions are in different countries and $G_{i} * G_{j}$ otherwise, where $G_{i}$ is the ratio of the federal government's expenditures to the total gross domestic product of that region. Exception is made when $\mathrm{i}=\mathrm{j}$; in that case $G_{i}$ denotes the ratio of the total federal and provincial/state governments' expenditures in that region to its GDP. The intuition for this specification is as follows: the provincial/state government induces

\footnotetext{
${ }^{39}$ The expression for $L_{i j}$ is derived as follows. Assume there are $N$ individually owned firms in each region, owned by $N$ consumers who speak two different languages: $n$ speak language $A$ only and $(N-n)$ speak language $B$ only. Each firm has flat production costs, is a price-taker, and its ability to make a sale is affected only by the language match between the producer and potential customer. Assume the extreme situation: a sale is only made if the languages spoken both match. Then, assuming sales are also made to oneself, the quantity of internal sales will be $n^{2}+(N-n)^{2}$ and the quantity of external sales $n_{1} n_{2}+\left(N-n_{1}\right)\left(N-n_{2}\right)$, as per the formula above.
} 
home bias in trade only at the intraregional level, while the federal government creates home bias both at intraregional and interregional levels ${ }^{40}$. Thus the internal trade of every region is subject to maximum government enhancement in a federal political system that exists both in Canada and the United States. ${ }^{41}$

Substituting (6), (7) and (8) into (3), taking logs and linearizing, we obtain:

$$
\begin{aligned}
& \ln \left(\frac{m_{i j}}{m_{i i}}\right)=\ln \left(\frac{v_{j}}{v_{i}}\right)-(\sigma-1) \delta \ln \left(\frac{d_{i j}}{d_{i i}}\right)-\sigma \ln \left(\frac{p_{j}}{p_{i}}\right)- \\
& -(\sigma-1) \theta \ln \left(1+T_{i j}\right)-(\sigma-1) \beta B_{i j}-(\sigma-1) \eta A D J_{i j}+ \\
& +(\sigma-1) \lambda\left(L_{i j}-L_{i i}\right)+(\sigma-1) \gamma\left(G_{i j}-G_{i i}\right)+e_{i j},
\end{aligned}
$$

where $e_{i j}=(\sigma-1)\left(\varepsilon_{i j}-\varepsilon_{i i}\right)$. Estimating this expression for bilateral flows between regions $i$ and $j$ produces an estimate of border effects as the coefficient on the country dummy $B_{i j}$

As the specification implies, and following Anderson \& Smith (1999) as well as Helliwell (1998), we estimate this equation for imports and exports separately. This procedure doubles the number of available observations as well as allows us to disaggregate border effects into import and export components. Estimates by regions can also be obtained by estimating a particular region's trade flows only.

\footnotetext{
${ }^{40}$ Theoretically, the federal and provincial/state governments could have different propensities to induce home bias out of their spending shares. We assume these to be equal for tractability purposes.

${ }^{41}$ The impact of government on trade in context of border effects literature was to date considered only in Crozet and Trionfetti (2002); however a specification for estimation was not explicitly derived, and government was introduced into a Head/Mayer type model ad hoc. Our model derives the impact of the government directly from theory.
} 
We apply this specification to trade flows between U.S. and Canada for 19882003. Cross-sectional regressions cannot incorporate tariffs due to perfect collinearity with the border dummy and thus tariffs are included only in panel regressions.

\subsection{Data}

We follow McCallum (1995) and Helliwell $(1996,1997)$ in restricting the sample to thirty largest U.S. states, including all those which border on Canada, and ten Canadian provinces. A detailed summary of the sources and adjustments for trade data is provided below, after we first describe how all the other data were obtained.

\subsubsection{General Data}

Regional GDP data at factor cost, both in current and chained dollars, are obtained from the Bureau of Economic Analysis and CANSIM. The ratio of current and constant regional GDPs gives us our best estimate of producer price indices, which are not available by region; these indices are then adjusted with the aggregate price level for 1988 to produce comparable price series for U.S. and Canadian regions. Distances, including more accurate internal population-weighted distances as described in Helliwell and Verdier (2001), were kindly provided by the former and are the same as used in Helliwell (2003). Aggregate estimates of effective tariff rates on goods for this period have been kindly provided by Sébastien LaRochelle-Côté from his Statistics Canada publication, Tariff Reduction and Employment in Canadian Manufacturing, 1988-1994, 
June 2005. Language data is based on home language questions of the U.S. and Canadian censuses for the English, Spanish and French languages, and interpolated for intercensal periods. U.S. government expenditures by region at the federal and state level were obtained from Consolidated Federal Funds Reports (CFFR) and internal databases kindly provided by the Bureau of Economic Analysis; comparable Canadian data were obtained from CANSIM.

\subsubsection{Canadian Interprovincial Trade Data}

Data on Canadian interprovincial trade flows, first identified by McCallum as usable in a regional gravity regression, are now available for years 1988 to 2003 . The quality of data is uneven throughout this period. 1988 data are available from the original source used by McCallum - the matrix of interprovincial goods trade provided in the occasional Statistics Canada publication, Interprovincial and International Trade Flows of Goods, 1984-1988, Input-Output Division, Technical Series \#49, June 1992. 19891991 data was obtained by us through a special request from Input-Output Division. These data were characterized as older and less reliable by Statistics Canada than modern post-1997 estimates. It also cannot be updated or re-estimated due to change of classifications. Insofar as it remains the only source of data on interprovincial trade flows for these years, we must continue to use it; however, concerns about data quality within this "early" period require that we estimate the 1988-1991 years separately, and treat comparisons with the results for other periods carefully. Since the results in the next 
section show the data to be largely consistent across the whole period, we later feel justified in working with estimates for the 1988-2003 panel as a whole.

Data between 1992 and 2003 are publicly available from CANSIM (tables 3860001 and 386-0002). Between 1992 and 1996, some of the data is suppressed and was reconstructed through the use of Statistics Canada catalogue 15-546, Interprovincial and International Trade in Canada, 1992-1998, which contains matrices of total interprovincial trade flows (goods and services together). Goods were separated from services on the basis of 1997 shares of goods in total regional exports. These shares were specific both to exporting and importing provinces; this estimation method was found to be superior to other methodologies considered, such as constant average shares or timebased shares, as the goods/service ratio in trade was found to be relatively stable for specific provincial pairs. These reconstructions make 1992-1996 the "middle" data period where some concerns over data quality remain due to suppressed values and the use of SIC classification. In the "late" 1997-2003 period interprovincial trade data are complete, estimated on NAICS basis and expected to be the best currently available data on the intranational trade flows.

All the data described includes intraregional trade flows, i.e. the shipments of every region to itself that are necessary for estimating the specification.

\subsubsection{U.S.-Canada Regional Trade}

These data are constructed following the approach of McCallum and Helliwell. The interprovincial goods trade matrix from the Input-Output Division (see above) also 
contains total exports to the world by province. This is combined with the international trade flows information (merchandise trade catalogues 65-202 and 65-203 from the International Trade Division of Statistics Canada, and Strategis Trade Data Online) which contains all the province-state flows. The latter source is based on customs data, which is by province of clearance - therefore the final destination of shipments remains more or less unknown. Therefore, the IT province-state trade is adjusted to match the more reliable totals from the I-O data.

Some of the shipments data are either too low or unobservable and are not reported. These missing observations occur only for a select number of small jurisdictions: Newfoundland and Prince Edward Island on Canadian side, and North Dakota, Montana, Arizona and a few other states on the U.S. side. These empty cells are primarily a zero data problem rather than missing data; following the practice of previous research, we eliminate the seventeen (17) observations where trade flows are 0 in any year between 1988 and 2003 for all years ( 272 observations in all, or less than $2.5 \%$ of the total of 11040). We have estimated variations on this approach: replacing missing data with zeros, partial elimination of the consistently missing data only, as well as complete elimination of all Newfoundland and PEI observations. The results vary somewhat across specifications, but all of our qualitative conclusions remain valid.

\subsubsection{U.S. Trade Data}

The only U.S. source of data comparable to Canadian intranational trade is the Commodity Flow Survey (CFS) by the U.S. Census Bureau. It estimates both intrastate 
and interstate shipments of goods by surveying the total shipping activity of domestic manufacturing, mining, wholesale and selected retail establishments every five years. The use of the CFS for estimating border effects was pioneered by Hillberry (1998) and has been used in several papers since, among them Anderson and van Wincoop (2001).

There are important distinctions between merchandise trade data and the shipments data reported by the CFS. The survey excludes some commodities, a part of mining and the whole of agriculture. Secondly, shipments destined for international destinations are still recorded if they are shipped domestically prior to leaving the United States, and imported shipments are similarly tracked from the port of entry to final destination. Finally, and most importantly, the survey tracks simply freight shipments, without claiming that the goods originate at the source. Thus the same product can be shipped multiple times between extractors, manufacturers, wholesalers, distributors and retailers. This inflates the value of shipments reported by CFS significantly.

Due to these large differences between trade and shipments data, as well as time period requirements (in the relevant time period 1988-2003, only three CFS datasets are available: 1993, 1997 and 2002), CFS interstate shipments data are not used in this paper. However, the use of the internal shipments (sent by states to themselves), which are available in the CFS data, is necessary to estimate intrastate trade flows for the final specification. Because of the trade inflation problem, an adjustment is necessary to bring CFS in line with other trade data. Following Helliwell $(1997,1998)$ and AvW (2001), we adjust CFS shipments data by the ratio of total U.S. domestic merchandise trade to total domestic shipments from the CFS. Domestic merchandise trade is estimated by subtracting merchandise exports from gross output in mostly goods producing sectors 
(agriculture, mining and manufacturing). This methodology produces adjustment factors of 3025/5846 for CFS 1993, 3550/6944 for CFS 1997 and 3606/8397 for CFS 2002. Scaling down by these factors, we obtain intrastate trade estimates for thirty U.S. states for these years.

To derive these estimates for all years, we first construct a measure of gross output by state (which is not available otherwise). Nationwide ratios of gross output to GDP by sector (agriculture, mining and manufacturing) are derived for every year, and then applied to state-specific GDP by sector. Then, considering the ratio of internal shipments to gross output a stable measure (which is confirmed through the existing CFS data), we use it to estimate internal shipments for each state for all other years between 1988 and 2003.

\subsection{Estimation Results}

The specification obtained in section 3 is estimated first in a cross-sectional manner, separately for every year in order to achieve comparability with previous results. This is followed by aggregate estimation using panel data techniques. Largely due to data concerns for some of the earlier years, but also to provide more manageable results, the panel is initially subdivided into three parts: 1988-1991, 1992-1996, and 1997-2003. We report the individual cross-sectional results together with the panel results for these time periods. After presenting these estimates, we then estimate the whole 1988-2003 period as one panel. This is followed by the estimation of border effects separately by province to test the size of the border effect for different jurisdictions. Next, we estimate border 
effects for imports and exports separately to account for the fact that the border might have a different resistance to North-South flows than vice versa. Lastly, we introduce time effects into the equation and chart the evolution of border effects through time.

\subsubsection{Estimation Methods}

Gravity equation estimation techniques vary in the literature; Helliwell (1988) and others find that simple ordinary least squares (OLS) estimates produce very similar results to those obtained using more advanced econometric methods. This is also confirmed by our results. After estimating with OLS first (with robust standard errors to correct for heteroskedasticity in the data), we consider other techniques that may be more appropriate and compare the results.

We first consider the panel data fixed effects model, using the within estimator, which is consistent and unbiased. Fixed effects models generally control for heterogeneity in the panel which is due to unobservable characteristics of the individual cases that are omitted from the model and do not vary over time. Introduction of full fixed effects is equivalent to defining a dummy variable for each case, eliminating all the between-cases variation from the estimation and keeping only the within-cases variation. While the fixed effects models are widely used with panel data, its use on our regional trade data must be accompanied by some reservations. There is a great deal of withingroup variation, particularly for smaller trading units, that can only be interpreted as "noise"; also, the variation with time is not large compared to between-group variation. Lastly, the use of full fixed effects is not effective in our case, as the border effect 
dummy and several other variables of interest are time-invariant and therefore are dropped during the transformation. Due to the above considerations, we implement a reduced fixed-effects model (which specifies a fixed effect for the presence of individual regions in the trading pair) as an additional specification.

The within estimator serves as a benchmark for the Hausman test which determines the appropriateness of the random effects model, which uses the estimator that is a weighted average of within and between effects. The result of the test shows that the random effects estimators are inconsistent and therefore the random effects model is not appropriate in this case.

We next consider the technique of Feasible Generalized Least Squares (FGLS). Just as the robust OLS, it produces consistent estimates, which will, however, be more efficient under the assumption of panel heteroskedasticity and thus preferred to the robust OLS.

To address the problem of heteroskedasticity of unknown form with instrumental variables, we also use the generalized method of moments (GMM) estimator which produces efficient estimates in this context.

Generally, all three estimators (robust OLS, FGLS with and without fixed effects, and GMM) produce very similar results throughout this study; this includes signs of coefficients, their significance and even their relative magnitude. Cases that exhibit significant differences from this pattern are discussed in the estimation description below. Our overall conclusion is that the use of OLS, despite its theoretical limitations, produces a viable approximation to the results obtained from more advanced techniques, and that OLS estimates may be relied upon in most cases in the context of our model. 


\subsubsection{Static Border Effects in a Regional Model}

We present estimation results by periods, with cross-sectional results for border effects followed by period panel estimates in the same table. Table 4.1 shows the results for the years 1988-1991. Equations (i) to (iv) present the cross-sectional effects for the individual years, equation $(v)$ is a robust OLS estimation of the four-year panel, $(v i)$ is a panel estimation with FGLS, and (vii) is the instrumental variable-GMM method. Under simple cross-sectional OLS, the border effect dummy takes the value of -1.81 in 1988 . The coefficient sign is negative as expected, since the dummy takes the value of 1 for cross-border flows. The exponent of the absolute value of the coefficient is the border effect, which equals 6.1 in 1988 . This border effect exhibits little variation over the next three years, reaching a marginally smaller effect of 5.7 by 1991. All of the border dummy coefficients are significant at $1 \%$.

Other variables generally behave as expected and exhibit significant coefficients with theoretically appropriate signs. The coefficients for the relative production variable are between 0.96 and 0.91 , which is close to the theoretically expected value of 1 . The effect of relative prices is negative, varying between -2.4 and -4.6 ; both relative production and relative price are significant at $1 \%$. 
Table 4.1 Canada - U.S. Border Effects, 1988-1991

\begin{tabular}{|c|c|c|c|c|c|c|c|}
\hline & \multicolumn{9}{|c|}{ Equations } \\
\hline $\begin{array}{c}\text { Year / } \\
\text { Method }\end{array}$ & $\mathbf{1 9 8 8}$ & $\mathbf{1 9 8 9}$ & $\mathbf{1 9 9 0}$ & $\mathbf{1 9 9 1}$ & $\mathbf{O L S}$ & $\begin{array}{c}\text { FGLS } \\
\text { Het. }\end{array}$ & GMM \\
\hline & $($ i $)$ & $($ ii $)$ & $(\mathrm{iii})$ & $(\mathrm{iv})$ & $(\mathrm{v})$ & $(\mathrm{vi})$ & $(\mathrm{vii})$ \\
\hline Border & $-1.81^{*}$ & $-1.73^{*}$ & $-1.83^{*}$ & $-1.74^{*}$ & $-0.67^{*}$ & $-0.76^{*}$ & $-0.43^{*}$ \\
\hline & $(0.16)$ & $(0.14)$ & $(0.14)$ & $(0.13)$ & $(0.12)$ & $(0.04)$ & $(0.15)$ \\
\hline $\begin{array}{c}\text { Rel. } \\
\text { Production }\end{array}$ & $0.96^{*}$ & $0.94^{*}$ & $0.91^{*}$ & $0.95^{*}$ & $0.99^{*}$ & $0.97^{*}$ & $1.01^{*}$ \\
\hline & $(0.04)$ & $(0.04)$ & $(0.04)$ & $(0.04)$ & $(0.02)$ & $(0.01)$ & $(0.03)$ \\
\hline Rel. Prices & $-2.39^{*}$ & $-2.65^{*}$ & $-4.57^{*}$ & $-4.55^{*}$ & $-1.72^{*}$ & $-1.86^{*}$ & -1.32 \\
\hline & $(0.76)$ & $(0.77)$ & $(0.92)$ & $(0.61)$ & $(0.40)$ & $(0.14)$ & $(0.71)$ \\
\hline Government & $14.91^{*}$ & $13.17^{*}$ & $9.44^{*}$ & $11.07^{*}$ & $10.98^{*}$ & $10.61^{*}$ & $9.79^{*}$ \\
\hline & $(0.87)$ & $(0.88)$ & $(0.67)$ & $(0.72)$ & $(0.37)$ & $(0.14)$ & $(0.60)$ \\
\hline Not Adjacent & $-0.96^{*}$ & $-0.97^{*}$ & $-0.86^{*}$ & $-0.89^{*}$ & $-0.86^{*}$ & $-0.73^{*}$ & $-0.80^{*}$ \\
\hline & $(0.19)$ & $(0.18)$ & $(0.19)$ & $(0.18)$ & $(0.09)$ & $(0.03)$ & $(0.11)$ \\
\hline Distance & $-0.94^{*}$ & $-0.90^{*}$ & $-1.02^{*}$ & $-1.00^{*}$ & $-1.01^{*}$ & $-1.01^{*}$ & $-1.06^{*}$ \\
\hline & $(0.08)$ & $(0.08)$ & $(0.08)$ & $(0.08)$ & $(0.04)$ & $(0.01)$ & $(0.05)$ \\
\hline Tariffs & & & & & $-36.87^{*}$ & $-34.38^{*}$ & $-44.56^{*}$ \\
\hline & & & & & $(2.97)$ & $(1.01)$ & $(4.12)$ \\
\hline Constant & 0.22 & -0.04 & -0.04 & 0.15 & 0.02 & $-0.11^{*}$ & -0.06 \\
\hline & $(0.21)$ & $(0.20)$ & $(0.20)$ & $(0.21)$ & $(0.10)$ & $(0.04)$ & $(0.13)$ \\
\hline Observations & 673 & 673 & 673 & 673 & 2692 & 2692 & 2692 \\
\hline R-squared & 0.66 & 0.66 & 0.63 & 0.67 & 0.66 & & \\
\hline Border Effect & $\mathbf{6 . 1}$ & $\mathbf{5 . 6}$ & $\mathbf{6 . 2}$ & $\mathbf{5 . 7}$ & $\mathbf{2 . 0}$ & $\mathbf{2 . 1}$ & $\mathbf{1 . 5}$ \\
\hline
\end{tabular}

Robust standard errors in parentheses; * denotes significance at 1\%

17 observations with 0 observed trade have been deleted

Distance and lack of adjacency both exhibit negative coefficients close to -1 , and are also significant at $1 \%$. Of note is the strong positive impact on trade of the relative government share. Its coefficient varies between 9 and 14 and is significant at $1 \%$. Note also that the constant term is not significant in the estimates; this is consistent with the fact that the specification being estimated does not contain a constant term. It is still included to avoid bias; however its lack of significance is an encouraging sign.

Linguistic affinity $L$ is the only variable whose inclusion does not result in strong conclusions one way or the other. The initial specification of $L$, discussed in the data section, resulted in non-significant coefficients close to zero. This was thought due to the lack of interaction between the second languages (French and Spanish) in the regional 
model. With state-to-state trade excluded from estimation, Canadian provinces with French-language minorities do not interact significantly with U.S. states, whose linguistic minorities of significant size are Spanish only. The only trading pair out of 673 observations that is likely to pick up the full intended effect of the linguistic affinity variable is thus Quebec and New Brunswick. An alternative specification for $L$ was considered, with dummies equal to 1 for regions with linguistic minorities above $10 \%$, and 0 otherwise. This modification resulted in language actually having a significant negative effect for some of the years, and insignificant effect for others.

This weak result may be due the two opposite effects of language (and the social networks and customs it is meant to represent) on trade. On one hand, trade in differentiated goods is expected to be higher between similar regions; on the other hand, different languages and customs may lead to a greater degree of differentiation among the varieties of goods, which may promote trade. This model and most standard models of monopolistic competition do not allow for the second effect. We incline, however, to a simpler explanation: the nature of the predominantly English-speaking regions examined in the model prevents a meaningful evaluation of the effect of this variable. There is simply not enough variation in the sample to identify the parameter. Better results are to be expected in an OECD setting. We decide to exclude it from our final specification in order to avoid additional multicollinearity; it should be noted, however, that including language in any specification does not affect the estimates for other variables to any degree, nor their significance.

Table 4.1 also reports estimation results for 1988-1991 as OLS, FGLS with heteroskedasticity correction and GMM panels as equations (v) to (vii); this setup allows 
us to include the tariffs variable into the equation. As expected, tariffs have a strong negative impact on trade in all the specifications. The inclusion of tariffs has a large impact on the border dummies coefficient, but does not greatly affect any other variables. ${ }^{42}$ The border effect as a result of tariff introduction is reduced from the crosssectional estimates of about 6 to 2.0 in OLS, 2.1 in FGLS and 1.5 in GMM.

This result shows that explicitly specifying tariffs as an explanatory variable in the equation rather than leaving it out as an unexplained component of border effects reduces the estimated border effect in 1988 roughly from 6 to 2 . It is an even more remarkable result when one considers that the average tariff levels in this year was at only about $2.5 \%$ for U.S. and $4.5 \%$ for Canada, and rapidly declined from there. We deal with the effect of tariff more extensively in the time series estimation section, but this basic result remains unchanged. Although some studies, like Helliwell (1988), have inferred that the declining tariffs may be responsible for the decrease in border effects, and others such as Fairfield (2001) have shown that with certain elasticity assumptions tariffs may be responsible for a large portion of border effects, we present for the first time an empirical result which states that two-thirds of the border effect is explained by a rather small tariff level.

Table 4.2 presents the results from the $1992-1996$ panel. These are very similar to the earlier period. The year-to-year border effect has declined very slightly, and is between 5 and 5.8, while all the other variables retain their significance and size. However, panel estimates in equations (vi) to (viii) show an increase in the border effect to $3.5-3.8$, which is almost double that of the 1988-1991 panel levels.

\footnotetext{
${ }^{42}$ In fact, the coefficient on relative production in those equations is for all intents and purposes equivalent to its theoretically expected value of 1 .
} 
Table 4.2. Canada - U.S. Border Effects, 1992-1996

\begin{tabular}{|c|c|c|c|c|c|c|c|c|}
\hline & \multicolumn{9}{|c|}{ Equations } \\
\hline Year / Method & $\mathbf{1 9 9 2}$ & $\mathbf{1 9 9 3}$ & $\mathbf{1 9 9 4}$ & $\mathbf{1 9 9 5}$ & $\mathbf{1 9 9 6}$ & OLS & $\begin{array}{c}\text { FGLS } \\
\text { Het. }\end{array}$ & GMM \\
\hline & $(\mathrm{i})$ & $(\mathrm{ii})$ & $(\mathrm{iii})$ & $(\mathrm{iv})$ & $(\mathrm{v})$ & $(\mathrm{vi})$ & $(\mathrm{vii})$ & $(\mathrm{viii})$ \\
\hline & $-1.71^{*}$ & $-1.60^{*}$ & $-1.64^{*}$ & $-1.76^{*}$ & $-1.69^{*}$ & $-1.25^{*}$ & $-1.34^{*}$ & $-1.27^{*}$ \\
\hline & $(0.13)$ & $(0.14)$ & $(0.13)$ & $(0.14)$ & $(0.15)$ & $(0.07)$ & $(0.03)$ & $(0.09)$ \\
\hline Bel. Production & $0.93^{*}$ & $0.91^{*}$ & $0.88^{*}$ & $0.88^{*}$ & $0.86^{*}$ & $0.90^{*}$ & $0.91^{*}$ & $0.91^{*}$ \\
\hline & $(0.03)$ & $(0.03)$ & $(0.03)$ & $(0.03)$ & $(0.03)$ & $(0.01)$ & $(0.00)$ & $(0.02)$ \\
\hline Rel. Prices & $-4.02^{*}$ & $-4.20^{*}$ & $-4.78^{*}$ & $-4.95^{*}$ & $-5.90^{*}$ & $-3.90^{*}$ & $-4.06^{*}$ & $-4.08^{*}$ \\
\hline & $(0.51)$ & $(0.50)$ & $(0.49)$ & $(0.50)$ & $(0.60)$ & $(0.25)$ & $(0.10)$ & $(0.33)$ \\
\hline Government & $10.08^{*}$ & $8.08^{*}$ & $6.84^{*}$ & $8.36^{*}$ & $7.35^{*}$ & $7.77^{*}$ & $7.56^{*}$ & $7.92^{*}$ \\
\hline & $(0.56)$ & $(0.47)$ & $(0.45)$ & $(0.46)$ & $(0.47)$ & $(0.22)$ & $(0.09)$ & $(0.28)$ \\
\hline Not Adjacent & $-0.84^{*}$ & $-0.76^{*}$ & $-0.66^{*}$ & $-0.53^{*}$ & $-0.66^{*}$ & $-0.68^{*}$ & $-0.52^{*}$ & $-0.67^{*}$ \\
\hline & $(0.18)$ & $(0.18)$ & $(0.17)$ & $(0.18)$ & $(0.18)$ & $(0.08)$ & $(0.03)$ & $(0.10)$ \\
\hline Distance & $-0.99^{*}$ & $-1.03^{*}$ & $-1.08^{*}$ & $-1.16^{*}$ & $-1.08^{*}$ & $-1.08^{*}$ & $-1.10^{*}$ & $-1.08^{*}$ \\
\hline & $(0.07)$ & $(0.08)$ & $(0.07)$ & $(0.07)$ & $(0.08)$ & $(0.03)$ & $(0.01)$ & $(0.04)$ \\
\hline Tariffs & & & & & & $-41.00^{*}$ & $-39.60^{*}$ & $-39.75^{*}$ \\
\hline & & & & & & $(4.11)$ & $(1.45)$ & $(4.75)$ \\
\hline Constant & 0.29 & 0.20 & 0.22 & $0.71^{*}$ & 0.39 & $0.32^{*}$ & $0.28^{*}$ & $0.35^{*}$ \\
\hline Observations & $(0.20)$ & $(0.20)$ & $(0.19)$ & $(0.21)$ & $(0.20)$ & $(0.09)$ & $(0.03)$ & $(0.12)$ \\
\hline R-squared & 673 & 673 & 673 & 673 & 673 & 3365 & 3365 & 3365 \\
\hline Border Effect & $\mathbf{5 . 5}$ & 0.67 & 0.67 & 0.67 & 0.65 & 0.67 & & \\
\hline & & $\mathbf{5 . 0}$ & $\mathbf{5 . 2}$ & $\mathbf{5 . 8}$ & $\mathbf{5 . 4}$ & $\mathbf{3 . 5}$ & $\mathbf{3 . 8}$ & $\mathbf{3 . 6}$ \\
\hline
\end{tabular}

Robust standard errors in parentheses; * denotes significance at $1 \%$

17 observations with 0 observed trade have been deleted

This result is consistent with the overall evidence, but requires explanation. If the decline in tariffs was the only new factor in 1992-1996, then the cross-sectional border effects in equations (i) to (v) should have declined significantly, and the panel effects correcting for tariffs should have remained constant. But the former remained stable, and the latter increased. This means that both of these border effects are pushed upwards by some unobserved factor not included in the model. The most natural explanation would be that as the tariffs have declined and their contribution to the cross-sectional border effect decreased, other factors such as non-tariff barriers (NTB) have been increasing in place of tariffs. Since usable time-series data on NTBs are not available, this must remain 
only a conjecture at the moment; yet it may be another piece of evidence, similar to McCallum's original demonstration, that casts doubt upon the picture of smooth transition from a national to a North American economy for the U.S., and especially for Canada.

Table 4.3 Canada - U.S. Border Effects, 1997-2003, cross-sectional

\begin{tabular}{|c|c|c|c|c|c|c|c|}
\hline & \multicolumn{7}{|c|}{ Equations } \\
\hline Year & $\mathbf{1 9 9 7}$ & $\mathbf{1 9 9 8}$ & $\mathbf{1 9 9 9}$ & $\mathbf{2 0 0 0}$ & $\mathbf{2 0 0 1}$ & $\mathbf{2 0 0 2}$ & $\mathbf{2 0 0 3}$ \\
\hline & $(\mathrm{i})$ & $(\mathrm{ii})$ & $(\mathrm{iii})$ & $(\mathrm{iv})$ & $(\mathrm{v})$ & $(\mathrm{vi})$ & $(\mathrm{vii})$ \\
\hline Border & $-1.63^{*}$ & $-1.62^{*}$ & $-1.62^{*}$ & $-1.55^{*}$ & $-1.64^{*}$ & $-1.61^{*}$ & $-1.60^{*}$ \\
\hline & $(0.14)$ & $(0.13)$ & $(0.13)$ & $(0.15)$ & $(0.14)$ & $(0.13)$ & $(0.15)$ \\
\hline Rel. Production & $0.95^{*}$ & $0.93^{*}$ & $0.98^{*}$ & $0.95^{*}$ & $0.94^{*}$ & $0.92^{*}$ & $0.83^{*}$ \\
\hline & $(0.03)$ & $(0.03)$ & $(0.03)$ & $(0.04)$ & $(0.04)$ & $(0.03)$ & $(0.04)$ \\
\hline Rel. Prices & $-6.93^{*}$ & $-5.62^{*}$ & $-7.69^{*}$ & $-13.44^{*}$ & $-11.55^{*}$ & $-10.33^{*}$ & $-9.68^{*}$ \\
\hline & $(0.57)$ & $(0.44)$ & $(0.53)$ & $(1.05)$ & $(0.99)$ & $(0.68)$ & $(0.94)$ \\
\hline Government & $8.03^{*}$ & $7.17^{*}$ & $7.97^{*}$ & $8.27^{*}$ & $6.71^{*}$ & $7.47^{*}$ & $8.32^{*}$ \\
\hline & $(0.48)$ & $(0.44)$ & $(0.45)$ & $(0.59)$ & $(0.53)$ & $(0.49)$ & $(0.69)$ \\
\hline Not Adjacent & $-0.78^{*}$ & $-0.75^{*}$ & $-0.77^{*}$ & $-1.00^{*}$ & $-1.05^{*}$ & $-1.04^{*}$ & $-1.28^{*}$ \\
\hline & $(0.18)$ & $(0.18)$ & $(0.18)$ & $(0.18)$ & $(0.18)$ & $(0.18)$ & $(0.20)$ \\
\hline Distance & $-1.02^{*}$ & $-1.00^{*}$ & $-0.99^{*}$ & $-0.86^{*}$ & $-0.83^{*}$ & $-0.85^{*}$ & $-0.70^{*}$ \\
\hline & $(0.08)$ & $(0.08)$ & $(0.08)$ & $(0.08)$ & $(0.08)$ & $(0.07)$ & $(0.08)$ \\
\hline Constant & 0.43 & 0.39 & $0.57^{*}$ & 0.45 & 0.40 & $0.53^{*}$ & 0.26 \\
\hline & $(0.21)$ & $(0.20)$ & $(0.21)$ & $(0.22)$ & $(0.22)$ & $(0.20)$ & $(0.22)$ \\
\hline Observations & 673 & 673 & 673 & 673 & 673 & 673 & 673 \\
\hline R-squared & 0.66 & 0.66 & 0.67 & 0.63 & 0.61 & 0.64 & 0.53 \\
\hline Border Effect & $\mathbf{5 . 1}$ & $\mathbf{5 . 1}$ & $\mathbf{5 . 1}$ & $\mathbf{4 . 7}$ & $\mathbf{5 . 2}$ & $\mathbf{5 . 0}$ & $\mathbf{5 . 0}$ \\
\hline
\end{tabular}

Robust standard errors in parentheses; * denotes significance at $1 \%$ 17 observations with 0 observed trade have been deleted

Cross-sectional border effects remained very stable in the last period of the sample, 1997-2003 (Table 4.3), on average equal to 5. Looking back at the whole period, we can conclude that cross-sectional border effects underwent a small and slow decline from 6.1 in 1988 to 5.0 in 2003. But is does not mean that border effects remained unaffected during this period; on the contrary, we are aware of at least two competing 
influences: declining tariffs ${ }^{43}$ had a downward impact, and unexplained factors had the opposite effect. The overall picture is not one of sharp decline as claimed in the earlier literature, but of a prolonged, gradual downward slide which occasionally reverses itself, as in 1995 and 2001. There are few changes in the behaviour of the other variables; we may note the decline in the distance coefficient, implying cheaper transportation in the last year of the sample. We are hesitant to make much of it, especially in light of the recent meta-analysis in Head \& Disdier (2006) showing persistently high, stable transportation elasticities since 1950; we only note with some satisfaction that their average distance effect estimate of -0.9 is exactly the same average effect that we obtain. There are some relatively large deviations in coefficients in 2003 , the last year of the sample; the fact that the interprovincial trade data for 2003 is preliminary and recent may account for a large part of this effect.

\footnotetext{
${ }^{43}$ These have generally reached 0 by 1998 , with some exceptions due to NAFTA rules-of-origin regulations. Some transaction costs involved in avoiding very small tariffs exceed
} 
Table 4.4 Canada - U.S. Border Effects, 1997-2003, panel

\begin{tabular}{|c|c|c|c|}
\hline & \multicolumn{3}{|c|}{ Equations } \\
\hline Method & OLS & FGLS Het. & GMM \\
\hline & $(i)$ & $(\mathrm{ii})$ & $(\mathrm{iii})$ \\
\hline Border & $-1.57^{*}$ & $-1.55^{*}$ & $-1.59^{*}$ \\
\hline Rel. Production & $(0.05)$ & $(0.03)$ & $(0.07)$ \\
\hline & $0.90^{*}$ & $0.89^{*}$ & $0.95^{*}$ \\
\hline Rel. Prices & $(0.01)$ & $(0.01)$ & $(0.02)$ \\
\hline & $-7.67^{*}$ & $-7.63^{*}$ & $-9.13^{*}$ \\
\hline Government & $(0.26)$ & $(0.13)$ & $(0.39)$ \\
\hline & $7.45^{*}$ & $6.98^{*}$ & $8.00^{*}$ \\
\hline Not Adjacent & $(0.20)$ & $(0.10)$ & $(0.27)$ \\
\hline & $-0.98^{*}$ & $-0.84^{*}$ & $-0.93^{*}$ \\
\hline Distance & $(0.07)$ & $(0.03)$ & $(0.09)$ \\
\hline & $-0.88^{*}$ & $-0.87^{*}$ & $-0.90^{*}$ \\
\hline Tariffs & $(0.03)$ & $(0.01)$ & $(0.04)$ \\
\hline Constant & $-109.03^{*}$ & $-95.41^{*}$ & $-100.86^{*}$ \\
\hline & $(22.51)$ & $(8.92)$ & $(22.39)$ \\
\hline Observations & $0.37^{*}$ & $0.16^{*}$ & $0.51^{*}$ \\
\hline R-squared & $(0.08)$ & $(0.04)$ & $(0.11)$ \\
\hline Border Effect & 4711 & 4711 & 4711 \\
\hline & 0.61 & & 4.9 \\
\hline & 4.8 & 4.7 & \\
\hline
\end{tabular}

Robust standard errors in parentheses; * denotes significance at 1\% 17 observations with 0 observed trade have been deleted

The panel effects for $1997-2003$ in Table 4.4 are very similar to Table 4.3 estimates; this is consistent with tariffs declining to 0 early on in this period, and the stable behaviour of the cross-sectional estimates. Table 4.4 shows that the panel border effect estimated for these years is close to 5 . All the estimation methods give similar results, all the variables take expected signs and all are significant at $1 \%$ level of confidence. $^{44}$

The evidence from three separate panels allows us to largely discard our previous concerns about data compatibility. The estimates for all variables are generally in line and

\footnotetext{
${ }^{44}$ The high coefficient on the tariff variable is due to the low initial size of the tariffs, and their decline to 0 shortly thereafter; in effect, it represents the high marginal impact of a near-zero tariff.
} 
there are no sharp jumps in the cross-sectional estimates. This allows us to pool all the data for 1988-2003 and estimate it as a sixteen-year panel (Table 4.5).

Table 4.5 Canada - U.S. border effect panels, 1988-2003

\begin{tabular}{|c|c|c|c|}
\hline & \multicolumn{3}{|c|}{ Equations } \\
\hline Method & OLS & FGLS Het. & GMM \\
\hline & $(i)$ & $(i i)$ & $($ iii $)$ \\
\hline Border & $-1.26^{*}$ & $-1.29^{*}$ & $-1.26^{*}$ \\
\hline Rel. Production & $(0.04)$ & $(0.02)$ & $(0.05)$ \\
\hline & $0.88^{*}$ & $0.87^{*}$ & $0.91^{*}$ \\
\hline Rel. Prices & $(0.01)$ & $(0.00)$ & $(0.01)$ \\
\hline & $-5.14^{*}$ & $-5.21^{*}$ & $-5.93^{*}$ \\
\hline Government & $(0.16)$ & $(0.09)$ & $(0.23)$ \\
\hline & $7.64^{*}$ & $6.99^{*}$ & $7.94^{*}$ \\
\hline Not Adjacent & $(0.14)$ & $(0.08)$ & $(0.20)$ \\
\hline & $-0.85^{*}$ & $-0.64^{*}$ & $-0.81^{*}$ \\
\hline Distance & $(0.05)$ & $(0.02)$ & $(0.06)$ \\
\hline & $-0.98^{*}$ & $-1.00^{*}$ & $-1.01^{*}$ \\
\hline Tariffs & $(0.02)$ & $(0.01)$ & $(0.03)$ \\
\hline Constant & $-36.98^{*}$ & $-34.19^{*}$ & $-37.51^{*}$ \\
\hline & $(0.99)$ & $(0.51)$ & $(1.28)$ \\
\hline Observations & $0.19^{*}$ & -0.00 & $0.27^{*}$ \\
\hline R-squared & $(0.05)$ & $(0.03)$ & $(0.07)$ \\
\hline Border Effect & 10768 & 10768 & 10768 \\
\hline & 0.63 & & 3.5 \\
\hline
\end{tabular}

Robust standard errors in parentheses; * denotes significance at $1 \%$ 17 observations with 0 observed trade have been deleted

Table 4.5 presents the results of this estimation. The border coefficient is estimated at -1.3 with all three techniques, and the implied Canada-U.S. border effect is 3.5-3.6 for these sixteen years as a whole. Predictably, all other coefficients are significant and their values close to those already discussed.

It is helpful to summarize the results described so far in this subsection graphically. Figure 4.1 shows, first, the slow decline of the cross-sectional border effect estimates from 6 to 5, the three separate FGLS and GMM panels, both showing the increase in border effects estimates that take tariffs into account, and the overall average 
border effect of 3.6 (exponent of the absolute value of -1.29 , the FGLS coefficient) for the 1988-2003 period. By 1997, with the effect of tariffs gone, the yearly and the panel estimates converge at 5 , but the tariff decrease only accounts for the decline of yearly effects from 6 to 5 , while the rise in the unexplained factors (presumably NTB) is responsible for the increase in panel estimates from 2 to 5 .

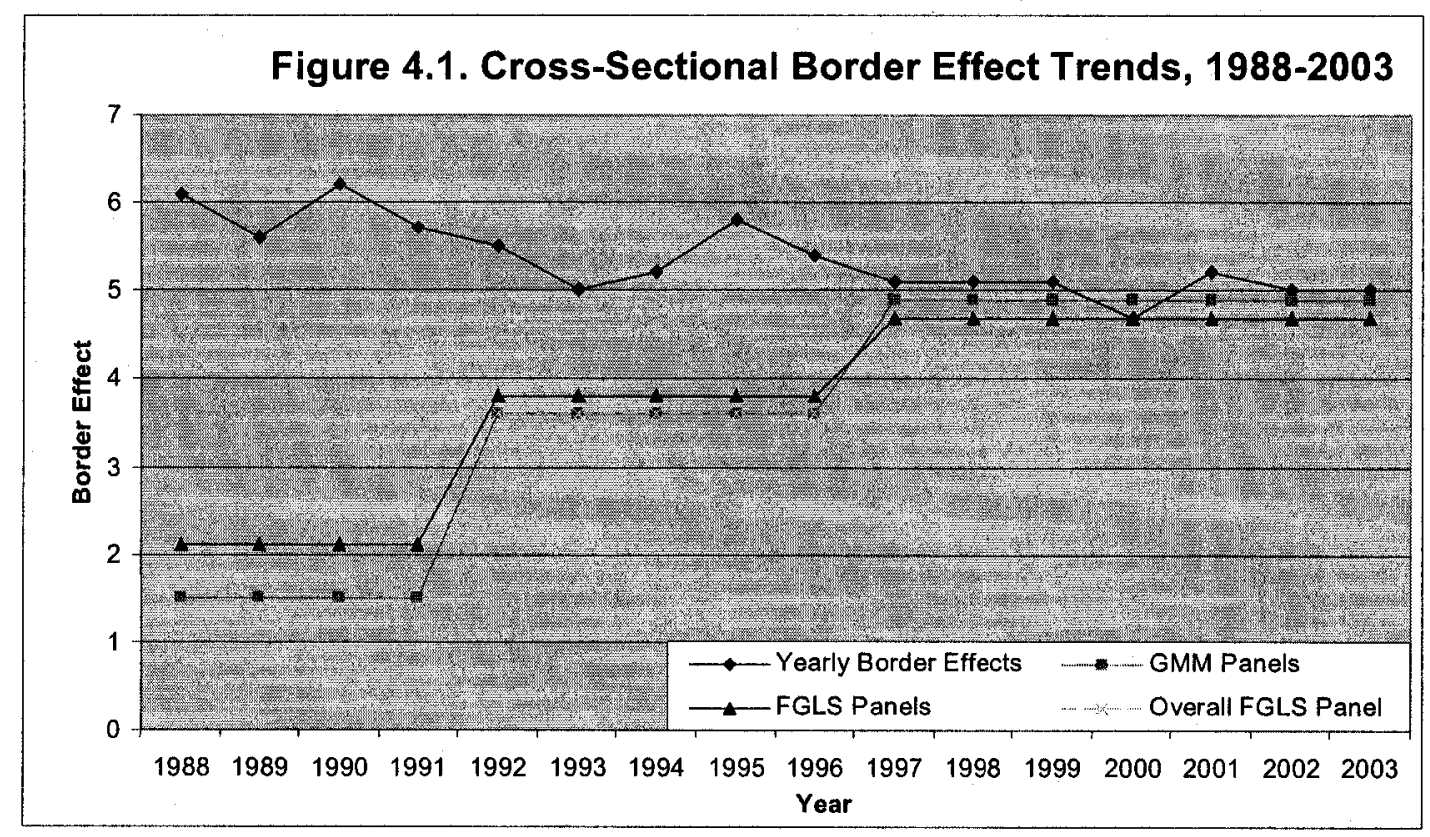

These estimates do not take the influence of time into account, and are primarily interesting for comparability with previously reported cross-sectional border effects estimated on a year-to-year basis. The results of direct influence of time on trade and border effects are reported in the next subsection. 
While the gradual elimination of merchandise trade tariffs following the CanadaU.S. FTA predictably led to the convergence of the yearly and panel estimates towards the end of the period at values around 5, it was remarked in the previous subsection that the panel estimates accounted for the greater portion of this convergence. Thus the existing tariffs, small though they were, used to account for a major portion of the border effect. Now their share of the border effect has been replaced by nearly as powerful traderestricting effects that are not explained by the model. Possible explanations include nontariff barriers and/or unaccounted-for changes in consumer preferences; these are of interest for further research.

In this subsection we wish to focus on the time dimension of the model. We are in possession of an unprecedented sixteen years of cross-sectional time series for CanadaU.S. trade and its time dynamics are crucial in helping us answer our research question. Once again, we will use OLS, FGLS and GMM, and also a combination of time-fixed and interaction time effects.

To begin with, we answer a smaller but revealing question: what exactly is the impact of tariffs on the size of border effect in a time-series context? We address this question by allowing the border dummy to vary with time (interaction time effects), but do not introduce fixed time effects in order to obtain results comparable to the earlier literature. Then we estimate the 1988-2003 panel in FGLS (our preferred estimation method) with tariffs in the equation, and without. Figure 4.2 presents the results. 
The estimated border effects with and without tariffs are the same at the end of this time period, as expected, but at the beginning there is a large gap between those estimates that control for tariffs and those that do not. Tariff inclusion decreases the border effect from about 12 in 1988 to roughly 4 . That is the same factor of two-thirds as was shown earlier.

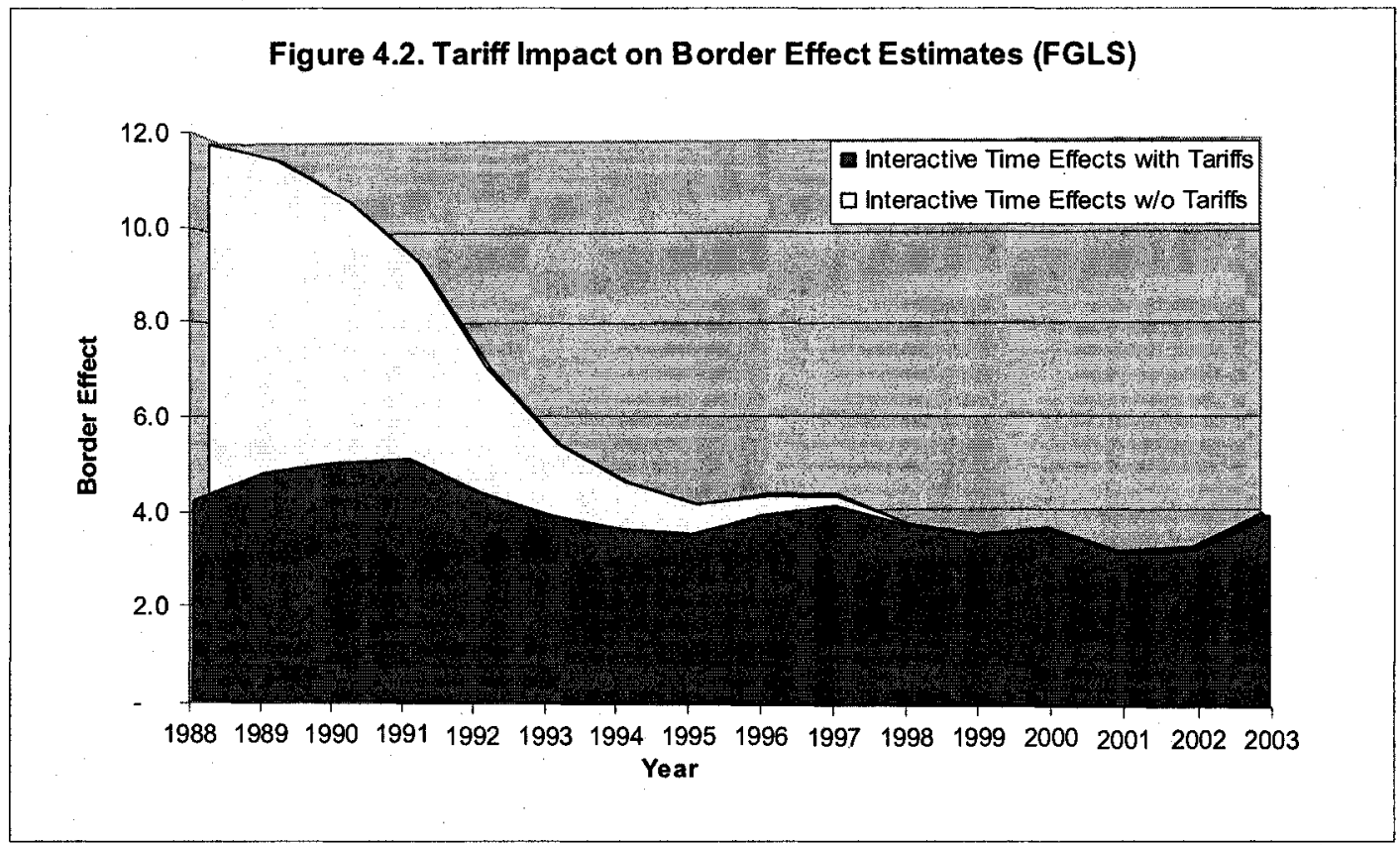

We are now in a better position to decompose the effect of changes introduced by this study compared to the earlier studies of McCallum (1995), Helliwell (1997) and Helliwell (1998). All three obtained very high border effects in 1988 (between 20 and 22 ), and the last two found sharply declining border effects after 1988 . We explain the discrepancy between our results and theirs in two stages. First, the specification estimated here relies on a theoretical derivation of a regional trade model and is producing results that have direct theoretical interpretation, unlike the empirical versions of the gravity 
equation. ${ }^{45}$ This discrepancy accounts for the difference between our border effect of 12 for 1988 and the early literature's approximate consensus at 20 . Secondly, tariffs were not explicitly a part of the gravity equation in the earlier literature. Tariffs can only be included in panel data estimation, and this fact alone limits the scope and usefulness of single-year cross-sectional estimates obtained by previous studies. The difference that tariff inclusion makes, as shown by Figure 4.2, would account for the second part of the aforementioned discrepancy, reducing the border effect estimate from 12 to 4 .

However, this result is derived only for illustration purposes and is not our preferred answer to the question "what was the true border effect in 1988?" The use of interaction time effects allows the border effect to vary from year to year as a result of various factors not captured by the model - political and economic climate, random events etc. These same effects, however, can have a direct influence on the dependent variable of our specification - the volume of trade. To take these into account, we estimate the panel with fixed time effects only, interaction time effects only, and then both together.

The results of this estimation are presented in Table 4.6. Equation (i) is our baseline FGLS model seen earlier in Table 4.5 and Figure 4.1 , without time effects. Equation (ii) introduces fixed time effects for each year (save one). These time dummies (coefficients not reported to save space) have, after the first few years, a strong positive effect on trade. This means trade was increasing with time independently of all the explanatory variables, either as a result of shocks or through a link with variables not controlled for by the specification. Once the fixed time effects are controlled for, the

\footnotetext{
${ }^{45}$ This includes the fact that our regional model has more explanatory variables as a result of theoretical derivation, such as prices and government.
} 
average border effect rises from 3.6 to 4.6 ; the only other change is the halving of the tariff coefficient from -34 to $-16^{46}$

Table 4.6 Border Effects in Time-Series Context, FGLS, 1988-2003

\begin{tabular}{|c|c|c|c|c|c|c|c|c|}
\hline & (i) & & (ii) & & (iii) & & (iv) & \\
\hline & Baseline & $\begin{array}{c}\text { Border } \\
\text { Effect }\end{array}$ & $\begin{array}{c}\text { Fixed } \\
\text { Time } \\
\text { Effects }\end{array}$ & $\begin{array}{c}\text { Border } \\
\text { Effect }\end{array}$ & $\begin{array}{c}\text { Interaction } \\
\text { Time } \\
\text { Effects }\end{array}$ & $\begin{array}{c}\text { Border } \\
\text { Effect }\end{array}$ & $\begin{array}{c}\text { Fixed \& } \\
\text { Interaction } \\
\text { Time } \\
\text { Effects } \\
\end{array}$ & $\begin{array}{l}\text { Border } \\
\text { Effect }\end{array}$ \\
\hline \multirow[t]{2}{*}{$\mathrm{B}$} & $-1.29^{*}$ & 3.6 & $-1.52^{*}$ & 4.6 & & & & \\
\hline & $(0.02)$ & & $(0.02)$ & & & & & \\
\hline B1988 & & & & & -1.44 & 4.2 & -0.78 & 2.2 \\
\hline B1989 & & & & & -1.56 & 4.8 & -0.88 & 2.4 \\
\hline B1990 & & & & & -1.61 & 5.0 & -1.08 & 2.9 \\
\hline B1991 & & & & & -1.62 & 5.1 & -1.14 & 3.1 \\
\hline B1992 & & & & & -1.48 & 4.4 & -1.25 & 3.5 \\
\hline B1993 & & & & & -1.36 & 3.9 & -1.30 & 3.7 \\
\hline B1994 & & & & & -1.28 & 3.6 & -1.44 & 4.2 \\
\hline B1995 & & & & & -1.26 & 3.5 & -1.47 & 4.3 \\
\hline B1996 & & & & & -1.37 & 3.9 & -1.55 & 4.7 \\
\hline B1997 & & & & & -1.41 & 4.1 & -1.54 & 4.7 \\
\hline B1998 & & & & & -1.30 & 3.7 & -1.62 & 5.1 \\
\hline B1999 & & & & & -1.26 & 3.5 & -1.63 & 5.1 \\
\hline $\mathrm{B} 2000$ & & & & & -1.29 & 3.6 & -1.59 & 4.9 \\
\hline $\mathrm{B} 2001$ & & & & & -1.13 & 3.1 & -1.76 & 5.8 \\
\hline $\mathrm{B} 2002$ & & & & & -1.15 & 3.2 & -1.75 & 5.8 \\
\hline B2003 & & & & & -1.37 & 3.9 & -1.71 & 5.5 \\
\hline \multirow[t]{2}{*}{$\begin{array}{c}\text { Rel. } \\
\text { Production }\end{array}$} & $0.87^{*}$ & & $0.87^{*}$ & & $0.87^{*}$ & & $0.88^{*}$ & \\
\hline & $(0.00)$ & & $(0.00)$ & & $(0.00)$ & & $(0.00)$ & \\
\hline \multirow[t]{2}{*}{ Rel. Prices } & $-5.21 *$ & & $-5.24^{*}$ & & $-5.21 *$ & & $-5.15^{*}$ & \\
\hline & $(0.09)$ & & $(0.09)$ & & $(0.10)$ & & $(0.10)$ & \\
\hline \multirow[t]{2}{*}{ Government } & $6.99^{*}$ & & $7.45^{*}$ & & $7.17^{*}$ & & $7.51^{*}$ & \\
\hline & $(0.08)$ & & $(0.08)$ & & $(0.08)$ & & $(0.08)$ & \\
\hline \multirow[t]{2}{*}{ Not Adjacent } & $-0.64 *$ & & $-0.70^{*}$ & & $-0.65^{*}$ & & $-0.69 *$ & \\
\hline & $(0.02)$ & & $(0.02)$ & & $(0.02)$ & & $(0.02)$ & \\
\hline \multirow[t]{2}{*}{ Distance } & $-1.00^{*}$ & & $-0.97^{*}$ & & $-0.99^{*}$ & & $-0.98^{*}$ & \\
\hline & $(0.01)$ & & $(0.01)$ & & $(0.01)$ & & $(0.01)$ & \\
\hline \multirow[t]{2}{*}{ Tariffs } & $-34.19^{*}$ & & $-15.70^{*}$ & & $-27.39^{*}$ & & $-28.20^{*}$ & \\
\hline & $(0.51)$ & & $(0.91)$ & & $(1.45)$ & & $(1.45)$ & \\
\hline \multirow[t]{2}{*}{ Constant } & -0.00 & & $-0.37^{*}$ & & 0.02 & & $-0.58^{*}$ & \\
\hline & $(0.03)$ & & $(0.04)$ & & $(0.03)$ & & $(0.05)$ & \\
\hline Observations & 10768 & & 10768 & & 10768 & & 10768 & \\
\hline
\end{tabular}

Robust standard errors in parentheses; * denotes significance at $1 \%$ 17 observations with 0 observed trade have been deleted

\footnotetext{
${ }^{46}$ This is not surprising - because tariffs were decreasing linearly with time, it would be natural for them to account for a portion of the time effect prior to its explicit introduction.
} 
Equation (iii) introduces interaction time effects into the baseline model; the resulting border effects are those shown in Figure 4.2. That equation results in a largely stable border effect through time, but with ups and downs that mirror the business cycle: spikes can be clearly seen in 1991, 1997 and 2002-2003. This demonstrates that there are fixed time effects in the data that need to be accounted for; thus we add fixed time effects to the interaction effects to obtain equation (iv).

Equation (iv) produces our final preferred estimates for 1988-2003 border dummies and all other coefficients. It reports a consistent increase in the border effect between Canada and U.S. from a 2.2 level in 1988 (exponent of 0.78 ) to 5.5 in 2003 (exponent of 1.71). A significant jump occurs in 2001 (from 4.9 to 5.8), and a slight drop in 2003 (from 5.8 to 5.5 ) - except for those, it is a smooth increasing trend. This contrasts both with the earlier conclusions of the literature about declining border effects, and with the stable pattern estimated by equation (iii). Border effects from all four equations of Table 4.6 are presented in Figure 4.3. Other coefficients are similar to those discussed in the previous subsection; non-adjacency has a somewhat smaller role in this specification, but is still negative and significant. 


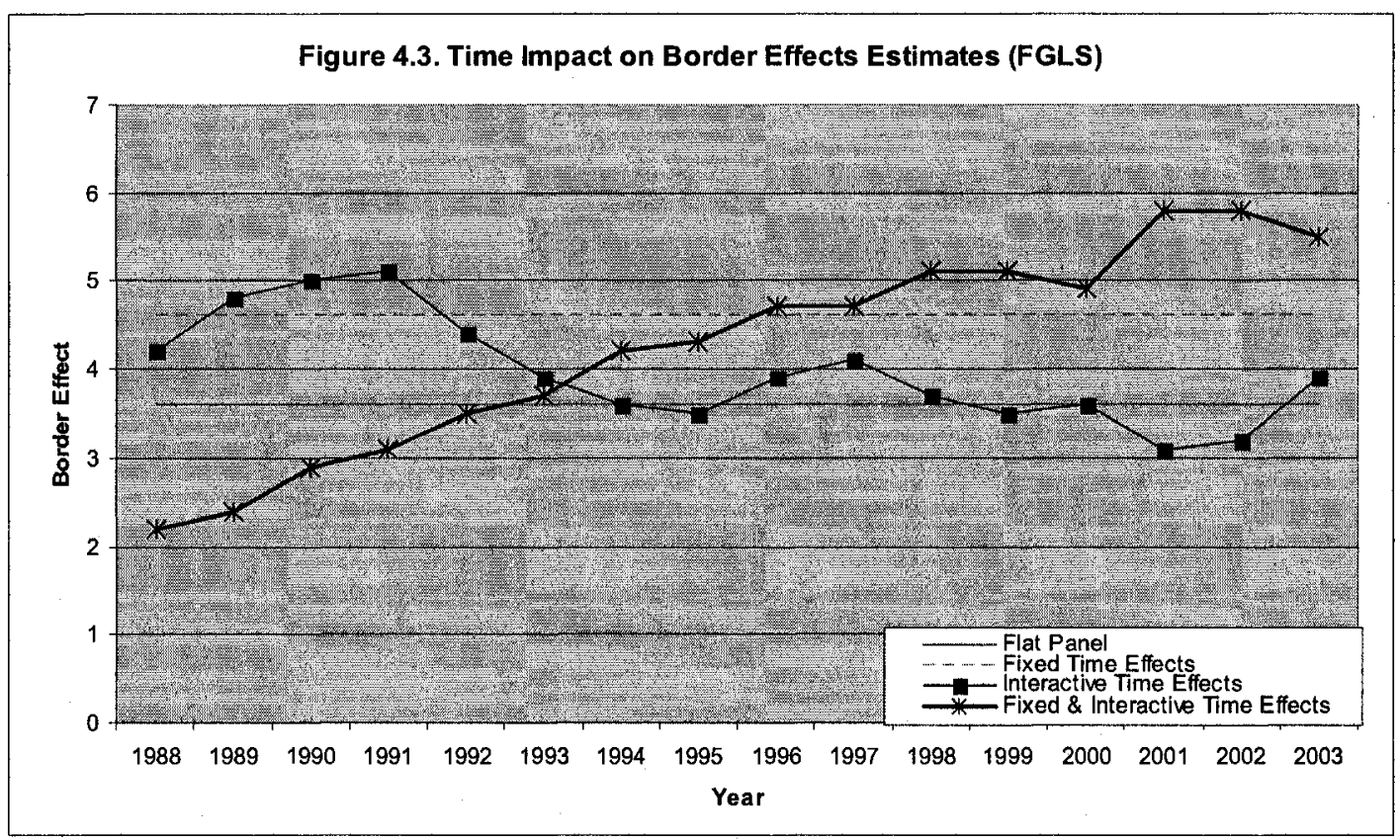

Having decomposed above the transition from the McCallum effect of 22 to the equation (iii) effect of 4 in 1988, we now must explain this last step between equation (iii) and equation (iv). The only difference between those is in the inclusion of fixed time effects in equation (iv). Because the trade data contains a time-dependent pattern (fixed time effects are, once again, positive and significant after the first few years), accounting for fixed time effects leaves less trade to be explained by the rest of the model. That in turn revises the finding of stable border effect to a finding of an increasing effect. In other words, trade has risen faster than predicted by the gravity equation during this period (which is consistent with the picture of relative growth in world trade since 1945), but not because the border effect between Canada and U.S. decreased; it is shown that this effect has actually increased throughout.

Lastly, we also consider a model with regional fixed effects. As the full fixedeffects model would eliminate time-invariant variables like distance, adjacency and the border dummy itself, a reduced model is specified. The presence of a particular region in 
the trading pair sets the value of its dummy variable to 1 . We introduce fixed effects into the FGLS estimation as conducted in Table 4.6, and report the results in Table 4.7.

Overall, these results exhibit similar trends and levels to previous estimates. The coefficient on relative production is markedly lower than the theoretical value of one; the role of adjacency is greater, while those of distance and government are smaller. The time path of the border effect estimates is somewhat smoother, but still trending in the same direction - from 2.4 in 1988 to 4.9 in 2003. 
Table 4.7 Regional and Time Fixed Effects Panel, FGLS, 1988-2003

\begin{tabular}{|c|c|c|c|c|c|c|c|c|}
\hline & (1) & & (2) & & (3) & & (4) & \\
\hline & Baseline & $\begin{array}{c}\text { Border } \\
\text { Effect }\end{array}$ & $\begin{array}{c}\text { Fixed } \\
\text { Time } \\
\text { Effects }\end{array}$ & $\begin{array}{c}\text { Border } \\
\text { Effect }\end{array}$ & $\begin{array}{c}\text { Interactive } \\
\text { Time } \\
\text { Effects }\end{array}$ & $\begin{array}{l}\text { Border } \\
\text { Effect }\end{array}$ & $\begin{array}{c}\text { Fixed \& } \\
\text { Interactive } \\
\text { Time } \\
\text { Effects }\end{array}$ & $\begin{array}{c}\text { Border } \\
\text { Effect }\end{array}$ \\
\hline \multirow[t]{2}{*}{$\mathrm{B}$} & $-1.23^{*}$ & 3.4 & $-1.43^{*}$ & 4.2 & & & & \\
\hline & $(0.04)$ & & $(0.04)$ & & & & & \\
\hline B1988 & & & & & -1.34 & 3.8 & -0.89 & 2.4 \\
\hline B1989 & & & & & -1.42 & 4.1 & -1.00 & 2.7 \\
\hline B1990 & & & & & -1.55 & 4.7 & -1.25 & 3.5 \\
\hline B1991 & & & & & -1.56 & 4.8 & -1.32 & 3.7 \\
\hline B1992 & & & & & -1.44 & 4.2 & -1.32 & 3.7 \\
\hline B1993 & & & & & -1.37 & 3.9 & -1.34 & 3.8 \\
\hline B1994 & & & & & -1.28 & 3.6 & -1.37 & 3.9 \\
\hline B1995 & & & & & -1.26 & 3.5 & -1.37 & 3.9 \\
\hline B1996 & & & & & -1.31 & 3.7 & -1.41 & 4.1 \\
\hline B1997 & & & & & -1.30 & 3.7 & -1.40 & 4.1 \\
\hline B1998 & & & & & -1.21 & 3.4 & -1.39 & 4.0 \\
\hline B1999 & & & & & -1.19 & 3.3 & -1.38 & 4.0 \\
\hline B2000 & & & & & -1.19 & 3.3 & -1.39 & 4.0 \\
\hline B2001 & & & & & -1.13 & 3.1 & -1.56 & 4.8 \\
\hline B2002 & & & & & -1.15 & 3.2 & -1.55 & 4.7 \\
\hline B2003 & & & & & -1.26 & 3.5 & -1.58 & 4.9 \\
\hline \multirow[t]{2}{*}{$\begin{array}{c}\text { Rel. } \\
\text { Production }\end{array}$} & $0.67^{*}$ & & $0.69^{*}$ & & $0.67^{*}$ & & $0.70^{*}$ & \\
\hline & $(0.01)$ & & $(0.01)$ & & $(0.01)$ & & $(0.01)$ & \\
\hline \multirow[t]{2}{*}{ Rel. Prices } & $-4.84 *$ & & $-4.75^{*}$ & & $-4.85^{*}$ & & $-4.74^{*}$ & \\
\hline & $(0.09)$ & & $(0.09)$ & & $(0.09)$ & & $(0.09)$ & \\
\hline \multirow[t]{2}{*}{ Government } & $3.10^{*}$ & & $3.95^{*}$ & & $3.33^{*}$ & & $3.97^{*}$ & \\
\hline & $(0.12)$ & & $(0.12)$ & & $(0.12)$ & & $(0.12)$ & \\
\hline \multirow[t]{2}{*}{ Not Adjacent } & $-1.43^{*}$ & & $-1.44^{*}$ & & $-1.44^{*}$ & & $-1.44^{*}$ & \\
\hline & $(0.03)$ & & $(0.03)$ & & $(0.03)$ & & $(0.03)$ & \\
\hline \multirow[t]{2}{*}{ Distance } & $-0.67^{*}$ & & $-0.66^{*}$ & & $-0.66^{*}$ & & $-0.66^{*}$ & \\
\hline & $(0.01)$ & & $(0.01)$ & & $(0.01)$ & & $(0.01)$ & \\
\hline \multirow[t]{2}{*}{ Tariffs } & $-25.97^{*}$ & & $-13.46^{*}$ & & $-19.77^{*}$ & & $-20.24^{*}$ & \\
\hline & $(0.53)$ & & $(0.90)$ & & $(1.33)$ & & $(1.33)$ & \\
\hline \multirow[t]{2}{*}{ Constant } & $-0.97^{*}$ & & $-1.02^{*}$ & & $-0.92^{*}$ & & $-1.25^{*}$ & \\
\hline & $(0.05)$ & & $(0.06)$ & & $(0.06)$ & & $(0.07)$ & \\
\hline Observations & 10768 & & 10768 & & 10768 & & 10768 & \\
\hline
\end{tabular}

Standard errors in parentheses; * significant at $1 \%$

17 observations with 0 observed trade have been deleted

Year and regional fixed effects are not reported

Baseline specification reported is for New Brunswick - Georgia trading pair which averages regional fixed effects at 0 
Since fixed effects dummies have to exclude one province and one state, the size of the border effects in this specification greatly depends on the choice of the trading pair; in effect, presented values are the border effects between the members of the chosen trading pair. To avoid presenting misleading results, estimation was conducted for such a trading pair that makes the average of all other fixed effects zero; thus the selection of New Brunswick and Georgia as the baseline. ${ }^{47}$

Our conclusion to this subsection is that consistently estimated Canada-U.S. border effects have been increasing between 1988 and 2003. This fact was obscured in the earlier research by three factors: the exclusion of tariff data, lack of theoretical foundation for the specifications used, and lack of time dimension in the data and estimation procedures.

\subsubsection{Border Effects by Province and Direction of Trade}

From a general question "how strong is the border effect", we now turn to the estimation of the width of this border in different regions and different directions. A country-wide border effect may not do justice to the behaviour of individual regions; since a part of our research question is to investigate regional behaviour, we adapt our specification to this task. We restrict our equation only to observations concerning a particular province to come up with a set of individual border effects for Canadian provinces. Because we are looking for cross-sectional border effects, we restrict our

\footnotetext{
${ }^{47}$ The values of the coefficients on the fixed effects themselves (not included to save space) are generally below 1. Mild positive effects (and thus smaller border effects than average) are shown by the biggest U.S. states (California, New York, Michigan); larger than average effects occur for Canadian maritime provinces, the Western provinces have smaller than average effects. The regional breakdown of border effects is explored more fully in the next subsection.
} 
sample period to $1997-2003$ due to the lack of tariff influence in this period. Following Helliwell (1988), we simplify the model by constraining all our explanatory variables to be uniform throughout this seven-year period. Thus border effects are allowed to vary by time and by province; all other variables vary only by province.

The results of this estimation are presented in Table 4.8. To obtain a comparable benchmark, we estimate this specification for all of Canada first; the results are largely consistent with Table 4.3, the small differences due to the imposed restrictions. Provincial effects are then estimated individually in the West-East direction.

The results indicate some variability among the provinces in their border effects, with most of the provinces below the Canadian average of 5 . All of the Canadian West (British Columbia, Alberta, Saskatchewan, Manitoba) exhibits smaller border effects than average, with Alberta the smallest at 2.7 in 2003. This is not surprising, as we should expect lower border effects for commodities, in which the West primarily specializes, rather than for manufactured goods, as observed by Helliwell (1998). However, Ontario and New Brunswick also follow this trend, and so does Quebec to a lesser extent. It is in the three relatively isolated Atlantic provinces, Newfoundland, Nova Scotia, and - to a lesser extent - Prince Edward Island - where the situation is reversed. The highest border effects occur consistently in Newfoundland, reaching above 20 in 2003 . The relative isolation of these provinces undoubtedly contributes to higher border effects here, which significantly exceed those reported in Helliwell (1998), both in relative and absolute value. As a rule, border effects are flat between 1997 and 2003 for most provinces; but since the data represents static cross-sectional estimates, the inclusion of time effects would create an upward border effect trend in most if not all provinces. 
Table 4.8 Border Effects by Province, 1997-2003

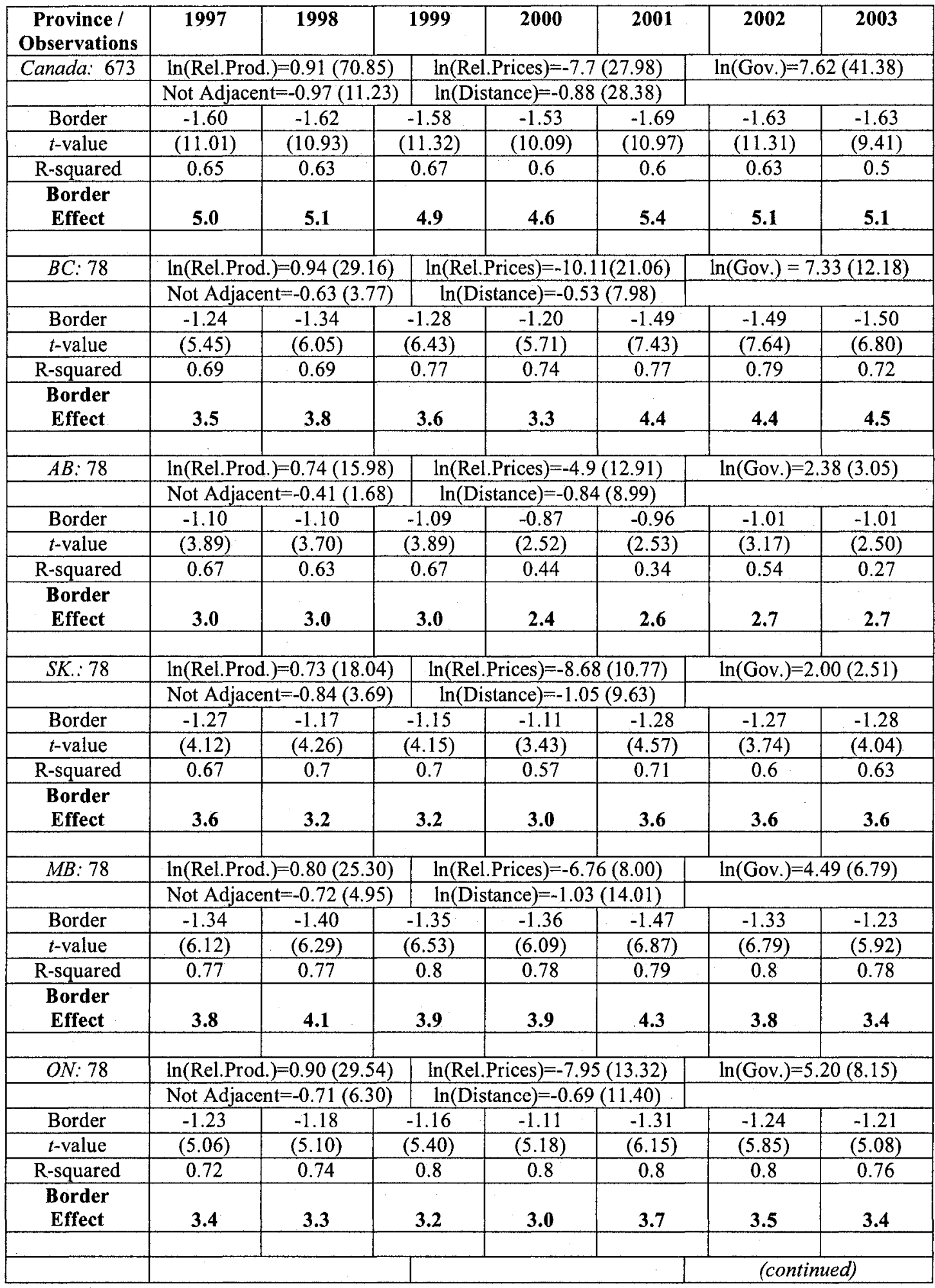




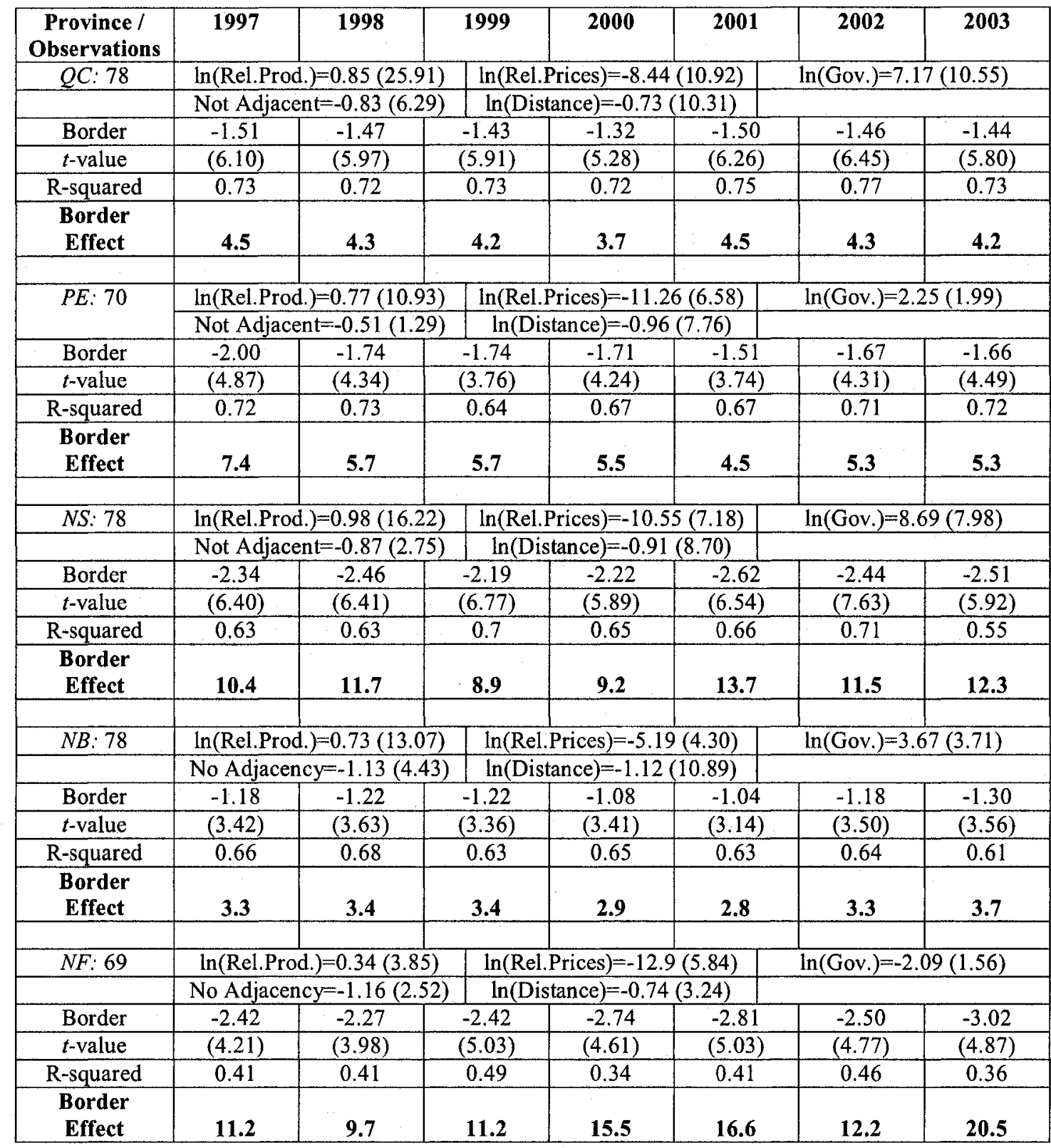

t-values in parentheses

17 observations with 0 observed trade have been deleted

Some interesting effects occur in some provinces for variables other than border effects in this estimation. Non-adjacency is not significant for Alberta, and the effect of government is much smaller here and in Saskatchewan than elsewhere. Distance is a smaller factor for British Columbia, Quebec (both home to oceanic ports) and Ontario 
(very large trade in auto parts with Michigan may be a contributing factor). And in Newfoundland, the coefficient of the government share is negative, though insignificant (no adequate explanation can be provided at this time).

Next, following Anderson \& Smith (1999) who first emphasized that the effect of the border might depend on the direction of trade, we modify our dataset in order to be able to take this into account. We break up our dataset into ten province-specific parts, which allows us to distinguish between individual interprovincial exports and imports in these datasets. Then we separate our border dummy into two dummies, for example $\mathrm{ABM}=1$ for interprovincial imports by Alberta and $\mathrm{ABX}=1$ for interprovincial exports by Alberta. Further, we define ABXUS=1 for Alberta's exports to the United States. In this setting, imports from U.S. are the baseline and every other type of trade is picked up by its own dummy variable. Therefore, our border for imports is the coefficient on ABM which directly indicates Alberta's propensity to import from other provinces over the U.S., and our border for exports is the difference between the coefficients on $A B X$ and ABXUS. As usual, estimated border effects are the exponents of the absolute values of these estimated coefficients. We present the results of this estimation for the year 1997 and the year 2003 to save space, and yet obtain some idea of the time path of the import and export border effects for the provinces.

Table 4.9 shows the results of this exercise. It first confirms what we already know: in a year-to-year setting, border effect for Canada remained stable at around 5 between 1997 and 2003. But the surprising result is that in 1997 the border effect for imports was 10.9 , five times the effect for exports (2.2); perhaps equally surprising is the growth of that difference to an order of magnitude by 2003 (16.8 for imports vs. 1.5 for 
exports, but resulting in the same average effect of 5). Put simply, this tells us that Canada as a whole has little aversion with regards to exporting to the United States, and has become more willing to do so between 1997 and 2003, to the degree that interprovincial exports are only 50\% more attractive than exports to the U.S. But it is on the import side that the border effects truly matter: Canada is relatively very unwilling to import from the United States. A Canadian province was 10.9 times more likely to import from another province than from the U.S. in 1997, and this aversion has grown to 16.8 by 2003. It is no exaggeration to say that at present, nearly the whole border effect between the two countries is due to the import effect on the Canadian side. 
Table 4.9 Border Coefficients for Exports and Imports, 1997 and 2003

\begin{tabular}{|l|c|c|c|c|c|}
\hline \multicolumn{1}{|c|}{1997} & & & Border for & Border for & \\
\cline { 1 - 2 } \multicolumn{1}{|c|}{ Province } & Border & R-squared & Exports & Imports & R-squared \\
\hline British Columbia & $-1.24(5.5)$ & 0.69 & $-0.28(7.8)$ & $-2.18(7.4)$ & 0.75 \\
\hline Alberta & $-1.10(3.9)$ & 0.67 & $-1.20(9.0)$ & $-1.85(5.1)$ & 0.71 \\
\hline Saskatchewan & $-1.27(4.1)$ & 0.67 & $-0.90(8.7)$ & $-1.92(4.5)$ & 0.70 \\
\hline Manitoba & $-1.34(6.1)$ & 0.77 & $-0.87(6.9)$ & $-1.80(6.1)$ & 0.80 \\
\hline Ontario & $-1.23(5.1)$ & 0.72 & $-0.96(4.7)$ & $-1.5(4.6)$ & 0.76 \\
\hline Quebec & $-1.51(6.1)$ & 0.73 & $-1.01(6.2)$ & $-1.9(5.7)$ & 0.77 \\
\hline Prince Edward I. & $-2.00(4.9)$ & 0.72 & $-0.69(2.6)$ & $-3.37(5.8)$ & 0.74 \\
\hline Nova Scotia & $-2.34(6.4)$ & 0.63 & $-1.00(5.0)$ & $-3.73(7.4)$ & 0.67 \\
\hline New Brunswick & $-1.18(3.4)$ & 0.66 & $-0.62(1.8)$ & $-1.73(3.5)$ & 0.66 \\
\hline Newfoundland & $-2.42(4.2)$ & 0.41 & $0.36(5.4)$ & $-5.00(6.7)$ & 0.53 \\
\hline Canada & $\mathbf{- 1 . 6 0 ( 1 1 . 0 )}$ & $\mathbf{0 . 6 5}$ & $\mathbf{- 0 . 8 0 ( 5 . 2 )}$ & $\mathbf{- 2 . 3 9 ( 1 5 . 3 )}$ & $\mathbf{0 . 6 5}$ \\
\hline $\begin{array}{l}\text { Implied Border } \\
\text { Effect, Canada }\end{array}$ & $\mathbf{5 . 0}$ & & & & \\
\hline
\end{tabular}

\begin{tabular}{|l|c|c|c|c|c|}
\hline \multicolumn{1}{|c|}{2003} & & Border for & Border for & \\
\cline { 1 - 2 } \multicolumn{1}{|c|}{ Province } & Border & R-squared & Exports & Imports & R-squared \\
\hline British Columbia & $-1.50(6.8)$ & 0.72 & $-0.30(10.1)$ & $-2.69(9.3)$ & 0.77 \\
\hline Alberta & $-1.01(2.5)$ & 0.27 & $-0.64(9.7)$ & $-2.03(5.0)$ & 0.66 \\
\hline Saskatchewan & $-1.28(4.0)$ & 0.63 & $-0.75(9.4)$ & $-1.98(5.2)$ & 0.74 \\
\hline Manitoba & $-1.23(5.9)$ & 0.78 & $-0.46(7.3)$ & $-2.01(7.0)$ & 0.80 \\
\hline Ontario & $-1.21(5.1)$ & 0.76 & $-0.41(6.3)$ & $-2.03(6.3)$ & 0.79 \\
\hline Quebec & $-1.44(5.8)$ & 0.73 & $-0.46(7.6)$ & $-2.36(7.11)$ & 0.78 \\
\hline Prince Edward I. & $-1.66(4.5)$ & 0.72 & $-0.07(2.9)$ & $-3.41(6.7)$ & 0.75 \\
\hline Nova Scotia & $-2.51(5.9)$ & 0.55 & $-0.49(8.0)$ & $-4.58(9.1)$ & 0.71 \\
\hline New Brunswick & $-1.30(3.6)$ & 0.61 & $-0.27(3.3)$ & $-2.31(4.6)$ & 0.64 \\
\hline Newfoundland & $-3.02(4.9)$ & 0.36 & $0.16(8.0)$ & $-5.82(7.4)$ & 0.52 \\
\hline Canada & $\mathbf{- 1 . 6 3 ( 9 . 4 )}$ & $\mathbf{0 . 5 0}$ & $\mathbf{- 0 . 4 2 ( 2 . 5 )}$ & $\mathbf{- 2 . 8 2 ( 1 6 . 7 )}$ & $\mathbf{0 . 5 9}$ \\
\hline $\begin{array}{l}\text { Implied Border } \\
\text { Effect, Canada }\end{array}$ & $\mathbf{5 . 1}$ & & & & \\
\hline
\end{tabular}

$t$-values in parentheses

17 observations with 0 observed trade have been deleted

Provincial results confirm and extend these findings. Newfoundland is unique among Canadian provinces in that it prefers exporting to the U.S. than to other Canadian provinces; however its extreme unwillingness to import from the U.S. makes its average border effect the largest among the provinces. Other export-friendly provinces include Prince Edward Island, British Columbia and New Brunswick - but the rest are not very far behind, either. Aside from the Atlantic provinces, there is a remarkable uniformity of 
border dummy coefficients across other provinces: roughly -0.5 for exports and between 2 and 2.6 for imports; this translates into 1.6 export effect and 7 to 13 import effect.

What could be the explanation for such a strong result? Let us look at the overall

Table 4.10 Aggregates of Canadian Merchandise Trade, 1997-2003

\begin{tabular}{|cccccccccc|}
\hline \$M. CAN & 1997 & 1998 & 1999 & 2000 & 2001 & 2002 & 2003 \\
\hline Canadian Total Exports to U.S. & 243,888 & 269,909 & 308,076 & 359,289 & 351,751 & 345,366 & 326,700 \\
\% growth since 1997 & - & $11 \%$ & $26 \%$ & $47 \%$ & $44 \%$ & $42 \%$ & $34 \%$ \\
\hline Canadian Total Imports from U.S. & 184,414 & 203,578 & 215,575 & 229,660 & 218,290 & 218,497 & 203,803 \\
\% growth since 1997 & - & $10 \%$ & $17 \%$ & $25 \%$ & $18 \%$ & $18 \%$ & $11 \%$ \\
Canadian Total Imports from China & 6,341 & 7,651 & 8,951 & 11,294 & 12,724 & 16,004 & 18,581 \\
\% growth since 1997 & - & $21 \%$ & $41 \%$ & $78 \%$ & $101 \%$ & $152 \%$ & $193 \%$ \\
Canadian Total Imports from Mexic & 7,022 & 7,682 & 9,536 & 12,060 & 12,123 & 12,744 & 12,190 \\
\% growth since 1997 & - & $9 \%$ & $36 \%$ & $72 \%$ & $73 \%$ & $81 \%$ & $74 \%$ \\
Canadian Total Imports from Korea & 2,838 & 3,312 & 3,572 & 5,282 & 4,605 & 4,865 & 5,108 \\
\% growth since 1997 & - & $17 \%$ & $26 \%$ & $86 \%$ & $62 \%$ & $71 \%$ & $80 \%$ \\
\hline Canadian Interprovincial Trade & $1,011,079$ & $1,046,572$ & $1,138,020$ & $1,293,130$ & $1,288,630$ & $1,307,980$ & $1,321,708$ \\
\% growth since 1997 & - & $4 \%$ & $13 \%$ & $28 \%$ & $27 \%$ & $29 \%$ & $31 \%$ \\
\hline
\end{tabular}

Canadian merchandise trade data between 1997 and 2003 (Table 4.10). We see that both the Canadian interprovincial trade and Canadian exports to the U.S. have grown roughly by a third during this time period, though exports to the U.S. have grown a little faster. Meanwhile, Canadian imports from the U.S. have grown only by $10 \%$. Lastly, Canadian imports from its major "low-cost labour" trading partners have grown much faster almost doubled for Mexico and South Korea, and tripled for China. At this aggregate level, the conclusions of Table 4.9 seem much more believable. Canadian exports to U.S. are growing faster than Canadian interprovincial trade, slightly decreasing the observed border effect for exports. Imports from U.S. are growing much slower than inteprovincial trade, thus increasing the observed border effect; and the shortfall in imports is 
increasingly being made up by import substitution from the developing economies such as China, Mexico and South Korea.

This raises a question about the border effects methodology employed. While in 1997 the effects of this import substitution were negligible, they were no longer such in 2003. A growth in attractiveness of imports from China (whether due to preferences, prices or other effects) must necessarily reduce the imports from the United States; but it is questionable whether translating this substitution effect into a higher border effect, as the current approach does, is entirely legitimate. A more proper assessment of the border effect would seem to be the comparison of Canadian imports from the United States to all Canadian trade, including imports from other major trading partners. Thus, while the Head/Mayer simplification in our model obviates the need for remoteness variables in the specification, a more extended specification might be necessary to produce an unbiased estimate of the border effect between the two countries. We believe that further research in this direction will produce an even better measure of integration as represented by the border effect.

Although the above point is believed to be the major reason for the drastic difference between import and export border effects, the quality of data could certainly contribute somewhat. The extremely high resistance of the three Atlantic provinces (Newfoundland, Nova Scotia and Prince Edward Island) to imports from the U.S. may indicate that the goods they import are wrongly attributed to the provinces through which they arrive, and not to their true origin in the United States. This effect is unlikely to be crucial as the elimination of these provinces does not change the main conclusions, but better data on the origin of goods could certainly help to correct this bias. 


\subsection{Conclusions and Further Research}

This paper has developed a regional model of trade in differentiated goods and applied it to the largest set of data ever used to estimate Canada-U.S. border effects. Taking advantage of this dataset, we are able to introduce several theoretically important variables overlooked in previous research, and estimate our specification with the use of time-series techniques. The model is robust and applicable to any set of regional data in the world; it bypasses the need for remoteness measures using the Head \& Mayer simplification, and is the first theory-derived regional model to estimate Canada-U.S. border effects with the use of this technique.

We reach several interesting conclusions in the process. First, border effects between Canada and U.S. estimated from this regional model are much lower than suggested by previous research. Our preferred estimates show that border effects range between 2.2 in 1988 and 5.5 in 2003 . We explain this result by our inclusion of tariffs into the estimated specification and the solid theoretical foundation that we have

developed. Second, the time dynamics of the border effects seem to be very different from those previously described in the literature. By introducing fixed and interactive time effects, we show that insofar as border effects stand for the unexplained tradereducing power of the Canada-U.S. border, they have grown significantly between 1988 and 2003. Third, we find that the shares of the national and regional governments in the regional economies of North America have a significant impact on the estimated border effects, and thus governments should be included as one of the explanatory factors in all future studies. Finally, we find that the overall Canada-U.S. border effect is largely 
import-driven, in the sense that Canadian provinces are quite willing to export to the U.S., but averse to importing from there. The resulting shortfall in imports is made up by importing from third countries. This is a strong demonstration of the fact that the border effects are not the same in the two directions, and should be estimated separately by future studies.

The above findings offer significant opportunities for further research, both into producing better estimates of border effects, and into interpreting these values. The effects of language as a proxy for social and cultural networks have not been made clear, which is due in our opinion to the largely monolingual environment of North America. A similar regional model might do better in Europe or elsewhere, pointing the way for better modeling of languages and networks that have an influence on cross-border trade. Also, variables other than language that proxy these networks well can add explanatory power and improve the specification.

The estimation procedure itself can crucially benefit from more and better data. A reliable intertemporal set of data on non-tariff barriers may be a key explanatory factor for the current border effects; it may indicate that the recent trade disputes between Canada and the U.S. are responsible for part of the increase in the border effect between the two countries. As there is a large increase in 2001 in our preferred estimates, it is hypothesized that the effect of the recent security measures imposed by the United States may also be partially responsible for the rising border effects in recent years. ${ }^{48}$

Measures of gross output by U.S. state, currently under development at the Bureau of Economic Analysis, can help produce more precise estimates. Inclusion of the

\footnotetext{
${ }^{48}$ Heightened scrutiny of immigration, tourism and trade may raise the cost of trade and discourage the formation of international trading networks.
} 
United States Consumer Flow Survey data may be an interesting extension to the model, although time-series exercises will not be available in that case.

Finally, while many changes have been made to the original McCallum (1995) methodology, its basic spirit remained intact until now. The core border effects methodology compares trade flows with a foreign country vis-à-vis internal trade benchmarks. We have shown above that this approach can be influenced by changes in the patterns of trade with third countries, and that it would be more proper to derive a single average border effect that takes into account trade with all major trading partners, with subsequent differentiation of this border effect into pairs of country-specific bilateral resistances to imports and exports. 


\section{Conclusion}

This thesis re-evaluates the research conducted in the area of border effects and combines theory and econometrics to obtain consistent estimates of these effects between Canada and the United States. Typical gravity models used previously are not well grounded in theory and generate biased results. They leave out crucial price and tariff variables, eschew panel data techniques that isolate the effects of time and heterogeneity, and thus lead to inflated (and otherwise distorted) border effect estimates. Our meta-analysis of the literature determines which variables and methods used in conducting the studies influence the resulting estimates. Preceded and informed by a chronological survey, it features an enhanced variable selection process and leads to a better meta-analytic specification. We confirm that border effects are statistically and economically significant and show that their size can be explained by the methodology of the study.

Based in part on these results, we derive a model of regional trade in differentiated goods which produces an effective specification for estimating border effects between Canada and U.S. This includes relative production, relative prices, relative distances, government, adjacency and tariffs. Our specification produces estimates superior to most previous research in a manner consistent with trade theory. The resulting cross-sectional border effects between Canada and the U.S. range between 5 and 6 , much lower than previous estimates. ${ }^{49}$

\footnotetext{
${ }^{49}$ This is not only smaller than McCallum's and Helliwell's estimates, but also significantly smaller than the Anderson and van Wincoop (2001) conclusion. As pointed out in Feenstra (2002), the AvW estimate of the ratio of adjusted intra-Canadian trade to cross-border trade is 10.5 , which is the proper statistic for comparison with other studies.
} 
However, simple cross-sectional results such as obtained almost exclusively by the literature can not include the tariffs as an explanatory variable and ignore the effects of time on trade and borders. We construct and estimate a 1988-2003 panel that allows us to include tariffs among explanatory variables and to use time-series techniques to refine the estimates and plot their time path. Our results show that, contrary to common belief, border effects between Canada and the U.S. have increased roughly from 2 to 5 within the 1988-2003 period; rising non-tariff barriers and changes in patterns of trade may have been responsible. Taking into account regional fixed effects does not influence this conclusion significantly. Two-thirds of McCallum's (1995) original border effect estimate for 1988 is shown to have been due to tariffs, proving the conjecture in the literature that small border costs can generate large border effects. Another new finding is that these results are dominated by the import effect, implying that Canadian provinces are much more averse to imports from U.S. than the U.S. states are to imports from Canada. Our preferred explanation for this result is the change in aggregate trading patterns with third countries that has taken place between 1997 and 2003 . We conclude that tracking trade with all of the country's major trading partners is essential for better border effect estimates in further research.

Overall, McCallum's basic finding that national borders matter remains in force, with some qualifications. First, the power of the borders themselves is of course illusory; in reality, it is the very existence of nations and all their policies that is restricting trade. International trade is generally restricted by two types of factors: consumer preferences for domestic goods and higher costs of international trade as opposed to internal trade. These two are due in turn to several variables, which can be incorporated theoretically 
and used to explain border effects in the manner shown in Chapter 4 . On the basis of findings of this thesis and the previous literature, we believe that a full explanation for border effects is to be sought along this path.

Second, as we reason that the borders are created and maintained by the enlightened self-interest of rational populations, the question of measuring their welfare effects seems to be associated with difficulties. In other words, if borders were welfaredecreasing on aggregate, they would disappear already - as they are slowly disappearing in Europe. Third, we point out that border effects are much smaller than previously believed, but the truly surprising fact is that they have been growing in the recent years. Even though the overall progress of the world economy towards globalization is undeniable, this progress may not proceed in a straight line, and should not be taken for granted. Local reversals of this global trend may and will happen. Whether our findings are the premonition of a break in the continuously increasing trend of global trade growth since 1945 , or a temporary phenomenon, only time can tell. 


\section{Appendix A}

\section{The Gravity Equation:}

\section{From History to Practice to Theory}

The gravity equation is a widely used specification for econometric analysis of various flows between countries/regions. In international trade, gravity equations typically analyze merchandise trade flows between two or more countries. In this setting, they are distinguished for being highly effective in explaining variation in trade data and for their robustness in doing so.

The original idea behind the equation is due to Newton's gravity law, which proposed that the force of attraction between two objects $i$ and $j, F i j$, is directly proportional to their masses, $M i$ and $M j$, and inversely proportional to the squared distance $D i j$ between them:

$$
F_{i j}=G \frac{M_{i}^{M} j}{D_{i j}^{2}},
$$

with $G$ being a gravitational constant.

With a slight change in notation, this specification was first applied, independently, by Tinbergen (1962) and Poyhonen (1963) to the analysis of trade flows between nations. Since that time, it has become a very popular method for explaining variation in bilateral trade.

The empirical gravity equation has been specified in many different ways in the literature. In its simplest form it is expressed as follows: 


$$
X_{i j}=A \frac{Y_{i} Y_{j}}{D_{i j}}
$$

where $i$ and $j$ are the two trading partners, $X_{i j}$ is the flow of trade between them (sometimes the sum of exports and imports, and sometimes a flow in one direction), $Y_{i}$ and $Y_{j}$ - trading partners" "economic masses", usually specified as GDPs, $D_{i j}$ - the "economic distance" between them, defined as the cost of transporting traded goods between the partners, and usually specified as the distance between their most important cities, and $A$ is a vector of other variables that may influence trade flows further through their linking or dividing effect on the two trading partners.

Theoretically, all of the variables in the above equation could be free to take various powers; note that in the original Newton's Law, distance takes the power of two. In practice, through experience with gravity equation, the consensus in the literature is that the best fit is achieved under (2), where both GDPs and distances carry the power of one.

Thus the simplest gravity specification in international trade that can be estimated is the logged form of (2) with small letters representing the natural logs of the variables above:

$$
x_{i j}=\beta_{0}+\beta_{1} y_{i}+\beta_{2} y_{j}-\beta_{3} d_{i j}+\beta_{4} a+\varepsilon,
$$

Both (2) and (3) imply that trade is expected to grow with the economic size of the partners and decrease with distance between them. The typical gravity equation may include several other variables in the $a$ vector, such as estimates of alternative trading opportunities, squared distance or GDP terms, and various dummies for common language, trading bloc etc. One commonly used specification includes population as an 
additional measure of the country's economic size; this specification is typically referred to as augmented gravity equation (although the term augmented may also be used for any equation incorporating additional variables).

Overall, this simple equation is one of the most successful empirical specifications in international economics; the gravity model is robust and powerful, routinely explaining $80 \%$ and more variation in trade between countries. Besides international trade, gravitational attraction was successfully used to explain migration, tourism, foreign investment and other interactions between countries and regions.

Concerns were raised in the economic literature that the intuitive appeal of the gravity equation and its shorthand representation of the forces of supply and demand bypass formal economic theory. These concerns were first addressed by Anderson (1979) who derived the gravity equation formally from expenditure share equations with commodities distinguished by place of production.

This derivation goes as follows. Anderson assumes identical homothetic preferences across countries which produce commodities differentiated by place of origin. In the simplest possible case, each country is completely specialized, i.e. produces one good only. Due to simple Cobb-Douglas preferences everywhere, the fraction of income spent on the product of country $i$ is identical in all countries, and denoted $b_{i}$. Choosing units so that prices are equal to unity, it can be stated that the value of imports of good $i$ by country $j$ is:

$$
M_{i j}=b_{i} Y_{j} \text {, }
$$

where $Y_{j}$ is income in country $j$. Meanwhile, the income of country $i$ must equal its sales:

$$
Y_{i}=b_{i}\left(\Sigma_{j} Y_{j}\right)
$$


Substituting for $b_{i}$ from (5) into (4), we obtain:

$$
M_{i j}=\frac{Y_{i} Y_{j}}{\Sigma Y_{j}}
$$

This is the simplest form of gravity equation without tariffs or transport costs. In a pure cross-section estimate, the denominator is simply an irrelevant scale term; thus (6) simply states that imports are directly proportional to the GDPs of the importer and exporter.

The subsequent introduction of the non-traded goods sector, many goods and transportation costs result in the following form of the theory-implied gravity equation:

$$
M_{i j}=\frac{m_{i} \phi_{i} Y_{i} \phi_{j} Y_{j}}{\Sigma_{j} \phi_{j} Y_{j}} \frac{1}{f\left(d_{i j}\right)}\left[\Sigma_{j} \frac{\phi_{j} Y_{j}}{\Sigma_{j} \phi_{j} Y_{j}} \frac{1}{f\left(d_{i j}\right)}\right]^{-1} U_{i j}
$$

where $m_{i}$ is the scale factor, $\phi_{i}$ and $\phi_{j}$ are expenditure shares on traded goods, $f\left(d_{i j}\right)$ is the specification of transportation costs as an increasing function of distance and the same across commodities, and $U_{i j}$ is a log-normal disturbance with an expectation of 0 .

This formulation is considered by the author to be the best case one can make theoretically for the gravity equation as it is usually estimated empirically. There are still three significant differences between the latter and what (7) implies: (7) is an aggregate equation, and not commodity-specific; $f\left(d_{i j}\right)$ is not necessarily log-linear; and finally, the term in square brackets is missing from the usual formulation of the gravity equation. These are the remoteness terms that denote the relative distance between the importer and all of his trading partners; their importance is underscored in further research, in particular Anderson and van Wincoop (2001). 
The specification developed in chapter 4 takes into account the points made above. It is an aggregate and not a commodity-specific model that we estimate. Experiments with different distance specifications indicate that the best explanatory power is achieved when distance is included log-linearly without powers. Finally, the need for remoteness terms is obviated in our specification by dividing trade flows through by internal trade flows.

Bergstrand (1985) presents a general equilibrium model of world trade with $\mathrm{N}$ countries, assuming one factor of production in each. A gravity equation arises from this system after a few simplifying assumptions. Assuming small open economies and identical utility and production functions, his set of equilibrium equations can be simplified to:

$$
\begin{aligned}
P X_{i j}= & Y_{i}^{(\sigma-1) /(\gamma+\sigma)} Y_{j}^{(\gamma+1) /(\gamma+\sigma)} C_{i j}^{-\sigma(\gamma+1) /(\gamma+\sigma)} T_{i j}^{-\sigma(\gamma+1) /(\gamma+\sigma)} E_{i j}^{\sigma(\gamma+1) /(\gamma+\sigma)} * \\
& *\left(\Sigma^{\prime} P_{i k}^{1+\gamma}\right)^{-(\sigma-1)(\gamma-\eta) /(1+\gamma)(\gamma+\sigma)}\left(\Sigma^{\prime \prime} P_{k j}^{\prime 1-\sigma}\right)^{(\gamma+1)(\sigma-\mu) /(1-\sigma)(\gamma+\sigma) *} \\
& *\left[\left(\Sigma^{\prime} P_{i k}^{1+\gamma}\right)^{(1+\eta) /(1+\gamma)}+P_{i i}^{1+\eta}\right]^{-(\sigma-1) /(\gamma+\sigma)}\left[\left(\Sigma^{\prime \prime} P_{k j}^{1-\sigma}\right)^{(1-\mu) /(1-\sigma)}+P_{j j}^{1-\mu}\right]^{-(\gamma+1) /(\gamma+\sigma)},
\end{aligned}
$$

where $P X_{i j}$ is the value of trade flow of $\operatorname{good} X$ at price $P$ from $i$ to $j, Y$ are expenditures, $\mu$ is the constant elasticity of substitution (CES) between domestic and importable goods for all countries, $\sigma$ is the CES among importable goods in all countries, $\eta$ is the constant elasticity of transformation (CET) between home and foreign production, $\gamma$ is the CET for production among export markets, $P_{k j}$ is the $k$-currency price of $k$ 's product sold in $j$ 's market, $P^{\prime}{ }_{k j}=P_{k j} T_{k j} C_{k j} / E_{k j}, T_{k j}$ is $j$ 's tariff rate on $k$ 's product plus 
unity, $C_{k j}$ is the transport cost factor to ship $k$ 's product to $j$, and $E_{k j}$ is the spot value of $j$ 's currency in terms of $k$ 's currency, $\Sigma^{\prime}$ is the summation over $k=1, \ldots, N$ excluding $i, \Sigma^{\prime \prime}$ is the summation over $k=1, \ldots, N$ excluding $j$.

This "generalized" gravity equation can be transformed further into a more simplified form, similar to that used empirically, if four additional assumptions are made. These are: perfect substitutability of goods, perfect arbitrage, zero tariffs and zero transport costs. The resulting equation is:

$$
P X_{i j}=(1 / 2) Y_{i}^{1 / 2} Y_{j}^{1 / 2}
$$

Overall, the generalized version (8) is considered more appropriate than (3) due to the restrictiveness of the four additional assumptions that lead to (9). The main point made by Bergstrand is that a gravity equation similar to (3) can be derived from his model, but if the aggregate trade flows are differentiated by place of origin, then (3) misspecifies the gravity equation by omitting, in particular, certain price variables. Our specification in chapter 4 takes these price variables into account.

Lastly, let us examine the contribution of Deardorff (1998) which derives the gravity equation from the Heckscher-Ohlin model under two differing sets of assumptions. First, under frictionless trade and homogeneous products, producers and consumers are perfectly indifferent between trading partners and choose them by random allocation. In this case, expected trade flows will correspond exactly to the gravity equation (6) if preferences are identical and homothetic, through a chain of reasoning similar to Anderson (1979). Under arbitrary preferences, it is still possible to get a similar result as long as exporter production shares and importer consumptions shares are not correlated. In essence, the gravity equation (6) then describes the average state of affairs 
in this market; if one country tends to "overproduce" the good that another country "overconsumes", then the gravity equation will underpredict trade, and vice versa.

Of more interest are the results in the case of impeded trade. Strictly positive barriers to trade, such as transportation costs, are defined for every good. Also, and crucially, every country produces different goods, implying full specialization as defined within the Heckscher-Ohlin model. Due to positive barriers to trade, no countries that achieve factor price equalization (FPE) can actually trade with each other, because their f.o.b. output prices are the same. This leads in turn to the conclusion that only one country will export any particular good to the world markets, taken further by the assumption that this good will only be produced in that one country. These goods are considered imperfect substitutes, and transportation costs are assumed to be of "iceberg" form, with a fraction of the good shipped between countries "melting" in transit.

Under identical Cobb-Douglas preferences, consumers in each country will spend a fixed share, $\beta_{i}$, of their income on goods from country $i$. Country's $i$ income $Y_{i}$ is:

$$
Y_{i}=p_{i} x_{i}=\Sigma_{j} \beta_{i} Y_{j}=\beta_{i} Y^{w}
$$

where $Y^{w}$ is world production. Hence $\beta_{i}=Y_{i} / Y_{w}$. If trade is valued on f.o.b. basis that is, exclusive of transport costs $t_{i j}$, it can be expressed as:

$$
T_{i j}^{f o b}=T_{i j}^{c i f} / t_{i j}=\frac{\beta_{i} Y_{j}}{t_{i j}}=\frac{Y_{i} Y_{j}}{t_{i j} Y^{w}},
$$

which is a familiar form of the basic gravity equation, inclusive of distance insofar as transportation costs are a simple function of distance.

Finally, assuming CES preferences instead of Cobb-Douglas, let consumers in country $j$ maximize their CES utility function: 
$U^{j}=\left(\Sigma_{i} \beta_{i} c_{i j}^{\frac{\sigma-1}{\sigma}}\right)^{\frac{\sigma}{\sigma-1}}$,

where $\sigma>0$ is the constant elasticity of substitution between any pair of countries' products. Maximizing this under c.i.f. prices of $t_{i j} p_{i}, j$ 's consumers constrained by $Y_{j}=$ $p_{j} x_{j}$ will obtain the optimal consumption $c_{i j}$ as:

$c_{i j}=\frac{1}{t_{i j} p_{i}} Y_{j} \beta_{i}\left(\frac{t_{i j} p_{i}}{p_{j}^{I}}\right)^{1-\sigma}$,

where $p_{j}^{I}=\left(\Sigma_{i} \beta_{i} t_{i j}^{1-\sigma} p_{i}^{1-\sigma}\right)^{1 /(1-\sigma)}$ represents the CES price index in country $j$.

Hence, the f.o.b. value of exports of country $i$ to country $j$ is:

$$
T_{i j}^{f o b}=\frac{1}{t_{i j}} Y_{j} \beta_{i}\left(\frac{t_{i j} p_{i}}{p_{j}^{I}}\right)^{1-\sigma}
$$

Defining $\theta_{i}$ as country's $i$ share of world income, relating it to $\beta_{i}$ and solving yields the final version of the gravity equation under CES in $\mathrm{H}-\mathrm{O}$ model:

$$
T_{i j}^{f o b}=\frac{Y_{i} Y_{j}}{Y^{w}} \frac{1}{t_{i j}}\left[\frac{\left(\frac{t_{i j}}{p_{j}^{I}}\right)^{1-\sigma}}{\sum_{h} \theta_{h}\left(\frac{t_{i h}}{p_{h}^{I}}\right)^{1-\sigma}}\right]
$$

which is a familiar result: trade is proportional to partners' incomes, inversely proportional to transportation costs that are a function of distance, and is affected by the remoteness variables that describe its relative distance to its trading partners. 


\section{Appendix B}

\section{Meta-Analysis Data}

\begin{tabular}{|c|c|c|c|c|c|c|}
\hline \# & YEAR & AUTHOR(S) & TITLE & IN & PUBLISHED & MAJOR \\
\hline 1 & 1995 & McCallum & National borders matter... & AER & 1 & 1 \\
\hline 2 & 2003 & AWW & Gravity with Gravitas... & AER & 1 & 1 \\
\hline 3 & 2003 & AWW & Gravity with Gravitas... & AER & 1 & 1 \\
\hline 4 & 1999 & AS & Do National borders... & RIE & 1 & 0 \\
\hline 5 & 1999 & AS & Canadian Provinces... & CJE & 1 & 0 \\
\hline 6 & 2003 & Brown & Overcoming Distance... & StCan & 1 & 0 \\
\hline 7 & 2004 & Brown & Overcoming Distance... & StCan & 1 & 0 \\
\hline 8 & 2004 & De Sousa \& Disdier & Trade, border... & Book & 1 & 0 \\
\hline 9 & 2001 & Fairfield & Canada-US borders... & & 0 & 0 \\
\hline 10 & 2000 & HM & Non-Europe... & RWE & 1 & 0 \\
\hline 11 & 2001 & HM & Effet frontiere.... & CEPII & 0.5 & 0 \\
\hline 12 & 2002 & HM & Illusory border effects... & CEPII & 0.5 & 0 \\
\hline 13 & 1996 & Helliwell & Quebec & CJE & 1 & 0 \\
\hline 14 & 1997 & Helliwell & National borders, trade... & NBER & 0.5 & 0 \\
\hline 15 & 1997 & Helliwell & National borders - Migration & NBER & 0.5 & 0 \\
\hline 16 & 2001 & Helliwell & Measuring Intemal... & CJE & 1 & 0 \\
\hline 17 & 2003 & Helliwell & Border Effects... & & 0 & 0 \\
\hline 18 & 1998 & Hillberry & Regional Trade... & JBS & 1 & 0 \\
\hline 19 & 2003 & HH & Intra-National... & REaS & 1 & 1 \\
\hline 20 & 2002 & Hillberry & Aggregation Bias... & CJE & 1 & 0 \\
\hline 21 & 2000 & Nitsch & National Borders... & CJE & 1 & 0 \\
\hline 22 & 1996 & Wei & Intra-National versus... & NBER & 0.5 & 0 \\
\hline 23 & 2000 & Wolf & Intranational Home Bias... & REaS & 1 & 1 \\
\hline 24 & 2002 & Feenstra & Consistent methods... & SJPE & 1 & 0 \\
\hline 25 & 2003 & Evans & The economic significance... & AER & 1 & 1 \\
\hline 26 & 2002 & Crozet & Effets-frontieres... & EI & 1 & 0 \\
\hline 27 & 2003 & Fidrmuc & Disintegration and trade & RIE & 1 & 0 \\
\hline
\end{tabular}




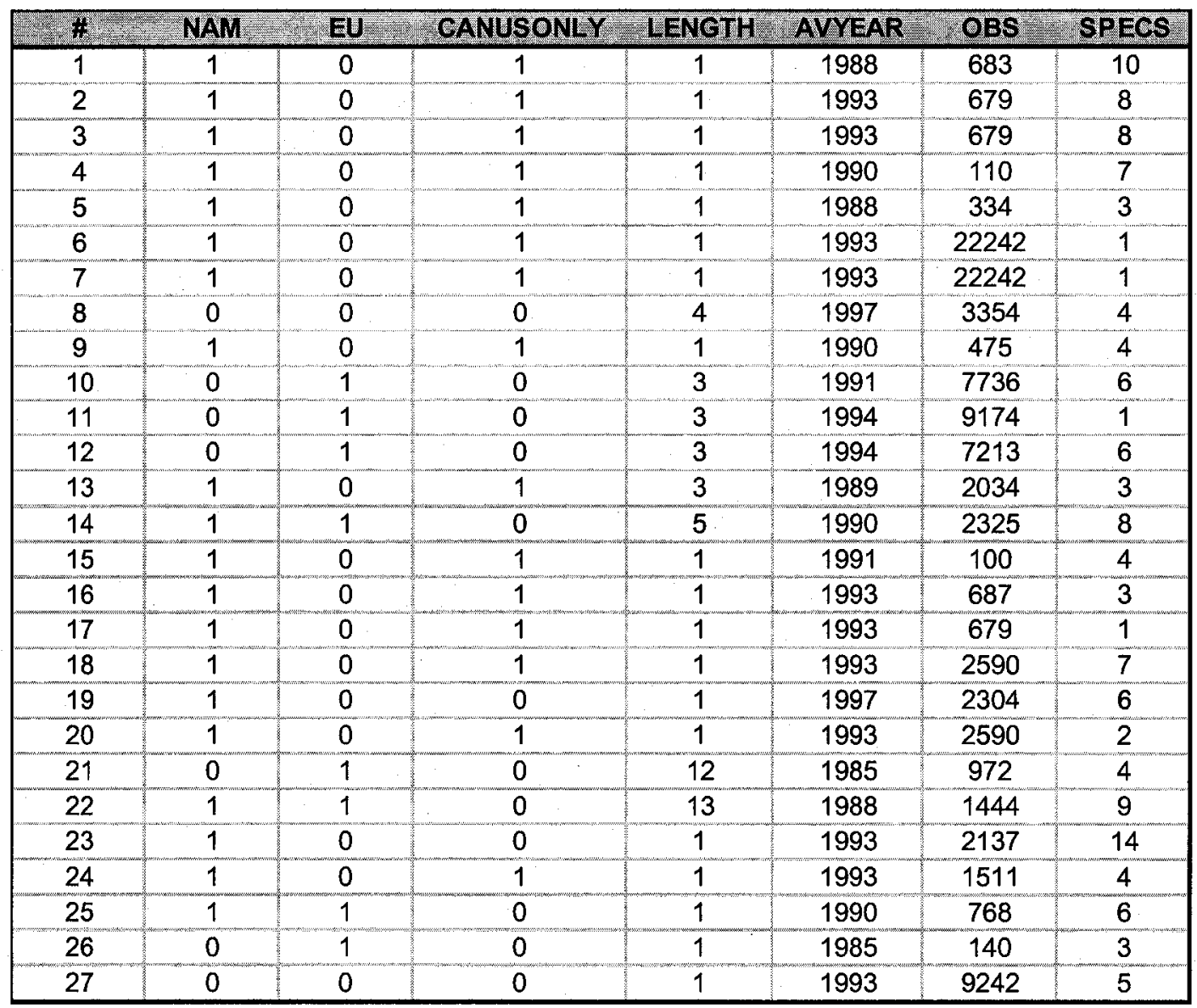




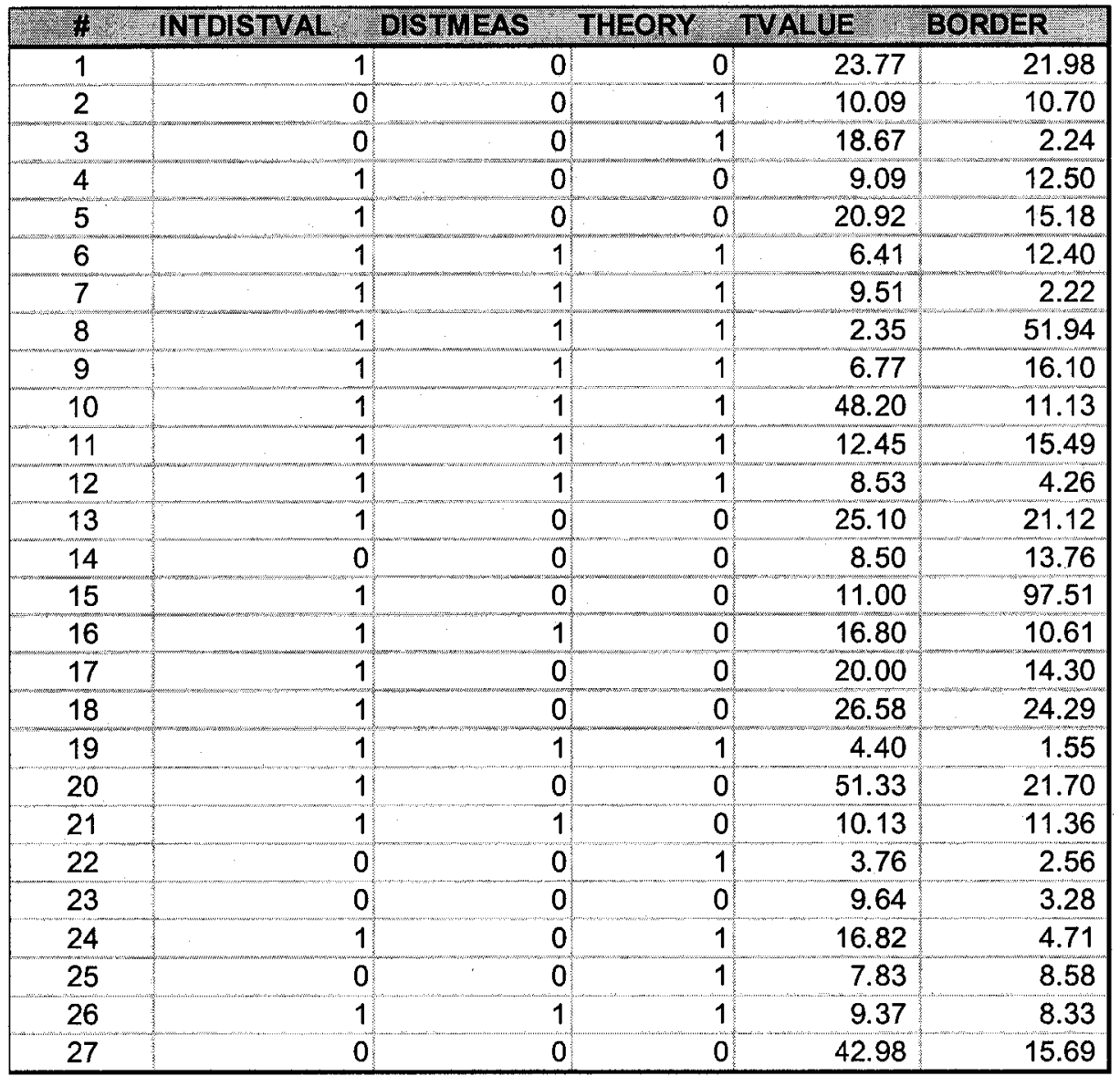




\begin{tabular}{|c|c|c|c|c|c|}
\hline \# & COMLANG & ADJ & TRMODE & DISTRIB & REMOTE \\
\hline 1 & 0 & 0 & 1 & 1 & 1 \\
\hline 2 & 0 & 0 & 1 & 1 & 0 \\
\hline 3 & 0 & 0 & 1 & 1 & 0 \\
\hline 4 & 0 & 0 & 1 & 1 & 1 \\
\hline 5 & 0 & 0 & 1 & 1 & 1 \\
\hline 6 & 0 & 0 & 1 & 0 & 0 \\
\hline 7 & 0 & 0 & 1 & 0 & 0 \\
\hline 8 & 0 & 0 & 1 & 1 & 1 \\
\hline 9 & 0 & 0 & 1 & 1 & 0 \\
\hline 10 & 0 & 1 & 1 & 1 & 0 \\
\hline 11 & 0 & 1 & 1 & 1 & 1 \\
\hline 12 & 0 & 0 & 1 & 1 & 1 \\
\hline 13 & 0 & 0 & 1 & 1 & 1 \\
\hline 14 & 0 & 0 & 0 & 1 & 0 \\
\hline 15 & 0 & 0 & 1 & 1 & 1 \\
\hline 16 & 0 & 0 & 1 & 1 & 0 \\
\hline 17 & 0 & 0 & 1 & 1 & 0 \\
\hline 18 & 0 & 0 & 1 & 0 & 0 \\
\hline 19 & 0 & 0 & 1 & 0 & 1 \\
\hline 20 & 0 & 0 & 1 & 1 & 1 \\
\hline 21 & 0 & 0 & 1 & 1 & 0 \\
\hline 22 & 0 & 0 & 1 & 1 & 0 \\
\hline 23 & 0 & 0 & 1 & 1 & 0 \\
\hline 24 & 0 & 0 & 1 & 1 & 0 \\
\hline 25 & 0 & 0 & 1 & 1 & 0 \\
\hline 26 & 1 & 1 & 1 & 1 & 1 \\
\hline 27 & 0 & 0 & 1 & 1 & 0 \\
\hline
\end{tabular}




\begin{tabular}{|c|c|c|c|c|c|c|}
\hline \# & TRBLOC & SPATIAL & SCONLY & LCONLY & GOV & B \\
\hline 1 & 0 & 1 & 1 & 0 & 0 & 3.09 \\
\hline 2 & 0 & 1 & 1 & 0 & 0 & 2.37 \\
\hline 3 & 0 & 1 & 0 & 1 & 0 & 0.81 \\
\hline 4 & 0 & 1 & 1 & 0 & 0 & 2.53 \\
\hline 5 & 0 & 1 & 1 & 0 & 0 & 2.72 \\
\hline 6 & 0 & 0 & 1 & 0 & 0 & 2.52 \\
\hline 7 & 0 & 0 & 0 & 1 & 0 & 0.80 \\
\hline 8 & 0 & 1 & 0 & 0 & 0 & 3.95 \\
\hline 9 & 0 & 0 & 0 & 0 & 0 & 2.78 \\
\hline 10 & 0 & 1 & 0 & 0 & 0 & 2.41 \\
\hline 11 & 0 & 1 & 0 & 0 & 0 & 2.74 \\
\hline 12 & 0 & 1 & 0 & 0 & 0 & 1.45 \\
\hline 13 & 0 & 1 & 1 & 0 & 0 & 3.05 \\
\hline 14 & 1 & 1 & 0 & 0 & 0 & 2.62 \\
\hline 15 & 0 & 1 & 1 & 0 & 0 & 4.58 \\
\hline 16 & 0 & 1 & 1 & 0 & 0 & 2.36 \\
\hline 17 & 0 & 1 & 1 & 0 & 0 & 2.66 \\
\hline 18 & 0 & 1 & 0 & 1 & 0 & 3.19 \\
\hline 19 & 0 & 0 & 0 & 0 & 0 & 0.44 \\
\hline 20 & 0 & 1 & 0 & 1 & 0 & 3.08 \\
\hline 21 & 1 & 1 & 0 & 0 & 0 & 2.43 \\
\hline 22 & 1 & 1 & 0 & 0 & 0 & 0.94 \\
\hline 23 & 0 & 1 & 0 & 0 & 0 & 1.19 \\
\hline 24 & 0 & 1 & 0 & 0 & 0 & 1.55 \\
\hline 25 & 0 & 1 & 0 & 0 & 0 & 2.15 \\
\hline 26 & 1 & 1 & 0 & 0 & 1 & 2.12 \\
\hline 27 & 0 & 1 & 0 & 0 & 0 & 2.75 \\
\hline
\end{tabular}




\section{Bibliography}

Anderson, James E. (1979) "A Theoretical Foundation for the Gravity Equation", American Economic Review, 69(1), pp. 106-16.

Anderson, James E. and Douglas Marcouiller (2002) "Insecurity and the Pattern of Trade: An Empirical Investigation", Review of Economics and Statistics, 84(2), pp. 342-52.

Anderson, James E. and Eric van Wincoop (2001) "Gravity with Gravitas: A Solution to the Border Puzzle", NBER working paper $\# 8079$.

Anderson, Michael A. and Stephen L.S. Smith (1999) "Canadian Provinces in World Trade: Engagement and Detachment”, Canadian Journal of Economics, 32(1), pp. 22-38.

Balistreri, Edward J. and Russell H. Hillberry (2006) "Trade Frictions and Welfare in the Gravity Model: How Much of the Iceberg Melts?", Canadian Journal of Economics, 39(1), pp. 247-65.

Begg, Colin B., and Madhuchhanda Mazumdar (1994) "Operating characteristics of a rank correlation test for publication bias", Biometrics, 50(4), pp.1088-1101.

Bergstrand, Jeffrey H. (1985) "The Gravity Equation in International Trade: Some Microeconomic Foundations and Empirical Evidence", The Review of Economics and Statistics, 67(3), pp. 474-81. 
Brown, Mark W. and William P. Anderson (2002) "Spatial Markets and the Potential for Economic Integration Between Canadian and U.S. Regions", Papers in Regional Science, 81(1), pp. 99-120.

Bougheas, Spiros, Panicos Demetriades and Edgar Morgenroth (1999) "Infrastructure, Transport Costs and Trade", Journal of International Economics, 47(1), pp. 169-89.

Coulombe, Serge (2005) "Border Effects and North American Economic Integration: Where Are We Now?', in Social and Labour Market Aspects of North American Linkages, edited by R.G. Harris and T. Lemieux, University of Calgary Press, pp. 83-112.

Crozet, Matthieu and Federico Trionfetti (2002) "Effets frontières entre les pays de l'Union Européenne : le poids des politiques d'achats publics", Economie Internationale, 89-90, pp. 189-208.

Davis, Donald R. (1998) “The Home Market, Trade and Industrial Structure", American Economic Review, 88(5), pp. 1264-76.

De Sousa, Jose and Anne-Celia Disdier (2002) "Trade, border effects and individual characteristics", mimeo, University of Paris. 
Deardorff, Alan (1998) "Determinants of Bilateral Trade: Does Gravity Work in a Frictionless World?", in The Regionalization of the World Economy, edited by J. Frankel, University of Chicago Press, pp. 7-28.

Dixit, Avinash K. and Joseph E. Stiglitz (1977) "Monopolistic Competition and Optimum Product Diversity", American Economic Review, 67(3), pp. 297-308.

Egger, Matthias, George D. Smith, Martin Schneider and Christoph Minder (1997) "Bias in meta-analysis detected by a simple, graphical test", British Medical Journal, 315, pp. 629-634.

Engel, Charles and John H. Rogers (1996) "How Wide Is the Border?" American Economic Review, 86(5), pp. 1112-25.

Engel, Charles and John H. Rogers (2001) "Deviations from Purchasing Power Parity: Causes and Welfare Costs", Journal of International Economics, 55(1), pp. 29-57.

Evenett; Simon J. and Wolfgang Keller (2002) "On Theories Explaining the Success of the Gravity Equation", Journal of Political Economy, 110(2), pp. 281-316.

Fairfield, Elton J. (2001) "Canada-US Border Effects: An Explanation" (Doctoral dissertation, U of Western Ontario, August 2001). 
Feenstra, Robert C. (2002) "Border Effects and the Gravity Equation: Consistent Methods for Estimation", Scottish Journal of Political Economy, 49(5), pp. 491-506.

Feenstra, Robert C., James R. Markusen and Andrew K. Rose (2001) "Using the Gravity Equation to Differentiate Among Alternative Theories of Trade", Canadian Journal of Economics, 34(2), pp. 430-47.

Feldstein, Martin and Charles Horioka (1980) "Domestic Saving and International Capital Flows", Economic Journal, 90(358), pp. 314-29.

Fidrmuc, Jarko and Jan (2001) "Disintegration and Trade", ZEI working paper, 43 pp.

Fisher, R.A. (1932) "Statistical Methods for Research Workers", $4^{\text {th }}$ ed., London, Oliver and Boyd.

Fitzsimons, Emla, Vincent Hogan and Peter J. Neary (1999) "Explaining the Volume of North-South Trade in Ireland: A Gravity Model Approach", Economic and Social Review, 30(4), pp. 381-401.

Frankel, Jeffrey and Andrew K. Rose (2002) "An Estimate of the Effect of Common Currencies on Trade and Income", Quarterly Journal of Economics, 117(2), pp. 437-66. 
Glass, Gene V. (1976) "Primary, Secondary and Meta-Analysis of Research", The Educational Researcher, 5(10), pp. 3-8.

Glass, Gene V. (1977) "Integrating Findings: The Meta-Analysis of Research", Review of Research in Education, 5, pp. 351-79.

Hausman, Jerry and William Taylor (1981), "Panel data and unobservable individual effects", Econometrica, 49(6), pp. 1377-98.

He, Jiang et al. (1999) "Passive Smoking and the Risk of Coronary Heart Disease: A Meta-Analysis of Epidemiologic Studies", New England Journal of Medicine, 340(12), pp. 920-26.

Head, Keith and Mayer, Thierry (2000) "Non-Europe: The Magnitude and Causes of Market Fragmentation in the EU", Weltwirtschaftliches Archiv, 136(2), pp. 284-314.

Head, Keith and Mayer, Thierry (2001) "Effet frontiere, integration economique et Forteresse Europe", CEPII working paper \# 06, 41 pp.

Head, Keith and Mayer, Thierry (2002) "Illusory Border Effects: Distance Mismeasurement Inflates Estimates of Home Bias in Trade", CEPII working paper \#01, $34 \mathrm{pp}$. 
Head, Keith and Disdier, Anne-Celia (2006) "The Puzzling Persistence of the Distance Effect on Bilateral Trade", Review of Economics and Statistics, forthcoming.

Held et al. (1989) "Calcium Channel Blockers in Acute Myocardial Infarction and Unstable Angina: An Overview", British Medical Journal, 299, pp. 1187-92.

Helliwell, John F. (1996) “Do National Borders Matter for Quebec's Trade?" Canadian Journal of Economics, 29(3), pp. 507-522.

Helliwell, John F. (1997) "National Borders, Trade and Migration”, NBER working paper $\# 6027,29$ pp.

Helliwell, John F. (1998) “How Much Do National Borders Matter?", Brookings Institution Press, Washington DC.

Helliwell, John F. and Genevieve Verdier (2001) "Measuring Internal Trade Distances: A New Method Applied to Estimate Provincial Border Effects in Canada", Canadian Journal of Economics, 34(4), pp. 1024-41.

Helliwell, John F. (2003) "Border Effects: Assessing Their Implications for Canadian Policy in a North American Context", mimeo, University of British Columbia. 
Helpman, Elhanan (1999) "The Structure of Foreign Trade", Journal of Economic Perspectives, 13(2), pp. 121-44.

Helpman, Elhanan and Paul R. Krugman (1985) "Market Structure and Foreign Trade", MIT Press, Cambridge, MA.

Hillberry, Russell (1998) "Regional Trade and "the Medicine Line": The National Border Effect in U.S. Commodity Flow Data", Journal of Borderlands Studies, 13(2), pp. 1-17.

Hillberry, Russell (2002) "Aggregation Bias, Compositional Change and the Border Effect", Canadian Journal of Economics, 35(3), pp. 517-30.

Hillberry, Russell and David Hummels (2002a) "Explaining Home Bias in Consumption: The Role of Intermediate Input Trade”, NBER working paper \#9020, $31 \mathrm{pp}$.

Hillberry, Russell and David Hummels (2002b) "Intra-National Home Bias: Some Explanations", NBER working paper \#9022, 10 pp.

Hunt, Morton (1997) "How Science Takes Stock: The Story of Meta-Analysis", Russell Sage Foundation, New York, NY.

Krugman, Paul (1980) "Scale Economies, Product Differentiation, and the Pattern of Trade", American Economic Review, 70(5), 950-59. 
Leamer, Edward E. (1997) “Access to Western Markets, and Eastern Effort Levels" in Lessons from the Economic Transition: Central and Eastern Europe in the 1990s, edited by S. Zecchini, Kluwer Academic Publishers, Dordrecht.

Leamer, Edward E. and James Levinsohn (1995) "International Trade Theory: The Evidence", in Handbook of International Economics, Vol. 3, edited by Gene M. Grossman and Kenneth Rogoff, Elsevier, pp. 1339-94.

Longhi, Simonetta, Peter Nijkamp and Jacques Poot (2005) "A Meta-Analytic Assessment of the Effect of Immigration on Wages", Journal of Economic Surveys, 19(3), pp. 451-477.

McCallum, John (1995) "National Borders Matter: Canada-U.S. Regional Trade Patterns", American Economic Review, 85(3), pp. 615-623.

Niebuhr, Annekatrin and Silvia Stiller (2002) "Integration Effects in Border Regions - A Survey of Economic Theory and Empirical Studies”, HWWA discussion paper \#179, 36 pp.

Nitsch, Volker (2000) 'National Borders and International Trade: Evidence From the European Union", Canadian Journal of Economics, 33(4), pp. 1091-1105. 
Obstfeld, Maurice and Kenneth Rogoff (2000) "The Six Major Puzzles in International Macroeconomics", NBER working paper \#7777, 65 pp.

Poirier, Dale J. (1995) "Intermediate Statistics and Econometrics: A Comparative Approach", MIT Press.

Poyhonen, Pentti (1963) “A Tentative Model for the Volume of Trade Between

Countries", Weltwirtschaftliches Archiv, 90(1), pp. 93-99.

Rogers, John H. and Hayden P. Smith (2001) "Border Effects Within the NAFTA Countries", International Finance Discussion Paper \#698, Board of Governors of the Federal Reserve System, $36 \mathrm{pp}$.

Rose, Andrew K. and T.D. Stanley (2005) "A Meta-Analysis of the Effect of Common Currencies on International Trade", Journal of Economic Surveys, 19(3), pp. 347-65.

Stanley, T.D. (1998) "New Wine in Old Bottles: A Meta-Analysis of Ricardian Equivalence", Southern Economic Journal, 64(3), pp. 713-27.

Stanley, T.D. (2001) “Wheat From Chaff: Meta-Analysis as Quantitative Literature Review", Journal of Economic Perspectives, 15(3), pp. 131-50. 
Stanley, T.D. (2004) “Meta-Regression Methods for Detecting and Estimating Empirical Effect in the Presence of Publication Bias", discussion paper 2004-2, Center for Entrepreneurial Studies, Hendrix College, Conway, AR.

Stanley, T.D. (2005) "Beyond Publication Bias", Journal of Economic Surveys, 19(3), pp. 309-45.

Stanley, T.D. and Stephen B. Jarrell (1998) “Gender Wage Discrimination Bias? A MetaRegression Analysis", Journal of Human Resources, 33(4), pp. 947-73.

Tinbergen, Jan (1962) "Shaping the World Economy: Suggestions for an International Economic Policy", The Twentieth Century Fund, New York, NY.

Wei, Shang-Jin (1996) "Intra-National Versus International Trade: How Stubborn are Nations in Global Integration?", NBER working paper \#5531, 41 pp.

Wolf, Holger C. (2000) "Intranational Home Bias in Trade," The Review of Economics and Statistics, 82(4), pp. 555-63.

Wolf, Nikolaus (2002) "The Polish reunification: border effects in Polish domestic trade (1918-1939)", mimeo, Free University of Berlin. 